Florida International University FIU Digital Commons

$4-1-2011$

\title{
Characterization,Sources,and Transformations of Dissolved Organic Matter (DOM) in the Florida Coastal Everglades (FCE)
}

Meilian Chen

Florida International University, meilianchen8@gmail.com

DOI: $10.25148 /$ etd.FI1 1050605

Follow this and additional works at: https://digitalcommons.fiu.edu/etd

\section{Recommended Citation}

Chen, Meilian, "Characterization,Sources,and Transformations of Dissolved Organic Matter (DOM) in the Florida Coastal Everglades (FCE)" (2011). FIU Electronic Theses and Dissertations. 390.

https://digitalcommons.fiu.edu/etd/390 


\title{
FLORIDA INTERNATIONAL UNIVERSITY
}

Miami, Florida

\section{CHARACTERIZATION, SOURCES, AND TRANSFORMATIONS OF DISSOLVED ORGANIC MATTER (DOM) IN FLORIDA COASTAL EVERGLADES (FCE)}

\author{
A dissertation submitted in partial fulfillment of the \\ requirements for the degree of \\ DOCTOR OF PHILOSOPHY \\ in \\ CHEMISTRY \\ by \\ Meilian Chen
}


To: Dean Kenneth Furton

College of Arts and Sciences

This dissertation, written by Meilian Chen, and entitled Characterization, Sources, and Transformations of Dissolved Organic Matter (DOM) in the Florida Coastal Everglades (FCE), having been approved in respect to style and intellectual content, is referred to you for judgment.

We have read this dissertation and recommend that it be approved.

$\begin{array}{r}\hline \text { Yong Cai } \\ \hline \text { Joseph Boyer } \\ \hline \text { David Chatfield } \\ \hline \text { Kenneth Furton } \\ \hline \text { Rudolf Jaffé, Major Professor }\end{array}$

Date of Defense: April 1, 2011

The dissertation of Meilian Chen is approved.

\begin{tabular}{r}
$\begin{array}{r}\text { Dean Kenneth Furton } \\
\text { College of Arts and Sciences }\end{array}$ \\
\hline Interim Dean Kevin O'Shea \\
University Graduate School
\end{tabular}

Florida International University, 2011 


\section{DEDICATION}

I dedicate this dissertation to my son Scott. Without his love and inspiration, this work would not have been finished. 


\section{ACKNOWLEDGMENTS}

I wish to thank the members of my committee for their support and patience.

Their understanding and support during the defense scheduling and their precious time and helpful comments is greatly appreciated.

Special thanks go to my advisor Dr. Rudolf Jaffé. I sincerely appreciate his support, help, enthusiasm, and valuable mentoring.

I would like to extend my appreciation to Drs. N. Maie and Y. Yamashita for warm encouragements, technical assistance and helpful discussions during the performance of this work. I want to thank Dr. R. Price for providing groundwater samples and helpful advice during that part of my research.

I would like to thank NSF through the FCE-LTER program and the Department of Chemistry and Biochemistry for financial support through teaching and research assistantship respectively. Thanks also go to the Wetland Ecosystem Laboratory for field support and the SERC Water Quality Laboratory for DOC analyses.

Finally, I would like to thank all my colleagues and friends here. They have made my work more productive and my life more colorful. I've enjoyed working with them so much that I even didn't realize almost six years have passed already. 


\author{
ABSTRACT OF THE DISSERTATION \\ CHARACTERIZATION, SOURCES, AND TRANSFORMATIONS OF \\ DISSOLVED ORGANIC MATTER (DOM) IN FLORIDA COASTAL \\ EVERGLADES (FCE)
}

by

Meilian Chen

Florida International University, 2011

Miami, Florida

Professor, Rudolf Jaffé, Major Professor

Dissolved organic matter (DOM) is one of the largest carbon reservoirs on this planet and is present in aquatic environments as a highly complex mixture of organic compounds. The Florida coastal Everglades (FCE) is one of the largest wetlands in the world. DOM in this system is an important biogeochemical component as most of the nitrogen $(\mathrm{N})$ and phosphorous $(\mathrm{P})$ are in organic forms. Achieving a better understanding of DOM dynamics in large coastal wetlands is critical, and a particularly important issue in the context of Everglades restoration.

In this work, the environmental dynamics of surface water DOM on spatial and temporal scales was investigated. In addition, photo- and bio-reactivity of this DOM was determined, surface-to-groundwater exchange of DOM was investigated, and the size distribution of freshwater DOM in Everglades was assessed. The data show that DOM dynamics in this ecosystem are controlled by both hydrological and ecological drivers and are clearly different on spatial scales and variable seasonally. 
The DOM reactivity data, modeled with a multi-pool first order degradation kinetics model, found that fluorescent DOM in FCE is generally photo-reactive and bio-refractory. Yet the sequential degradation proved a "priming effect" of sunlight on the bacterial uptake and reworking of this subtropical wetland DOM. Interestingly, specific PARAFAC components were found to have different photo- and bio-degradation rates, suggesting a highly heterogeneous nature of fluorophores associated with the DOM. Surface-to-groundwater exchange of DOM was observed in different regions of the system, and compositional differences were associated with source and photo-reactivity. Lastly, the high degree of heterogeneity of DOM associated fluorophores suggested based on the degradation studies was confirmed through the EEM-PARAFAC analysis of DOM along a molecular size continuum, suggesting that the fluorescence characteristics of DOM are highly controlled by different size fractions and as such can exhibit significant differences in reactivity. 


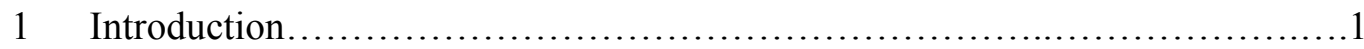

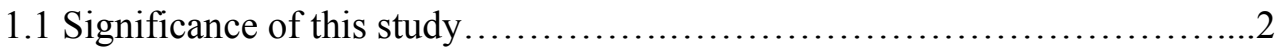

2 Spatial and temporal variation of dissolved organic matter in an oligotrophic subtropical coastal wetland................................. 7

2.1 Abstract.............................................................. 8

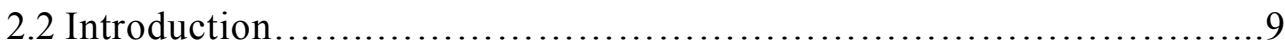

2.3 Sampling and experimental methods............................... 12

2.3.1 Description of sites........................................... 12

2.3.2 Sampling ..................................................... 15

2.3.3 Analytical measurements of DOC, UV-vis, EEM, and PARAFAC modeling..................................... 17

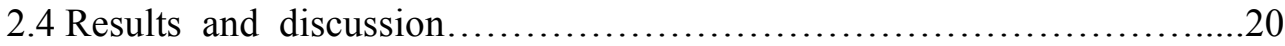

2.4.1 Spatial clustering and Seasonality..............................21

2.4.2 Cross-site and cross-season Comparison of DOC, FI, $\mathrm{S}_{\mathrm{R}}, a(254) * \ldots . .26$

2.4.3 Cross-site and cross-season Comparison of EEM-PARAFAC components............................................ 31

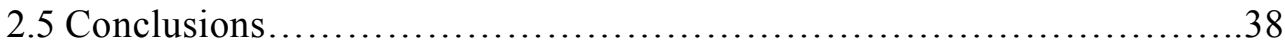

3 Assessment of photo- and bio-rectivity of Dissolved organic matter From biomass and soil leachates and surface water in the Florida coastal Everglades.......................................................40

3.1 Abstract.........................................................4

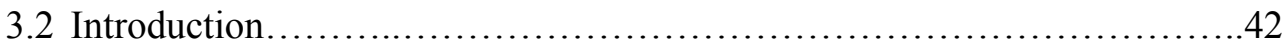

3.3 Sampling and experimental methods ................................47

3.3.1 Sampling .................................................47

3.3.2 Leaching experiemnts.........................................49

3.3.3 Photodegradation experiemnts.................................52

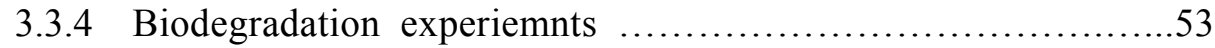

3.3.5 Sequential photo- and biodegradation experiments.................54

3.3.6 Analytical measurements ..................................54

3.3.7 PARAFAC model fitting and residue component validation.........55

3.3.8 Multi- and single-pool kinetics modeling and PCA statistics........57

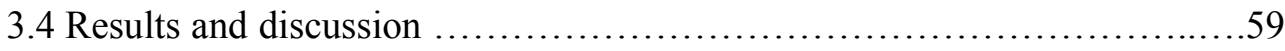

3.4.1 EEM-PARAFAC modeling results...............................59

3.4.2 Qualitative assessemnt of DOM photo- and bio-reactivity..........62

3.4.3 Quantitative assessemnt of DOM photo- and bio-reactivity.........65 
3.4.4 Reactivity comparison of bioamss leachate, soil leachate, and Surface water.............................................78

3.4.5 Correlation of biodegradable DOC versus protein-like Components.............................................. 82

3.5 Conclusions and Environmental implications............................ 85

4 Study of dissolved organic matter from groundwater and surface water in the Florida coastal Everglades..........................................99

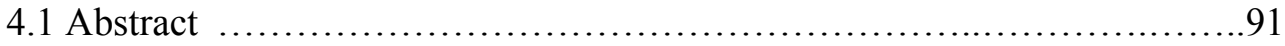

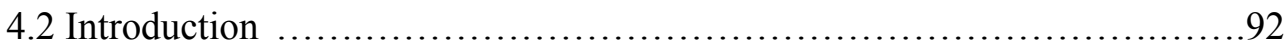

4.3 Sampling and experimental methods ................................. 96

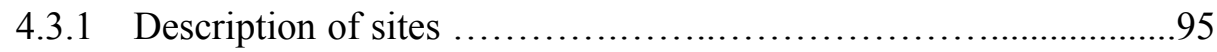

4.3.2 Sampling ......................................................... 98

4.3.3 Analytical measurements ....................................99

4.3.4 Parallel factor analysis........................................101

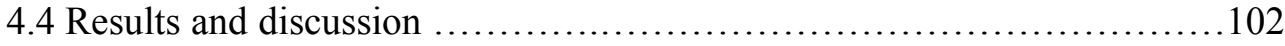

4.4.1 Water chemistry and optical parameters.........................102

4.4.2 Classification of water samples via PCA..........................104

4.4.3 Effects of DOM sources and precursor tupes ...................105

4.4.3.1 Diagenetic effects of photo- and bio-degradation .........108

4.4.3.2 Trends of DOC, $a(254)$, and

EEM-PARAFAC compoents..........................109

4.5 Conclusions and Environmental implications .............................113

5 Molecular size based Characterization of dissolved organic matter using size exclusion chromatography and excitation-emission matrix and parallel factor analysis ........................................................... 115

5.1 Abstract ............................................................. 116

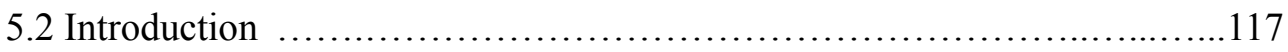

5.3 Sampling and experimental methods ............................119

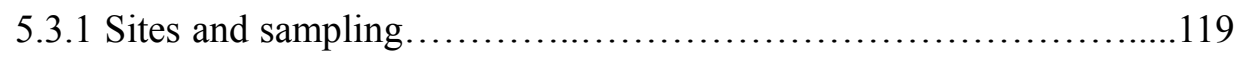

5.3.2 Molecular size fractionation...................................121

5.3.3 Analytical measurements and PARAFAC modeling..................123

5.4 Results and discussion .......................................... 125

5.4.1 EEM-PARAFAC components contribution to

different MW fractions...........................................125

5.4.2 Cross-fraction comparison of FI and
EEM-PARAFAC compoents.................................133

5.4.3 Cross-site comparison of FI and

EEM-PARAFAC components..............................126

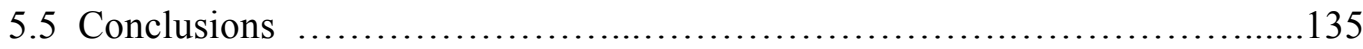




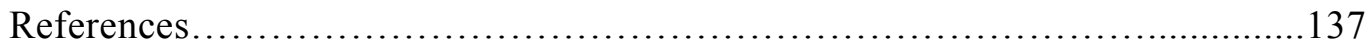

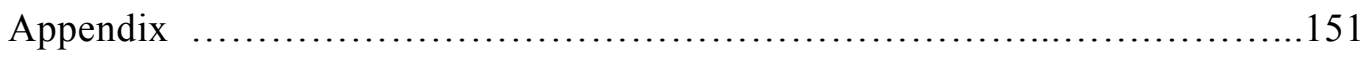

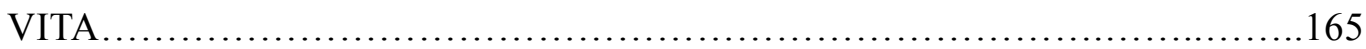




\section{LIST OF TABLES}

TABLE

PAGE

2.1 Sampling sites vegetation and soil types and hydrography $\ldots \ldots \ldots \ldots \ldots \ldots \ldots \ldots$

2.2 Summary of Excitation/Emission maxima, major sources, and seasonal and spatial patterns of EEM-PARAFA components.................21

3.1 Summary of sampling sites and sample descriptions.........................48

3.2 Major sources and reactivity of EEM-PARAFAC components...................60

3.3A Photo- and bio-degradation trends and kinetics data for UV

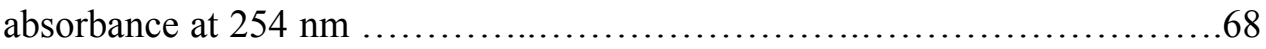

3.3B Examples of degradation trends and kinetics data...................77

4.1 Summary of water chemistry and optical parameters........................103

5.1 Retention time and estimated apparent molecular weight (AMW) for eight fractions..................................................122

5.2 Molecular weight distribution characteristics of components..................126

5.3 Contributions of EEM-PARAFAC components to size fractions...............129 


\section{LIST OF FIGURES}

FIGURE

2.1Sampling transects for Shark River Slough (SRS) and Taylor

Slough (TS) in the Florida coastal Everglades...........................14

2.2 Spectral characteristics and contour plots of eight-component model for

FCE surface water dataset

2.3 Cluster analysis (Ward method of normalized data) of 14 sampling sites in FCE based on the DOM EEM-PARAFAC data

2.4 Examples of year-to-year trends of dissolved organic matter (6-year) and C1 fluorescence intensity (4-year) for freshwater marsh site SRS-3 and mangrove site $\mathrm{TS} / \mathrm{Ph}-7$

2.5 Examples of seasonal variation of DOC (6-year) and Fluorescence Index (4-year) at peat- based freshwater marsh sites SRS1-3 based on box plots

2.6 Cross-site and cross-season comparison of 6-year's DOC and $a(254)^{*}$; and 4-year's fluorescence index (FI) and Spectral ratio.

2.7 Cross-site and cross-season comparison of relative abundance of EEM-PARAFAC components.

2.8 PCA of overall four-year monthly monitoring of EEM-PARAFAC data.......

3.1 Flow chart of leaching and photo- and bio-degradation experiments

3.2 Comparison of SunTest irradiation intensity with natural sunlight in

South Florida. .53

3.3 Comparison of relative EEM-PARAFAC composition of DOM from different source materials

3.4 Principal components analysis of biomass leachate vs. surface water (a) and soil leachate vs. surface water (b) during photo-, bio- and sequential photo plus bio degradation based on EEM-PARAFAC data

3.5A Examples of absorbance at $254 \mathrm{~nm}$ (A254) photo-degradation patterns and kinetics data fitted into a multi-pool first-order decay model 
3.5B Examples of absorbance at $254 \mathrm{~nm}$ (A254) biodegradation patterns and kinetics.

3.5C Examples of EEM-PARAFAC components photo-degradation patterns and kinetics data

3.6 Examples of comparison of photo- ( 7 days) and bio-reactivity (28 days) of EEM-PARAFAC components for biomass leachate, soil leachate, and surface water in FCE.

3.7 PCA comparison of photo- and bio-reactivity of humic-like $\mathrm{C} 1$ and protein-like

C7 among three sources

3.8 Correlation of \% BDOC loss versus each and the sum of two protein-like EEM-PARAFAC components 83

4.1 Conceptual diagram depicting sources of DOM in FCE ground water and surface water

4.2 Sampling sites in Florida coastal Everglades (FCE). Groundwater and surface water were collected from S332 basin area and Northeastern FL Bay.

4.3 PCA for EEM-PARAFAC results of all the surface and ground water samples

4.4 Trends in UV absorption coefficient at $254 \mathrm{~nm}$, and DOC, along with absolute (fluorescence intensity) and relative (out of the total of 8 components) abundance of EEM-PARAFAC terrestrial humic-like $(\mathrm{C} 1, \mathrm{C} 2, \mathrm{C} 3, \mathrm{C} 5)$ and protein-like $(\mathrm{C} 7$ and $\mathrm{C} 8)$ components

5.1 Sampling sites (SRS2, TS2, and C111) in Florida Everglades

5.2 SEC chromatograms with UV-Vis detection at $280 \mathrm{~nm}$ for the three samples studied here.

5.3 Chromatograms of size exclusion chromatography (SEC) with UV-Vis detector $(\lambda=280 \mathrm{~nm})$ and splitting of eight fractions according to the peaks.

5.4 Cross-fractionation cross-site comparison of DOM composition. 130 
5.6 Trends of Fluorescence Index (FI) starting from the original whole sample to eight fractions with elution order................................134

5.7 Comparison of component 3 (C3) and component 6 (C6) among three sites and eight fractions....................................... 134 
Chapter 1:

Introduction 


\subsection{Significance of this study}

Dubbed as the "River of Grass," the Everglades are undergoing the world's largest wetland restoration after more than one century of anthropogenic alteration (http://www.evergladesplan.org/) The aim is to restore the quality, quantity, timing, and distribution of water flow as close as possible to its pristine state. As a unique oligotrophic subtropical coastal wetland, the Everglades ecosystem has provided diverse habitats for myriads of wild creatures for millennia of years and thus needs to be preserved.

Among diverse ecological factors, the anthropogenic effects on the Everglades ecosystem have altered natural biogeochemical cycles. One critical component of these is dissolved organic matter (DOM). This carbon-based substrate is an assemblage of complex organic molecules with a wide range of molecular weights and chemical characteristics which is ubiquitous in the aquatic environment. DOM plays a central role in the biogeochemical cycles of the Florida Coastal Everglades (FCE) as it represents a major form of organic matter in watersheds. It fuels the microbial loop, attenuates light intensity to protect aquatic vegetation and fauna, and controls primary productivity of aquatic organisms (Findlay and Sinsabaugh 2003; Hansell and Carlson 2002). Furthermore, DOM also influences fish migration habits, drinking water trihalomethane formation, metal speciation and transport, and hydrophobic contaminants transport and toxicity in the water bodies (Findlay and Sinsabaugh 2003; Stabenau and Zika 2004; Osborne et al., 2007). Although much 
research has been devoted to DOM studies in the Everglades in recent years (Jaffé et al., 2004; Jaffé et al., 2008; Maie et al. 2008; Yamashita and Jaffé, 2008;Yamashita et al., 2010), little is known about its environmental dynamics on spatial and temporal scales, its reactivity and interaction with groundwater in this system.

Because of its heterogeneous nature, the characterization of DOM and the monitoring of its compositional features has been an analytical challenge for decades. However, various spectroscopic and chromatographic analytical techniques have been used successfully to study DOM. Among these are UV-Vis and fluorescence techniques (including 3D Fluorescence/Excitation Emission Matrix), ESI-MS, ${ }^{13} \mathrm{C}-\mathrm{NMR}$, capillary electrophoresis, pyrolysis-GC/MS, FT-ICR/MS and others (Lu et al., 2003; Maie et al., 2005; Jones et al., 2004; Mopper et al., 2007; Gonsior et al., 2009). Fluorescence methods are widely used to characterize DOM because of its simplicity, sensitivity, low sample volume, and high throughput (Coble 1996; McKnight et al., 2001; Stedmon and Markager 2003; Cory and McKnight 2005;Jaffe et al., 2008; Jellman et al. 2010). Of particular interest in this field is the technique of Excitation Emission Matrix (EEM) fluorescence, which merges a series of emission scans from excitations over a range of wavelengths, potentially allowing for the complete spectral characterization of DOM samples (Coble 1996). Statistical treatment of the EEM data can contribute tremendously to unravel the compositional complexity, and parallel factor analysis (PARAFAC) is one of the most promising tools for this purpose. PARAFAC is a three-way statistical model which is ideally suited to address the complex trilinear character of EEMs. It can decompose the EEM 
data matrix into trilinear terms and a residual array and separate EEMs of complex mixtures into their individual fluorescent components (Stedmon and Markager 2003 \& 2005; Cory and McKnight, 2005). The combination of EEM and PARAFAC has proven to be a very powerful tool for studying the biogeochemistry of DOM (Cory and McKnight, 2005; Chen et al., 2010; Yamashita et al., 2010; and others), and has been widely applied in this dissertation research.

Although the importance of estuarine and coastal waters in the global DOM cycling has been recognized, sources, transport, and transformation of DOM are not well understood. As such, the research of this dissertation has focused on investigating the sources, transformations, and spatial and temporal variations of DOM in the FCE ecosystem making use primarily of the EEM-PARAFAC technique. As such, this dissertation research is based on supporting the FCE LTER project, where different hypotheses are being tested with regards to ecosystem responses to restoration efforts. One part of the general hypotheses of the FCE-LTER (FCE1) that specifically addresses the DOM issue is:

Hypothesis 2: Interannual and long-term changes in freshwater flow control the magnitude of nutrient and organic matter inputs to the estuarine zone, while ecological processes in the freshwater marsh and coastal ocean control the quality and characteristics of those inputs. This sub-hypothesis is followed up with specific questions, such as: 
Question 4: How are the quality and/or quantity of DOM in source water altered by changing freshwater flow versus internal processes occurring at a given location in the landscape? How are local ecosystem processes controlled by changes in source water DOM?

Based on the above, the specific objectives of this project are:

(1) To characterize Everglades surface water DOM on a spatiotemporal scale using EEM - PARAFAC.

(2) To assess the reactivity of DOM in the FCE using plant and soil leachates, subject to photo- and bio-degradation processes;

(3) To investigate photo- and bio-reactivity of surface water DOM in FCE in order to assess its labile vs refractory character with respect to its residence time for this particular environment;

(4) To characterize DOM from groundwater as a potential non-biotic end-member source;

(5) To characterize the molecular weight distribution of Everglades DOM using a combination of EEM-PARAFAC size exclusion chromatography (SEC) techniques.

The approaches that have been used in this project are listed below:

(1) Surface water DOM was monitored for optical properties through UV-Vis and EEM/PARAFAC measurements, during a 4 year period, monthly at all 14 LTER sites; 
(2) Biomass (sawgrass, spikerush, mangrove, periphyton, seagrass) and soil (peat, marl, mangrove mud and Florida Bay sediments) leachates were subjected to photoand bio-incubation, and combined photo plus bio-incubations to assess reactivity of DOM in this ecosystem and attempt to determine source proxies;

(3) Photo- and bio-degradation kinetics of DOM in surface water samples were conducted to determine DOM reactivity;

(4) DOM characterization studies of groundwater in the FCE was performed in order to assess potential non-biotic source contributions to surface waters. DOM from groundwater samples from both the freshwater marsh and Florida Bay sites, during both dry and wet seasons, were characterized;

(5) To assess DOM characteristics along a molecular weight continuum, three different DOM samples from the Everglades freshwater environments (peat marsh, marl marsh and a canal) were fractionated using size exclusion chromatography separation on an HPLC system and individual size fractions characterized by EEM/PARAFAC. 


\section{Chapter 2}

Spatial and temporal variation of dissolved organic

matter characteristics in an oilgotrophic subtropical coastal wetland 


\subsection{Abstract:}

The dynamics of dissolved organic matter (DOM) are a function of diverse ecological drivers such as hydrology, geomorphology, primary productivity, and of organic matter degradation processes. Here we present 4-yr DOM characterization data (total organic carbon and optical properties) from monthly surface water samples collected at fourteen sampling stations along two transects within the greater Everglades ecosystem, a subtropical oligotrophic coastal freshwater wetland-mangrove-estuarine ecosystem. Among other optical properties measurements, we applied a high throughput and sensitive spectroscopic method, namely Excitation Emission Matrix (EEM) fluorescence coupled with Parallel Factor Analysis (PARAFAC) in an attempt to assess quantitative and qualitative variations of DOM on both spatial and temporal scales. Eight fluorescence components were modeled through PARAFAC with six humic-like and two protein-like components being identified. The data presented clear spatial clustering and seasonal variations. For example, freshwater marsh DOM was enriched in higher plant and soil-derived humic-like compounds, while estuarine sites were more enriched in algae- and microbial-derived humic-like and protein-like inputs. Coastal estuarine sites were significantly controlled by hydrology, while DOM dynamics in Florida Bay were seasonally driven by both primary productivity and hydrology. Peat-based freshwater marsh sites could be clearly differentiated from marl-based sites based on EEM-PARAFAC data. Bulk DOC data and proxies like FI, $\mathrm{S}_{\mathrm{R}}$, and $a(254) *$ displayed clear spatial and seasonal variations as well. The present study highlights the use of 
long-term optical properties monitoring as an effective technique to investigate the DOM dynamics in wetland ecosystems.

\subsection{Introduction:}

The major impetus of long-term environmental monitoring and ecological restoration is often initiated by the ecosystem deterioration. Historically, the Everglades was a vast watershed with an area of about $28,000 \mathrm{~km}^{2}$ ranging from the Kissimmee River and Lake Okeechobee region to the north, down south to Florida Bay. Starting the $1880 \mathrm{~s}$, numerous canals (over 2,500 km), levees, and water control structures were constructed (Light and Dineen 1994). The dramatic hydrological alteration of the Florida Everglades during the last century, the agricultural land use practices in the north, and the urbanization along the east and throughout the Florida Keys during recent decades, have created an alarming impact on the structure and function of this ecosystem, resulting in hydropattern changes, eutrophication, hypersalinity, vegetation shifts, algal blooms, and massive seagrass dieoffs, among others (Robblee et al., 1991; Stober et al., 1996; Boyer et al., 2006). As one of the largest wetlands in the world, the Florida Everglades are undergoing an unprecedented ecological restoration aiming at restoring the quality, quantity, and timing of water flow, which will result in significant impacts on carbon and nutrient biogeochemical cycling and thus ecological changes to this ecosystem.

The Florida coastal Everglades (FCE) is a subtropical oligotrophic coastal wetland renowned for its oligotrophic "upside-down" characteristics (Childers et al, 
2006), with the main source of phosphorus being supplied by the marine endmember rather than the terrestrial endmember (Fourqurean et al., 1992; Chen and Twilley 1999). Dissolved organic matter (DOM) in the Florida Everglades is a particularly important biogeochemical component as most of the nitrogen $(\mathrm{N})$ and phosphorus $(\mathrm{P})$ $(>90 \%)$ is in an organic form (Boyer and Fourqurean 1997; Boyer et al., 2006). The P-limited oligotrophic nature of this ecosystem makes it more sensitive to the nutrients changes (Noe et al., 2001; Boyer and Fourqurean 1999; Gaiser et al., 2004) and imposes a more urgent need to advance the understanding of DOM dynamics and associated nutrients in this environment.

The dynamics of DOM in the Everglades are complex given its variable sources and fate as a function of diverse factors such as hydrology, geomorphology, primary productivity, and organic matter degradation processes (Qualls and Richardson 2003; Jaffé et al., 2004; Maie et al., 2006a; Scully et al., 2004; Yamashita et al., 2010). The subtropical coastal wetland is characterized by a freshwater to marine gradient ranging from freshwater marshes, through mangrove fringe to the seagrass dominated Florida Bay estuary and as such is spatially very diverse. Furthermore, it has typical wet and dry seasons, with most of the rainfall typically from May to October (see http://www.evergladesplan.org/), suggesting that strong seasonal variations in DOM dynamics are likely.

Previous studies in Everglades have shown that DOM plays a central role in carbon and nutrients cycling since most of the $\mathrm{N}$ and $\mathrm{P}$ are in an organic form in the Everglades (Boyer and Fourqurean 1997; Boyer et al., 2006; Maie et al., 2006b. 
Previous studies have shown that DOM can be autochthonously produced by local emergent, floating and submerged biomass (Maie et al., 2006c; Scully et al., 2004); in situ soil organic matter diffusion and oxidation (Yamashita et al., 2010); precipitation; exchange between surface and ground water (Chen et al., 2010); and canal inputs (Lu et al., 2003). Its quantity and quality were shown to be controlled by DOM source strength with differences driven by a variety of factors such as hydrology, primary productivity, geomorphology, seasonality, land use, and biogeochemical processes (Wang et al., 2002; Qualls et al., 2003; Lu et al., 2003; Jaffé et al., 2004; Maie et al., 2006a; Yamashita et al., 2010). Despite these studies, still little information is available on the spatial and temporal variability of the quantity and quality of DOM in the Everglades, which is critical for the assessment of freshwater marsh and estuarine biogeochemistry in the context of ongoing Everglades' restoration efforts and/or global climate change.

Ultraviolet-visible and fluorescence spectroscopic techniques have been widely used to study the dynamics of DOM in a variety of aquatic environments (Coble et al., 1996; Baker 2001; McKnight et al., 2001, Hudson et al., 2007; Jaffé et al., 2008; Shank et al., 2010; Fellman et al., 2010). Fluorescence techniques including excitation-emission matrix (EEM) fluorescence, not only have the advantages of high sample throughput and sensitivity, but also can differentiate different types of fluorophores (Coble et al., 1996). In recent years, excitation emission matrix fluorescence (EEM) combined with parallel factor analysis (PARAFAC) has become one of the methods of choice for DOM dynamics studies 
because of the ability of the statistical PARAFAC model to further separate EEM spectra into multiple groups of fluorophores (Stedmon et al., 2003; Cory and McKnight 2005; Jaffé et al.,2008; Fellman et al., 2010). Thus, both spatial and seasonal dynamics in DOM composition have been successfully explored using fluorescence techniques (e.g., Jaffe et al., 2008; Borisover et al., 2009; Vouve et al., 2009; Omori et al., 2010; Yamashita et al., 2010). The present study investigates the spatial and temporal trends of DOM quantity and quality in the geomorphologically and seasonally heterogeneous environment of the Everglades, using bulk DOC and UV-Vis measurements combined with an EEM-PARAFAC components assessment approach. Because of the different sources and environmental conditions in each of the sub-environments in the Everglades, the freshwater marshes, fringe mangroves, and marine estuarine environments are hypothesized to have

spatially distinct DOM characteristics (e.g., Maie et al., 2005). Seasonally driven variations in precipitation, hydrology, and primary productivity are also hypothesized to control seasonal patterns in DOM sources and characteristics (e.g. Maie et al., 2006a).

\subsection{Sampling and experimental methods}

\subsubsection{Sites description}

This study was conducted in major water flow paths that drain the Everglades (Fig.2.1), and represent permanent study sites of the FCE-LTER (http://fce.lternet.edu/). Water flows through the Everglades as slow sheet flow along 
a topographic gradient of about $1 \mathrm{~m}$ per $56 \mathrm{~km}$ (Light and Dineen 1994). Vegetation zonation patterns are clearly defined in this ecosystem. Freshwater marsh sites are dominated by sawgrass, interspersed with tree islands, wet prairie and slough communities. Periphyton mats are ubiquitous in the oligotrophic Everglades and are a fundamental component base of local food webs and a regulator of nutrients cycling (Browder 1994). The longer hydroperiod Shark River Slough (SRS) sites are characterized by peat-based soil while the soils at the shorter hydroperiod Taylor Slough (TS) sites are less organic and marl-based freshwater marshes. Water in this system is largely derived from local rainfall, and from canal inputs that are regulated by the South Florida Water Management District (SFWMD). A fringe of mangrove forests is located along the coast and on islands throughout Florida Bay. Seagrass communities dominate the subtidal Florida Bay estuary. The upstream Everglades Agricultural Area (EAA) and Water Conservation Areas (WCA) are connected with Everglades National Park (ENP) through canals and ENP receives point-source inputs of WCA water through pumping stations. Groundwater-surface water exchange with the underlying Biscayne Aquifer is possible especially during the dry season when the water head is low (Price et al., 2006b).

As shown in Fig.2.1, six of the study sites (SRS-1 to SRS-6) are located along the Shark River Slough (SRS), located along the general N-to-S water flow. While SRS-1, SRS-2, SRS-3 sites are all peat-based freshwater marsh sites, SRS-1 site is located at the S-12 structure along the Tamiami canal which controls canal inputs from the WCAs into the SRS. Tidal influence strongly affects SRS-6 and SRS-5, 


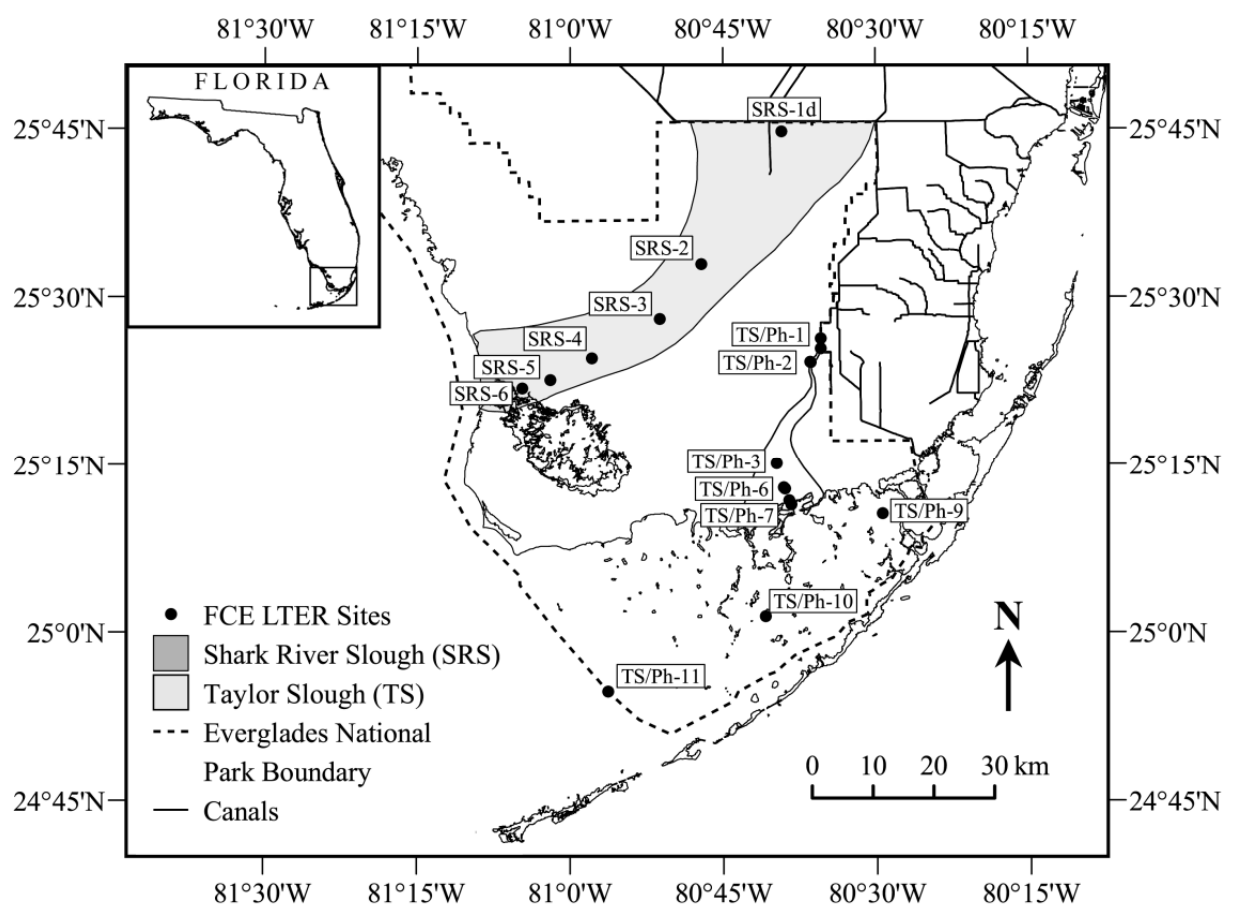

Fig.2.1 Sampling transects for Shark River Slough (SRS) and Taylor Slough (TS) in the Florida coastal Everglades.

but reaches SRS-4 with significant attenuation. As for the Taylor Slough transect, the water enters from the L-31 W canal controlled by the S332D pump structure, flowing through the freshwater marsh to the mangrove estuaries and to the subtidal Florida Bay estuary, a shallow, compartmentalized, lagoonal ecosystem (Briceno and Boyer 2010). Precipitation, rather than the terrestrial runoff, is the largest source of freshwater to the Florida Bay estuary. The TS/Ph-6 and TS/Ph-7 sites are oligohaline estuarine ecotone sites which are dominated by wind forcing and hydrological exchange with Florida Bay since tidal action is significantly dampened by the shallow mud banks throughout the bay. TS/Ph-9, TS/Ph-10, and $\mathrm{TS} / \mathrm{Ph}-11$ are three sites situated along a NE-to-SW gradient in Florida Bay. Unlike the other 11 sites, these 
three sites are not located along the predominant water flow path. On the basis of this description, the sampling sites can be categorized spatially as freshwater marsh (peat) SRS-1 to 3, freshwater marsh (marl) TS/Ph-1 to 3, mangrove estuarine (peat) SRS-4 to 6, mangrove estuarine (marl) $\mathrm{TS} / \mathrm{Ph}-6$ to 7 , and seagrass-dominated Florida Bay (FB) estuary TS/Ph-9 to 11 . SRS-1 and TS/Ph-1 are the two sites most influenced by canal inputs. Characteristics of the vegetation, soil type, and hydrography for each site are summarized in Table 2.1.

\subsubsection{Sampling}

Surface water samples were collected monthly from October 2002 (for DOC, $\mathrm{FI}_{1}$ and $a_{254}$ ) to September 2004, and from October 2004 (DOC, $\mathrm{FI}_{2}, a_{254}$, and all other optical properties described below) to September 2008 for 14 sites along the SRS and $\mathrm{TS} / \mathrm{Ph}$ transects. Some freshwater marsh sites, especially $\mathrm{TS} / \mathrm{Ph}$ sites, became dry during the peak of the dry season (typically between January to May) so surface water samples were missing occasionally for these sites in this dataset. Samples were collected in pre-cleaned, acid-washed, brown, high density polyethylene bottles (Nalgene). Containers were rinsed three times before sample collection. All surface water samples were filtered in the lab through pre-combusted $0.7 \mu \mathrm{m} \mathrm{GF} / \mathrm{F}$ filters and stored in a refrigerator until analyses within one week of collection. Samples collected between May and October were classified as wet season, while those collected between November and April were classified as representative of the dry season. 
Table 2.1 Sampling sites vegetation and soil types and hydrography.

\begin{tabular}{|c|c|c|}
\hline site & Dominant DOM sources and hydrogaphy & $\begin{array}{l}\text { Latitude / } \\
\text { Longitude }\end{array}$ \\
\hline \multicolumn{3}{|l|}{$\begin{array}{l}\text { Freshwater } \\
\text { marsh }\end{array}$} \\
\hline SRS-1 & $\begin{array}{l}\text { sawgrass interspersed with Eleocharis/Panicum; } \\
\text { peat soil; seasonally driven sheetflow }\end{array}$ & $25.7463 /-80.6537$ \\
\hline SRS-2 & $\begin{array}{l}\text { sawgrass interspersed with Eleocharis/Panicum; } \\
\text { peat soil; seasonally driven sheetflow }\end{array}$ & $25.5497 /-80.7852$ \\
\hline SSR-3 & $\begin{array}{l}\text { sawgrass interspersed with Eleocharis/Panicum; } \\
\text { peat soil; seasonally driven sheetflow }\end{array}$ & $25.4682 /-80.8533$ \\
\hline $\mathrm{TS} / \mathrm{Ph}-1$ & $\begin{array}{l}\text { sparse sawgrass marsh; } \\
\text { wetland marl; seasonally driven sheetflow }\end{array}$ & $25.4239 /-80.5902$ \\
\hline $\mathrm{TS} / \mathrm{Ph}-2$ & $\begin{array}{l}\text { sparse sawgrass marsh; } \\
\text { wetland marly peat; seasonally driven sheetflow }\end{array}$ & $25.4036 /-80.6069$ \\
\hline $\mathrm{TS} / \mathrm{Ph}-3$ & $\begin{array}{l}\text { sparse sawgrass marsh; } \\
\text { wetland marly peat; seasonally driven sheetflow }\end{array}$ & 25.2524 / -80.6627 \\
\hline \multicolumn{3}{|l|}{$\begin{array}{l}\text { Mangrove } \\
\text { fringe }\end{array}$} \\
\hline SRS-4 & $\begin{array}{l}\text { mangrove forest; wetland peat; seasonally } \\
\text { driven } \\
\text { freshwater and tidally driven oceanic inputs } \\
\text { mangrove forest; wetland peat; seasonally }\end{array}$ & $25.4098 /-80.9643$ \\
\hline SRS-5 & $\begin{array}{l}\text { driven } \\
\text { freshwater and tidally driven oceanic inputs } \\
\text { mangrove forest; wetland peat; seasonally }\end{array}$ & $25.3770 /-81.0323$ \\
\hline SRS-6 & $\begin{array}{l}\text { driven } \\
\text { freshwater and tidally driven oceanic inputs } \\
\text { mangrove forest; wetland peat; seasonally }\end{array}$ & $25.3646 /-81.0779$ \\
\hline $\mathrm{TS} / \mathrm{Ph}-6$ & driven & $25.2142 /-80.6491$ \\
\hline $\mathrm{TS} / \mathrm{Ph}-7$ & $\begin{array}{l}\text { freshwater and wind-driven estuarine inputs } \\
\text { mangrove forest; wetland peat; seasonally } \\
\text { driven } \\
\text { freshwater and wind-driven estuarine inputs }\end{array}$ & $25.1908 /-80.6391$ \\
\hline \multicolumn{3}{|l|}{ Florida Bay } \\
\hline $\mathrm{TS} / \mathrm{Ph}-9$ & $\begin{array}{l}\text { sparse seagrass; calcitic marl; estuarine with } \\
\text { minimal tidal energy, wind-driven movement }\end{array}$ & 25.1769 / - -80.4898 \\
\hline $\mathrm{TS} / \mathrm{Ph}-10$ & $\begin{array}{l}\text { seagrass; calcitic marl; estuarine with } \\
\text { minimal tidal energy, wind-driven movement }\end{array}$ & $25.0248 /-80.6810$ \\
\hline $\mathrm{TS} / \mathrm{Ph}-11$ & $\begin{array}{l}\text { seagrass; calcitic marl; estuarine with average } \\
\text { tidal energy, some wind-driven movement }\end{array}$ & $24.9129 /-80.9380$ \\
\hline
\end{tabular}




\subsubsection{Analytical measurements of DOC, UV-Vis, EEM, and PARAFAC modeling}

The DOC concentrations were measured using the high-temperature catalytic combustion method on a Shimadzu TOC-V total organic carbon analyzer. The UV absorption coefficient at $254 \mathrm{~nm}(a(254))$ was determined using a Varian Cary 50 bio spectrophotometer with a $1 \mathrm{~cm}$ quartz cuvette scanning from $240 \mathrm{~nm}$ to $800 \mathrm{~nm}$. The DOC data were used to calculate the specific ultraviolet absorbance, $a(254)^{*}$, which is an indicator of DOM aromaticity and defined as the UV absorption coefficient $a(254)$ in inverse meters normalized to DOC concentration in $\mathrm{mg} / \mathrm{L}$ (Hansell \& Carlson 2002; Weishaar et al., 2003). The UV-Vis spectrum slope ratio $\left(S_{R}\right)$ of $275-295 \mathrm{~nm}$ to 350-400 nm, a proxy for the molecular weight distribution of DOM (Helms et al., 2008), was also determined. A Horiba Jovin Yvon SPEX Fluoromax-3 spectrofluorometer equipped with a $150 \mathrm{~W}$ continuous output Xe arc lamp was applied to measure EEMs as previously reported (Chen et al., 2010). Briefly, slits were set at $5.7 \mathrm{~nm}$ for excitation and $2 \mathrm{~nm}$ for emission. Forty-four emissions scans were acquired at excitation wavelength $\left(\lambda_{\mathrm{ex}}\right)$ between 240 and $455 \mathrm{~nm}$ at $5 \mathrm{~nm}$ steps. The emission wavelengths were scanned from $\lambda_{\mathrm{ex}}+10 \mathrm{~nm}$ to $\lambda_{\mathrm{ex}}+250 \mathrm{~nm}$ (i.e., between 250 and $705 \mathrm{~nm}$ ) in $2 \mathrm{~nm}$ steps (Maie et al., 2006b). Fluorescence was acquired in signal over reference ratio mode $(\mathrm{S} / \mathrm{R})$ to eliminate potential effects of the Xe lamp fluctuation. Lastly, for samples collected from October 2002 to September 2004 the Fluorescence Index $\left(\mathrm{FI}_{1}\right)$ was determined as the ratio of the emission intensity at a wavelength of $450 \mathrm{~nm}$ to that at $500 \mathrm{~nm}$, obtained with an excitation of $370 \mathrm{~nm}$ (McKnight et al., 2001). For all samples collected thereafter the ratio of the emission 
intensity at a wavelength of $470 \mathrm{~nm}$ to that at $520 \mathrm{~nm}$ was used, as this modified FI $\left(\mathrm{FI}_{2}\right)$ has been shown to be a more robust means to determine this parameter (Jaffé et al., 2008). While only the data for the 2004 to 2008 period are presented here, the spatial and seasonal patterns observed for the 2002 to 2004 sample set showed to be very similar (Parish, 2006). Additional details on the optical measurements and post-acquisition steps for correction and standardization procedures can be found elsewhere (Chen et al., 2010).

PARAFAC can statistically decompose EEMs into fluorescent groups (components), on the basis of an alternating least square (ALS) algorithm (Bro 1997). The mathematical equation is shown as follows (Eq.1).

$$
\begin{aligned}
& \mathrm{x}_{\mathrm{ijk}}=\sum_{c=1}^{C} \mathrm{a}_{\mathrm{ic}} \mathrm{b}_{\mathrm{jc}} \mathrm{c}_{\mathrm{kc}}+\mathrm{R}_{\mathrm{ijk}} \\
& \mathrm{i}=1, \ldots, \mathrm{I} ; \mathrm{j}=1, \ldots, \mathrm{J} ; \mathrm{k}=1, \ldots, \mathrm{K}
\end{aligned}
$$

where $\mathrm{x}_{\mathrm{ijk}}$ is the fluorescence intensity of the ith sample at emission wavelength $\mathrm{j}$ and excitation wavelength $\mathrm{k}$. The variable $\mathrm{c}$ defines the number of components for the model and $\mathrm{R}_{\mathrm{ijk}}$ is the residue that represents the residue remained after modeling or fitting. $\mathrm{a}_{\mathrm{ic}}$ is proportional to the concentration of the cth component in the ith sample (i.e. "scores"); $b_{j c}$ and $c_{k c}$ are "loadings" of the emission and excitation spectra for the cth component, which are linearly related to the fluorescence quantum efficiency at emission wavelength $\mathrm{j}$ and specific absorption coefficient at excitation wavelength $\mathrm{k}$, respectively. 

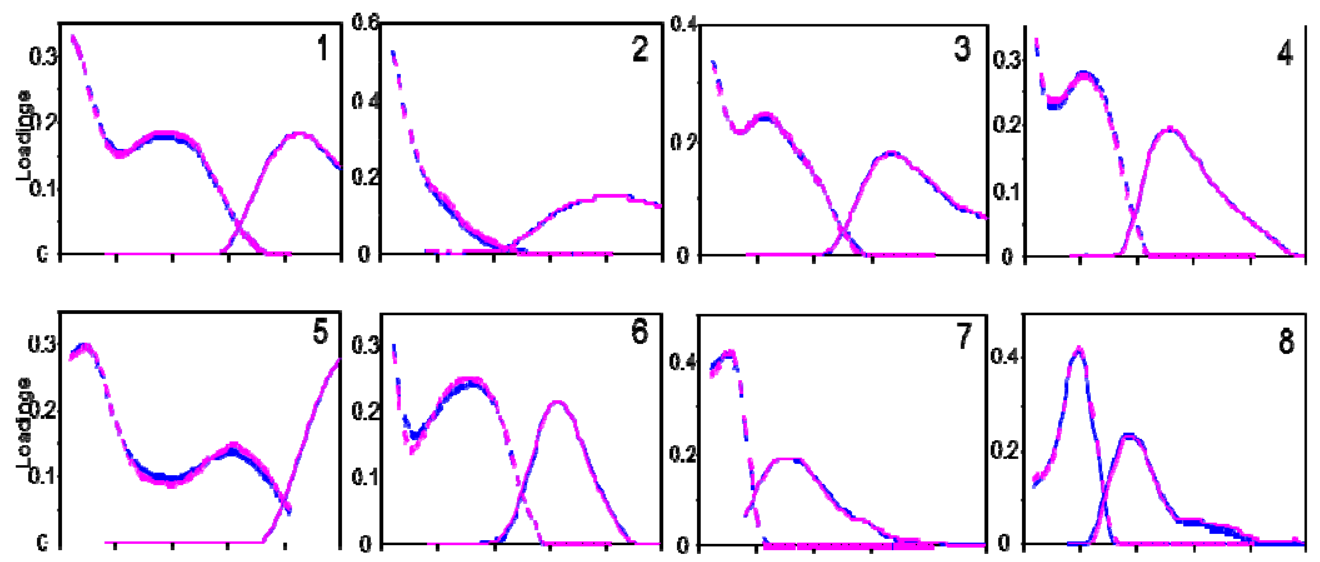

$250300350 \quad 100 \quad 150$
Wevelength ( $\mathrm{rm})$

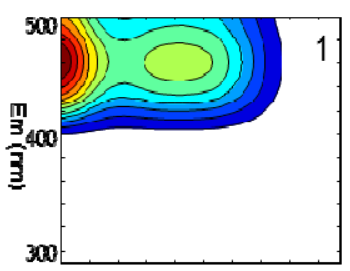

Wwelength $(\mathrm{nm})$

Wowength (nm)

Wwelength $(\mathrm{nm})$
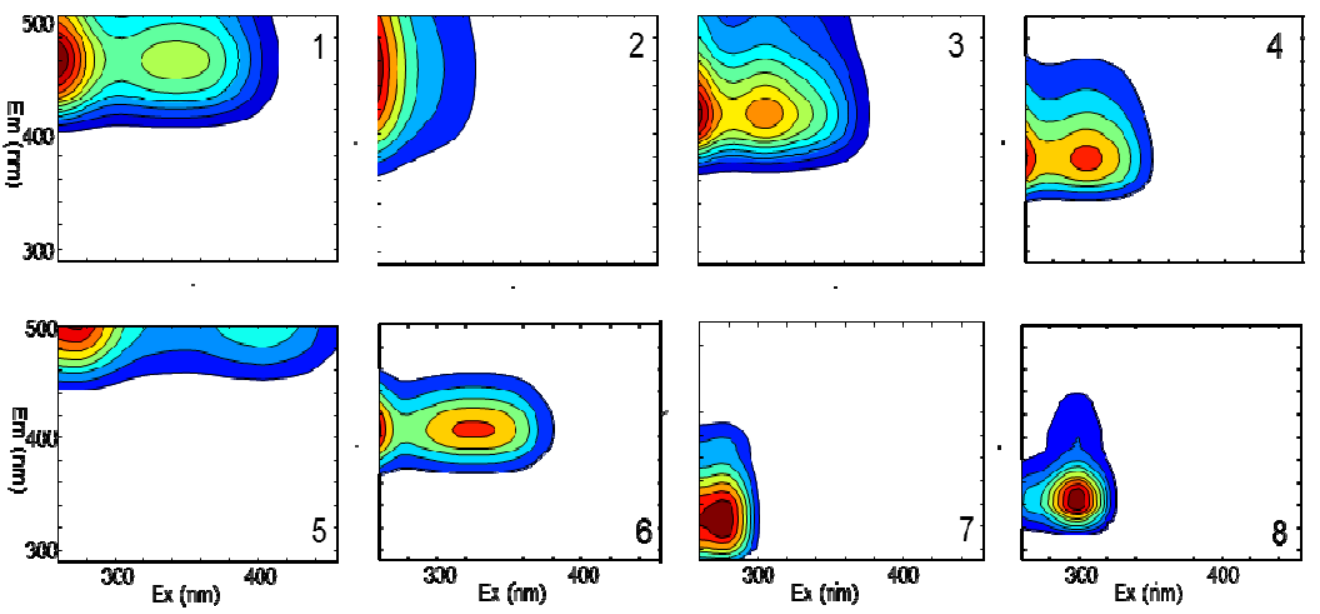

Fig.2.2 Spectral characteristics and contour plots of eight-component model for FCE surface water dataset $(n=1394)$. The Dotted lines show the excitation loadings and the solid lines show the emission loadings. Correlation of the split-half validation data is indicated.

The PARAFAC modeling can be obtained by both creating and validating the model using the complete dataset of EEMs, or by fitting the EEMs to an already established PARAFAC model. In the present study, a total of more than one thousand samples of the monthly monitoring surface water samples together with some Everglades/Florida Bay surface water samples collected for other studies (e.g. Yamashita et al., 2010), 
were used to create and an Everglades surface water PARAFAC model. The analysis was carried out in MATLAB 7.0.4. (Mathworks, Natick, MA) with the DOMFluor toolbox and validated as previously described (Stedmon and Bro 2008). Eight EEM-PARAFAC components were obtained after parallel factor analysis (PARAFAC) modeling of the EEM data, consisting of six humic-like and two protein-like components as summarized in Table 2.2. PARAFAC component spectral characteristics (Fig. 2.2) and split-half validation can be found elsewhere (Chen et al., 2010).

\subsection{Results and discussion:}

\subsubsection{Spatial clustering and seasonality}

To assess spatial DOM composition patterns, cluster analysis of all EEM-PARAFAC data from the 14 sampling sites (Fig.2.1), sampled monthly for four years was performed. To explore the patterns of spatial clustering first can help to categorize the 14 stations into several "groups" and thus aid in making this large, long-term, multi-station dataset more comprehensive for the following seasonality investigation. The data show a clear spatial clustering of the different sub-environments with regards to the EEM-PARAFAC composition of the DOM (Fig. 2.3). Interestingly, the clustering observed for the $\mathrm{TS} / \mathrm{Ph}$ sites was quite similar to that obtained previously for ultrafiltered DOM (UDOM) and characterized by pyrolysis-GC/MS (Maie et al., 2005). As such, the freshwater marsh sites for SRS (peat soils) clustered separately from $\mathrm{TS} / \mathrm{Ph}$ freshwater marshes (marl soils) 
Table 2.2 Summary of Excitation/Emission maxima, major sources, and seasonal and spatial patterns of EEM-PARAFAC components.

\begin{tabular}{|c|c|c|}
\hline component & items & $\begin{array}{l}\text { summary of componens seasonlity and spatial } \\
\text { patterns in FCE }\end{array}$ \\
\hline \multirow[t]{4}{*}{$\mathrm{C} 1$} & nature: & humic-like. \\
\hline & seasonality: & no clear pattern \\
\hline & & higher abundance in marsh and mangrove while \\
\hline & spatial: & lower in FB \\
\hline \multirow[t]{3}{*}{$\mathrm{C} 2$} & nature: & humic-like \\
\hline & seasonality: & higher abundance in the dry season \\
\hline & spatial: & highest abundances in SRS freshwater marsh sites \\
\hline \multirow[t]{4}{*}{$\mathrm{C} 3$} & nature: & humic-like \\
\hline & seasonality: & higher abundances in wet season except for FB \\
\hline & & higher abundance in marsh and mangrove while \\
\hline & spatial: & lower in FB \\
\hline \multirow[t]{2}{*}{$\mathrm{C} 4$} & nature: & humic-like \\
\hline & $\begin{array}{l}\text { seasonality: } \\
\text { spatial: }\end{array}$ & $\begin{array}{l}\text { generally slightly higher in the dry season } \\
\text { highest abundanes in FB sites }\end{array}$ \\
\hline \multirow[t]{4}{*}{$\mathrm{C} 5$} & nature: & humic-like. \\
\hline & seasonality: & generlly higher abundances in the wet season \\
\hline & & higher abundances in mangrove sites while lowest \\
\hline & spatial: & in FB \\
\hline \multirow[t]{2}{*}{ C6 } & nature: & humic-like \\
\hline & $\begin{array}{l}\text { seasonality: } \\
\text { spatial: }\end{array}$ & $\begin{array}{l}\text { generlly higher abundances in the dry season } \\
\text { relative higher abundances in FB }\end{array}$ \\
\hline \multirow[t]{3}{*}{$\mathrm{C} 7$} & nature: & protein-like \\
\hline & seasonality: & generally higher abundances in the wet season \\
\hline & spatial: & significant higher abundances in FB sites \\
\hline \multirow[t]{3}{*}{$\mathrm{C} 8$} & nature: & protein-like \\
\hline & seasonality: & no clear pattern; wide variation \\
\hline & spatial: & higher abundances in FB sites \\
\hline
\end{tabular}

suggesting a clear distinction in their DOM composition. Similarly, SRS and TS/Ph mangrove sites clustered separately implying, that although vegetation cover was similar soil properties, inundation patterns, tidal and upstream influences may all contribute to compositional differences of their DOM. Lastly, the Florida Bay sites 
expectedly all clustered separately from the freshwater and mangrove sites, as the DOM sources in the Bay are strongly influenced by the seasgrass communities (Maie et al., 2005) although some seasonal hydrological and primary productivity influences have also been noted (Maie et al., 2006a).

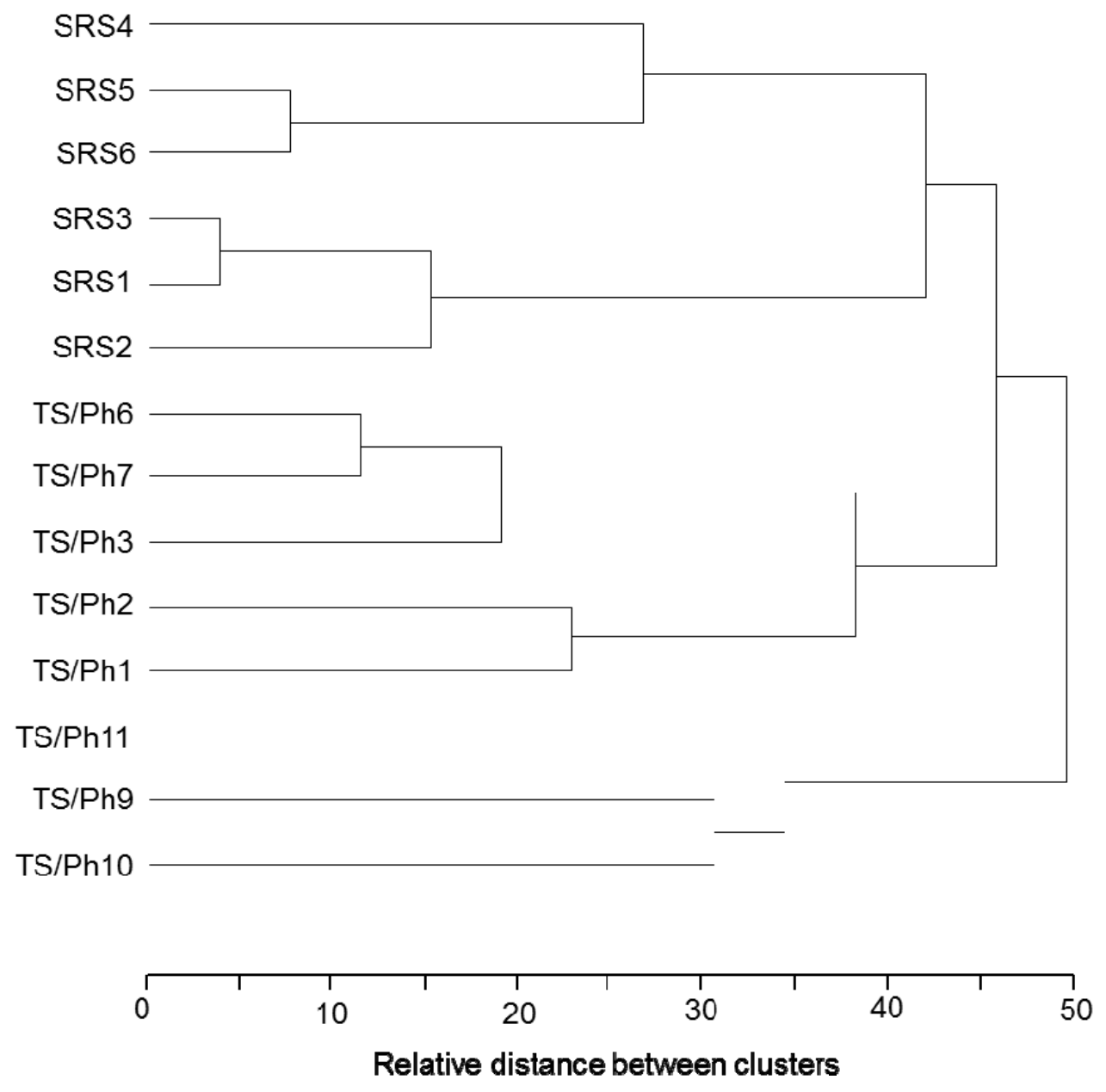

Fig.2.3 Cluster analysis (Ward method of normalized data) of 14 sampling sites in FCE based on the EEM-PARAFAC data of DOM. 
With regards to seasonality, examples for the DOC and the fluorescence intensity of the humic-like $\mathrm{C} 1$, the most abundant, ubiquitous, fluorescent component in Everglades DOM (Yamashita et al., 2010), are shown in Fig. 2.4a and 2.4b respectively, using the peat-based freshwater marsh site SRS-3 and the mangrove site TS/Ph-7 as examples. A consistent but opposed seasonality is observed at both sites during the wet and dry season, for both the DOC and $\mathrm{C} 1$ data, implying different drivers for DOM dynamics at different sites. Commonly, both parameters show higher values of DOC and $\mathrm{C} 1$ during the dry season for SRS3, while the opposite was the case for $\mathrm{TS} / \mathrm{Ph} 7$. The higher abundance during the dry season at the freshwater marsh SRS-3 site may be attributed to several possible factors: First, a concentration effect during the dry season's high evaporation rates and to the increased impact of canal water input from the WCAs during the dry season's enhanced pumping, which would increment DOM loadings at SRS. Alternative hypotheses to be tested are an increased soil derived DOM pool and/or enhanced ground-to-surface water exchange during the dry season. However, the case of the mangrove estuarine site $\mathrm{TS} / \mathrm{Ph}-7$ is quite different. The $\mathrm{TS} / \mathrm{Ph}-7$ is located at the mouth of Taylor Slough which is severely affected by the hydrological exchange between the freshwater marshes and Florida Bay. Much higher concentration of both DOC and the humic-like DOM were observed during the wet season as a result of enhanced terrestrial end-member transport from the freshwater marsh and mangrove forest with the increased freshwater head, as compared to an enhanced Florida Bay water intrusion and mixing during the dry season, resulting in much lower DOC and particularly the humic-like 

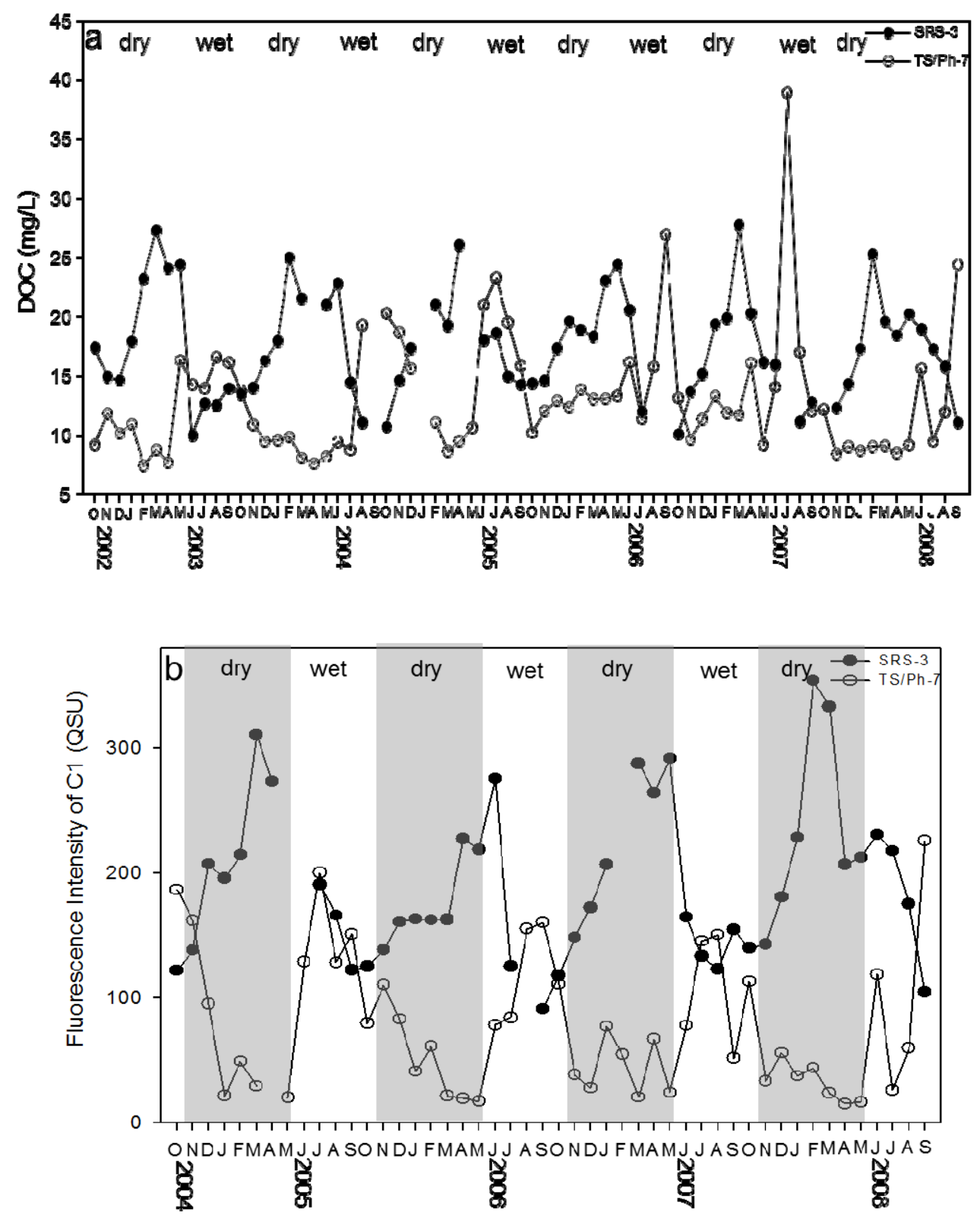

Fig.2.4 Examples of year-to-year trends of dissolved organic matter (6-year) and C1 fluorescence intensity (4-year) for freshwater marsh site SRS-3 and mangrove site TS/Ph-7. 2002-2004 DOC data is from Parish thesis (2006).

C1 abundance. Similar distributions were observed for $a(254) *$ (data not shown).

Thus, hydrological processes seemed to be the dominant drivers of seasonality for both sites discussed above. 
On the basis of the above-described spatial patterns (Fig. 2.3), which seem derived from biomass cover characteristics and soil type and considering that hydrological drivers will likely influence the seasonal patterns (e.g., Maie et al.,
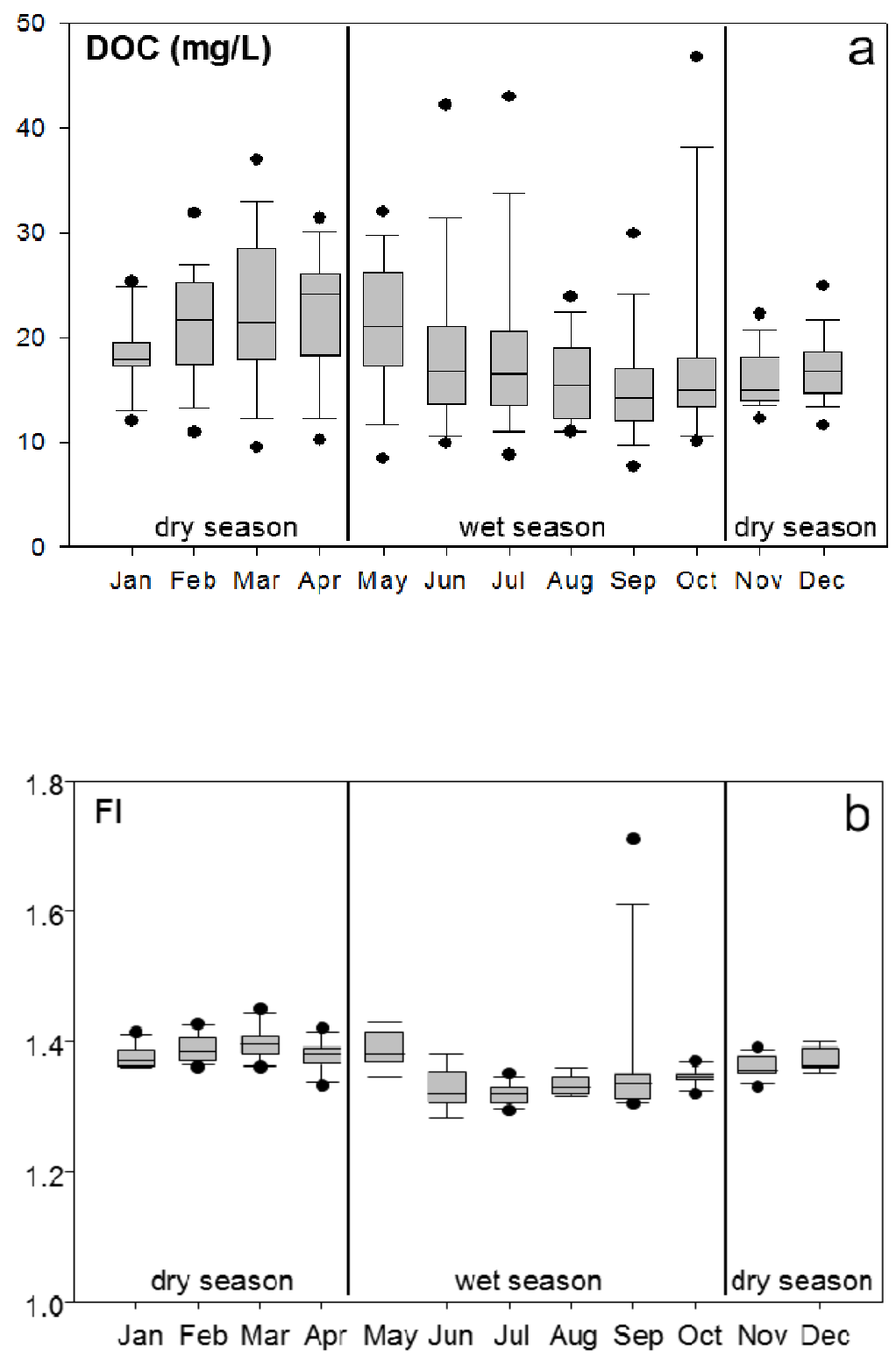

Fig.2.5 Examples of seasonal variation of DOC (6-year) and Fluorescence Index (4-year) at peat- based freshwater marsh sites SRS1-3 based on box plots. 
2006a; Jaffé et al., 2008), the data were reorganized into monthly averages based on sub-environment type. An example for the SRS freshwater sites (SRS1-3) is shown in Figure 2.5 representing seasonal patterns for $\mathrm{DOC}$ and fluorescence index $\left(\mathrm{FI}_{2}\right.$, referred to as FI from here on). The DOC data plotted in this modified format agree with the data shown previously for the seasonal distribution, where, the DOC levels were observed to be highest at the end of the dry to beginning of the wet season, and lowest values towards the end of the wet season. Qualitatively, the FI values (Fig.2.5b) were higher during the dry compared to the wet season, suggesting enrichments in microbial and soil-derived DOM components during the dry and wet season respectively. Thus, the previous suggestion (see above) that high DOC levels during the dry season could be in part derived from higher soil inputs does not seem to be applicable, and concentration that result from increased evaporation and canal inputs (management) are more likely sources to explain this observation. However, canal inputs are usually characterized as high in humic-like DOM (Lu et al., 2003; Yamashita et al., 2010), thus suggesting that the concentration effect due to evaporation may be dominant. Taken together, very clear seasonal and spatial patterns were demonstrated across the studied landscape over a four years period.

\subsubsection{Cross-site and cross-season comparison of DOC, FI, $\mathrm{S}_{\mathrm{R}}, a(254)^{*}$}

In an attempt to further condense the large dataset into figures that summarized seasonal data, sampling sites were condensed on the basis of the environment "type" as follows: peat-based freshwater marsh sites (SRS-1, SRS-2, 
SRS-3), marl-based freshwater marsh sites (TS/Ph-1, TS/Ph-2, TS/Ph-3), SRS-mangrove sites (SRS-4, SRS-5, SRS-6), TS/Ph-mangrove sites (TS/Ph-6, TS/Ph-7), and estuary-FB sites (TS/Ph-9, TS/Ph-10, TS/Ph-11). In addition, seasonal data were combined into wet (May-October) and dry (November-April) seasons. This approach greatly facilitated the cross-season and cross-site comparison of DOM quantity and quality as shown in Fig.2.6.

Cross-site and cross-season comparison of DOC, $a(254)^{*}$, fluorescence index (FI), and spectral ratio $\left(\mathrm{S}_{\mathrm{R}}\right)$ are shown in Fig.2.7a to 2.7d. Different letters and asterisk * symbol, beside boxes stand for significantly different by nonparametric significance tests (Asymptotic significance $<0.01$ ). The DOC values ranged from 1.5 to 46.7 mg C L $\mathrm{m}^{-1}$. Peat-based freshwater marsh sites (SRS-1, SRS-2, RS-3) showed significant higher concentration of DOC in the dry season compared to the wet season, whereas marl-based freshwater sites (TS/Ph-1, TS/Ph-2, TS/Ph-3) had significantly lower values during the dry season (Asymptotic significance $<0.01$ ). The difference between the long and short hydroperiod freshwater marsh sites may in part be due to the periodical dry-out of the $\mathrm{TS} / \mathrm{Ph}$ sites, which may result in high DOC levels at the early wet season due to DOC leaching when dry periphyton mats and surface souls become re-hydrated. DOC-based seasonality was not obvious for any of the other sites, suggesting different drivers control DOC at the mangrove and Florida Bay sites. The $a(254)^{*}$ is a proxy of DOM aromaticity, and wet season peat-based SRS-mangrove sites have significantly higher (Asymptotic significance $<0.01)$ a(254)* than all the other sites (Fig.2.6b), suggesting the higher aromaticity character of the 
mangrove leachate which may be contributed by woody vascular plant-derived aromatic polyphenols (Maie et al., 2006c; Scully et al., 2004). There is a general trend
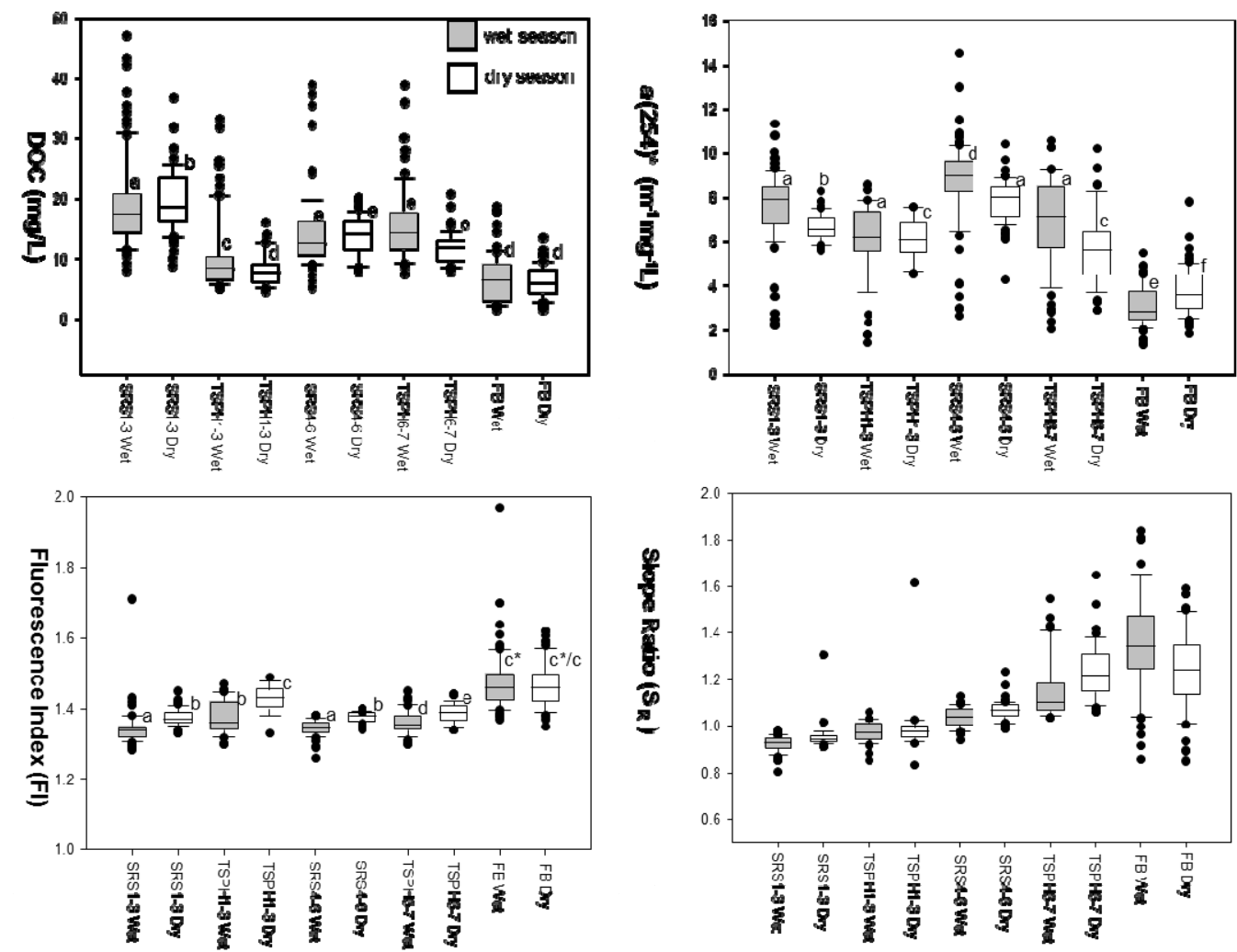

Fig.2.6 Cross-site and cross-season comparison of 6-year's DOC and a(254)*; and 4-year's fluorescence index (FI) and Spectral ratio (SR). Different letters, or same letter with or without asterisk *, beside boxes stand for significantly different among all sub-region by nonparametric significance tests (Asymp. Sig. $<0.01)$.

of higher aromaticity in the wet season except for Florida Bay sites, potentially because increased higher plants biomass inputs (increased primary productivity) and soil leachates during the wet season. In addition, since such aromatic DOM is usually 
considered more photo-reactive (Hansell \& Carlson 2002 and reference therein), deeper water depth and shorter water residence times during the wet season could reduce the solar exposure as compared to that of the dry season enhancing the $a(254)^{*}$ values. Florida Bay sites showed the lowest $a(254) *$ values, which is expected considering that most DOC in the bay is derived from the seagrass community and reported to be highly enriched in carbohydrates (Maie et al., 2005). The seasonal changes were also different to those observed for the other sites, with higher aromaticity during the dry season. However, wet/dry seasonality influences Florida Bay differently, as DOM dynamics in this area have been found to depend on seagrass primary productivity and freshwater discharge (Maie et al., 2006a; Jaffé et al., 2008; Maie et al., personal communication) that have a different time-dependency to that used here, where the later occurs during the late wet season which is part of the dry season as defined in this study.

The FI is a proxy of DOM source typically presenting lower values (1.2-1.4) for terrestrially derived DOM and higher values (1.6-1.9) for microbially derived DOM (McKnight et al., 2001; Jaffe et al., 2008). For the studied sites, the FI values ranged from 1.26 to 1.97 throughout the Everglades landscape (Fig.2.6c), with the highest values observed in Florida Bay, while the SRS mangrove sites had the lowest value during the wet season. With the exception of Florida Bay, the FI was significant higher during the dry season. The general trend of the FI was expectedly opposed to that of the $a(254)^{*}$. Higher dry season FI values at the estuarine mangrove sites reflect the tidal/marine DOM inputs during that season, while the freshwater marsh sites are 
less influenced by soil-derived DOM, and showing an enriched microbial DOM signal during the dry season. The short hydroperiod $\mathrm{TS} / \mathrm{Ph}$ freshwater sites are more prone to such microbial influences, supporting the fact that they showed higher FI value than the other freshwater marsh and mangrove sites.

Slope ratio $\left(\mathrm{S}_{\mathrm{R}}\right)$ values, an optical measure inversely proportional to the molecular weight of DOM (Helms et al., 2008), was previously shown to increase along a general North-to-South transect across the Everglades, with lower $\mathrm{S}_{\mathrm{R}}$ values in the most northern WCAs and higher values in ENP (Yamashita et al., 2010), suggesting a transition from soil derived DOM to biomass derived DOM along this transect. Similarly, but at a smaller geographic scale, in this study an increased $S_{R}$ value across the freshwater marsh to mangrove fringe to marine estuary environments was observed (Fig.2.6d), suggesting a trend of decreasing molecular weight across the terrestrial to marine end member. There is a general trend of lower molecular weights during the dry season (except for the Florida Bay sites), which is consistent with the general trend of lower aromaticity and increased microbial sources during the dry season as shown before, suggesting high molecular weight (MW) soil-derived DOM in the wet, and lower MW microbial-derived DOM in the dry season. Higher water residence times, combined with more shallow water periods during the dry season may also enhance photo-degradation leading to a reduction in the overall molecular weight of the DOM (Lou and Xie 2006). However, photo-degradation of DOM has been reported to decrease the FI values which were observed to actually be higher during the dry season, thus suggesting that photo-degradation may not be the 
determining process controlling $S_{R}$ values in the FCE. Higher $S_{R}$ values in Florida Bay in the wet season may be associated with high low molecular weight phytoplankton-derived, rather than terrestrial higher plants-derived DOM in the wet season as compared to in the dry season.

\subsubsection{Cross-site and cross-season comparison of EEM-PARAFAC components}

With respect to the seasonal distribution of the EEM-PARAFAC components, these are shown in Figure 2.7a to 2.7h. In Figure 2.7a the distribution of component $\mathrm{C} 1$, a humic-like component which is ubiquitous in aquatic environments and abundant in biomass and soil, showed the highest relative abundance of the eight PARAFAC components observed. While the total EEM fluorescence corresponding to C1 ranged from $18.5 \%$ to $36.5 \%$ with lowest relative abundance in Florida Bay (Fig.2.7a), implying a significant terrestrial DOM input to all sites, no consistent seasonal pattern was observed. The relative abundance of $\mathrm{C} 1 \%$ was a little lower for FB sites in wet season, while TS/Ph-mangrove sites displayed a little lower value in dry season because of Florida Bay water intrusions.

The C2 component, which is believed to be a photoproduct and/or photo-refractory component (Chen et al., 2010), and has also been found in high abundance in canal water draining agricultural areas in the northern Everglades Agricultural Area (EAA) (Yamashita et al., 2010), displayed a pronounced and uniform seasonal pattern of higher abundance in the dry season for all sites (Fig.2.7b). Highest abundances were observed for the freshwater marsh sites of SRS-1 to 3, 
which are likely the most influenced by drainage from the EAA, particularly during the dry season (Yamashita et al., 2010). Accelerated decomposition and export of "old" peat derived DOM as a result of the agricultural land use may be responsible for the higher abundance of $\mathrm{C} 2$ in the dry season when more canal water from the WCAs enters ENP. Wang et al. (2002) found that at least some of the "old" historic peat-derived DOM was decomposed during their residence time in the surface water in the northern Everglades and transported by canals southwards. Similarly, Yamashita et al. (2010) reported significant canal transport of C2 from the EAA towards ENP. Thus it is not surprising that this component was observed at higher relative abundance at the SRS1 to 3 sites. In addition, enhanced influence of solar exposure because of shallower water depth and longer water residence time during the dry season could also potentially contribute further to the higher $\mathrm{C} 2$ abundance during the dry season.

Another humic-like component $\mathrm{C} 3$, which has been found to be usually less abundant compared to $\mathrm{C} 1$, showed a clearer seasonal pattern. Relative abundance of $\mathrm{C} 3 \%$ reached as high as $28.7 \%$ during the wet season in the marl-based $\mathrm{TS} / \mathrm{Ph}$ freshwater marsh sites, but was lower in abundance and occasionally absent for the Florida Bay sites (Fig.2.7c), suggesting a primary terrestrial source for this component. A general trend of higher $\mathrm{C} 3 \%$ values in the wet season compared to the dry season, suggests its source from soils and/or decomposition of higher plant organic matter. FB sites behaved the opposite, possibly caused by the fact that water discharge to FB from the Everglades peaks during the latter part of the wet season (Jaffé et al., 2008). 
The humic-like component $\mathrm{C} 4$ has traditionally been termed as 'marine humic-like' (Coble 1996) but has also been found in freshwaters (Chen et al., 2010; Yamashita et al., 2010), and as such is generally referred to as a microbial humic-like component. Recently it has been detected in some higher plant tissue leachates and could also be produced during DOM degradation (Chen 2011, Dissertation Chapter 3). In this study a general trend of slightly higher abundance during the dry season was observed in most cases (Fig.2.8d). Such increased microbial activity during the dry season confirms the patterns observed for the fluorescence index (FI) data (Fig.2.7c). Florida Bay sites showed significantly higher abundance than the rest freshwater marsh and mangrove sites, suggesting a major marine end-member input for $\mathrm{C} 4$.

Component $\mathrm{C} 5$ is believed to be a red-shifted humic-like component, which is also ubiquitous in biomass and soil but generally less abundant than C1 in the Everglades ecosystem (Yamashita et al., 2010). It showed similar behavior to $\mathrm{C} 1$ but generally showed better defined spatial and seasonal patterns (Fig.2.7e), with mangroves sites having significantly higher abundance and Florida Bay sites the lowest. Its abundance during the wet season dominated over the dry season in most cases, as in the case of C3. Components similar to C5 had been found to be relatively enriched in soils and sediments especially in the humic acid fraction (Santin et al., 2009), and thus could reflect enhanced soil derived DOM contributions during the wet season.

Component C6 is known to be photosensitive and thus has been found enriched in Everglades groundwater compared to surface waters (Chen et al., 2010). It 

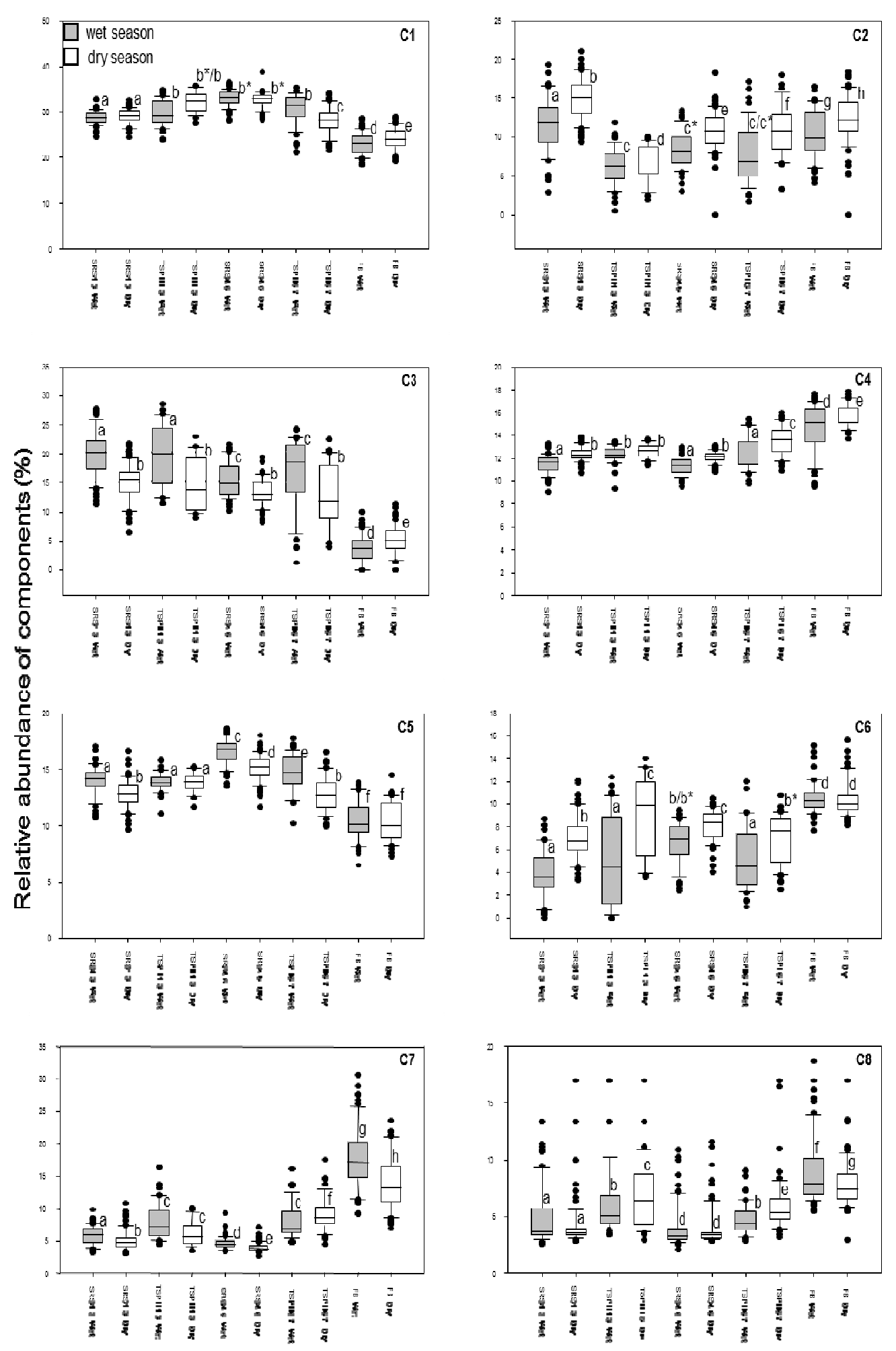

Fig.2.7 Cross-site and cross-season comparison of relative abundance of EEM-PARAFAC components. 
has also been reported to be abundant in DOM derived from soil oxidation from agricultural areas of the Everglades (Yamashita et al., 2010), and consequently can be expected to be enriched in canal waters. It was also found to be relative enriched in peat soil leachates and to increase during bio-incubation (Chen 2011; Dissertation chapter 3). A general trend of higher abundances of C6 during the dry season was observed in this study, suggesting enhanced canal water inputs to the freshwater marsh sites, increased groundwater input during the dry season when the water head is low, and/or increased microbial activity during the dry season (see also FI trends). FB sites showed relative higher abundances, consistent with the observation that C6 was found to be enriched in seagrass leachates (Dissertation chapter 3).

The abundance of component C7, classified as a protein-like (tyrosine-like and/or blue-shifted tryptophan-like) component (Chen et al., 2010; Yamashita et al., 2010), was significantly higher at the Florida Bay sites, particularly during the wet season (Fig.2.7g) when the primary productivity was highest (early wet season; Jaffé et al., 2008) suggesting that C7 is mostly biomass-derived. The TS/Ph-mangrove sites showed higher values in the dry season as a result of the higher protein-like DOM derived from Florida Bay water intrusion, a trend also previously observed for $\mathrm{C} 4$ and FI.

The relative abundance of another protein-like component (tryptophan-like), C8 (Chen et al., 2010; Yamashita et al., 2010), was among the lowest of all EEM components, and as such is most sensitive to influences by the fluctuations of other 
more abundant components. Thus, the $\mathrm{C} 8$ distribution (Fig.2.8h) showed large ranges in abundance values in the box plot, indicating sporadically big variations for this component at each sub-environment and suggesting a potentially different dominant source as compared to $\mathrm{C} 7$. It is not surprising that both $\mathrm{C} 7$ and $\mathrm{C} 8$ showed relative higher abundance at the Florida Bay sites during wet season, consistent with that higher abundance of protein-like DOM from the marine end-member.

To assess an overall spatial and temporal profile for DOM in the Everglades, principal component analysis (PCA) of all four year monthly monitoring EEM-PARAFAC data from all sites $(\mathrm{n}=568)$ was carried out (Fig.2.8). The resulting score and loading plots are shown in Figure 2.8a and 2.8b respectively. Principal Component (PC) 1 accounted for 57\% and PC2 accounted for another $16 \%$ of the variability. As illustrated in the loading plot of PCA (Fig.2.8b), PC1 was negatively correlated with the humic-like components $\mathrm{C} 1, \mathrm{C} 3$, and $\mathrm{C} 5$, whereas the microbial humic-like and protein-like components $\mathrm{C} 4, \mathrm{C} 6, \mathrm{C} 7$, and $\mathrm{C} 8$ were positively correlated. While PC1 seems to be a source-related variable ('terrestrial' vs. 'microbial'), PC2 seems to be controlled primarily by component $\mathrm{C} 2$, suggesting either the diagenetic status (photodegradation) of the DOM (Chen et al., 2010), or the influence of DOM inputs from the WCAs or agricultural soils (Yamashita et al., 2010).

Hence, the PCA clustering of sample types seems to make sense in that FB surface water samples were dominated by microbial humic-like and protein-like fluorophores (i.e. showing a positive correlation with PC1), while the freshwater and 

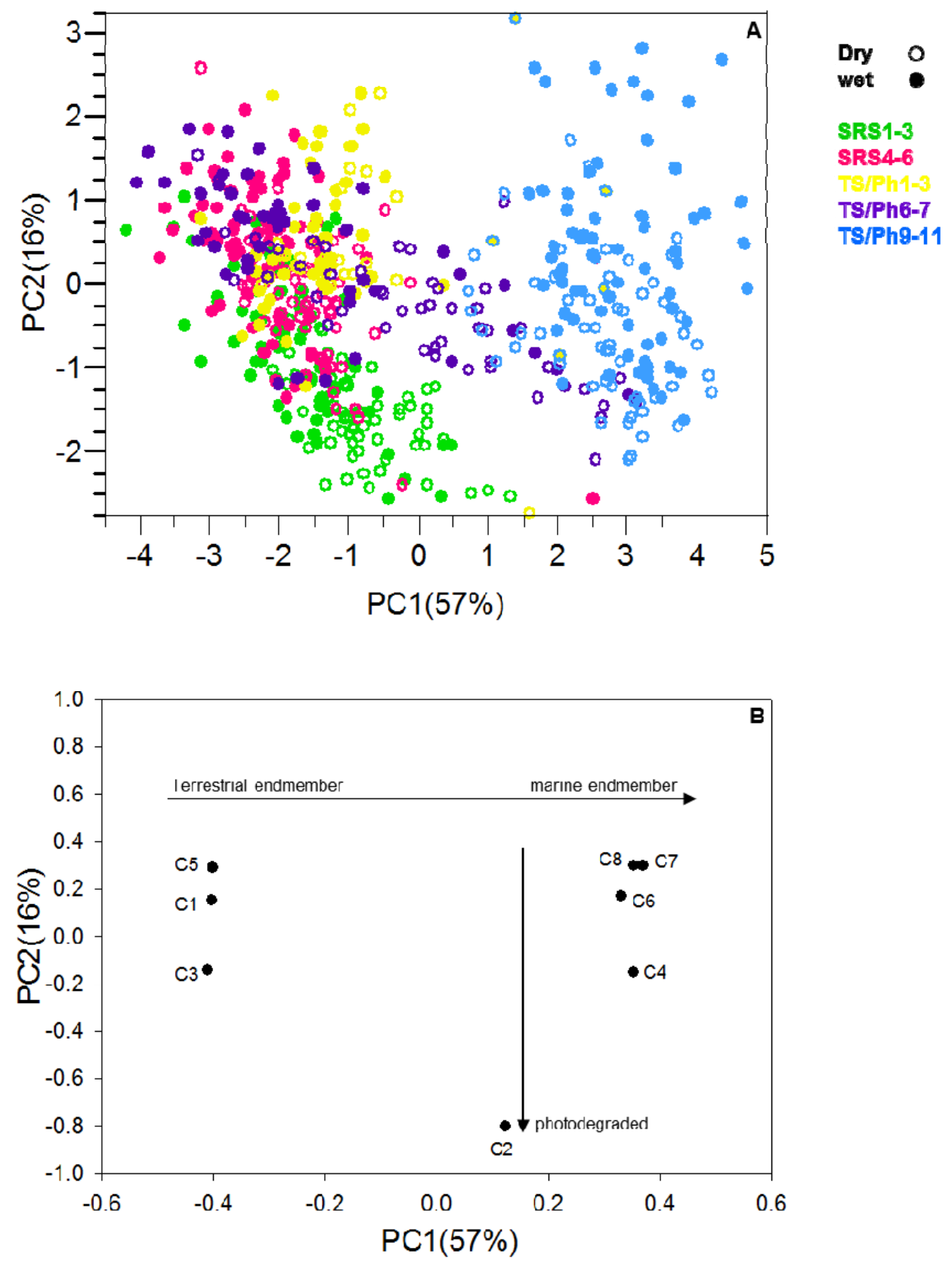

Fig.2.8 PCA of overall four-year monthly monitoring EEM-PARAFAC data $(n=568)$. (A) score plot; (B) loading plot.

mangrove sites seemed controlled by the humic-like components (i.e. negative correlation with $\mathrm{PC} 1)$. Samples from the $\mathrm{TS} / \mathrm{Ph}$ mangrove sites showed a broad 
distribution with regards to $\mathrm{PC} 1$, ranging from the marine to freshwater end-members, suggesting a strong seasonal influence, whereby dry season samples were more closely influenced by FB water intrusions, while wet season samples were clearly hydrologically influenced by the upstream sources. Similarly, wet season freshwater marsh sites were more strongly influenced by humic-like components (soil sources during wet season) showing a more negative correlation with $\mathrm{PC} 1$ compared to the dry season samples which were found to be more microbially influenced. As for PC2, the influence of C2 seems to be strongest on the SRS freshwater marsh sites, as these are most influenced by WCA derived DOM inputs. Expectedly, this effect was enhanced during the dry season.

\subsection{Conclusions:}

Clear variations in quantity and quality (i.e., composition) of DOM in the greater Everglades were observed on both spatial and temporal scales. Local ecological drivers such as biomass type and primary productivity as well as regional climatic influences such as wet and dry seasons were all found to have a significant effect on DOM dynamics. Hydrology is a crucial component in the Everglades as a physical driver controlling the water level, hydroperiod, water residence time, vertical and horizontal hydrological exchange, tidal mixing and salt water intrusions, which can all influence DOM composition and dynamics by affecting vegetation and soil types and patterns, and transport characteristics. The data presented above suggests that soil type and associated plant cover, can affect DOM quality and quantity in 
wetlands. The low value of DOC in marl-based Taylor Slough freshwater sites and biogenetic carbonate mud-based Florida Bay (FB) sites suggested lower inputs of DOC as compared to soils in the peat-based freshwater marsh sites and peat-based mangrove sites. This difference was not only quantitative but also qualitative as reflected in higher microbial $\mathrm{DOM}$ contributions for the $\mathrm{TS} / \mathrm{Ph}$ and $\mathrm{FB}$ sites. In addition, seasonal variations in primary productivity can also affect DOM quantity and quality. Primary productivity is higher during the summer wet season resulting in increased biomass leaching, exudation, and throughfall in comparison to the dry season. Primary productivity based changes in DOM dynamics were particularly strong in Florida Bay where seagrass communities are responsible for the production of a significant portion of the DOM pool (see also: Maie et al., 2005; Maie et al., 2006a). Anthropogenic effects of water management in the Everglades on water depth, water residence time, and increased water delivery from the canals particularly during the dry season, all represent important drivers controlling DOM spatial and temporal patterns. This study exemplifies the effectiveness of applying optical properties and in particular EEM-PARAFAC in the assessment of DOM dynamics on large spatial and temporal scales. Such studies are essential to better understand potential effects of climate change, management, and other anthropogenic influences on carbon and nutrient cycling in aquatic ecosystems. This is particularly true for Everglades, a subtropical oligotrophic coastal wetland suffering from century-long hydrological alterations and ecological deterioration, but which is presently undergoing an unprecedented restoration effort. 


\section{Chapter 3}

Assessment of Photo- and Bio-reactivity of Dissolved Organic Matter from Biomass and Soil Leachate and Surface Water in the Florida Everglades using Excitation-emission Matrix and Parallel Factor Analysis 


\subsection{Abstract}

Dissolved organic matter (DOM) is one of the largest carbon reservoirs on earth ( $\sim 700 \mathrm{Gt} \mathrm{C})$. While the environmental dynamics of this carbon pool have been widely studied, there is a paucity of detailed and comprehensive information available regarding contributions from different sources as well as on its photo- and bio-reactivity particularly for large wetland systems. An extensive suite of biomass and soil leachates together with surface water samples from Florida coastal Everglades (FCE) were investigated in an attempt to trace the sources and transformations of DOM qualitatively and quantitatively via excitation-emission matrix (EEM) fluorescence, combined with parallel factor analysis (PARAFAC) through controlled laboratory experiments. Qualitatively speaking, photo-degradation results showed that while most of the EEM-PARAFAC components displayed photo-decay, some displayed no apparent change or mixed decay/formation patterns, and a few showed photo-productions. In contrast, most EEM-PARAFAC components proved to be bio-refractory except for some of the components from biomass leachate. The sequential degradation (photo- followed by bio-degradation), showed a "priming effect" of light exposure on the biodegradation of DOM, and the combination of these two processes resulted in a DOM composition more similar to that of the natural surface water. Quantitatively speaking, the reactivity rate constants for each EEM-PARAFAC component from different source after fitting into a multi-pool first order kinetics model, displayed vast differences suggesting a complex composition of fluorophores for each PARAFAC component, most likely the result of different 
structures, speciation and conformation, and molecular weight distributions. The relative reactivity of DOM determined as labile, semi-labile and refractory from different sources generally displayed an order of biomass leachate $>$ soil leachate $>$ natural surface water, based on an estimated water residence time of about two months for the specific study area, Everglades National Park. While photo-reactivity seems to be potentially more important in controlling the fate of DOM in this system, bio-reactivity by itself was characterized as mainly refractory for the fluorescent DOM. This study confirms the applicability of EEM-PARAFAC components to trace DOM sources, degradation state, and reactivity. Furthermore, the results highlighted the importance of solar irradiation in wetland DOM biogeochemical cycling. In addition, this call for a cautious approach when direct comparisons between EEM-PARAFAC components in different ecosystems are performed as components with similar fluorescence characteristics can actually present very different photo- and bio-reactivity due to different structural features or speciation states.

\subsection{Introduction:}

DOM is one of the most mobile, dynamic, and largest carbon reservoirs on Earth $(\sim 700 \mathrm{Gt} \mathrm{C})$, larger than all the carbon fixed by biomass $(\sim 600 \mathrm{Gt} \mathrm{C})$, and comparable to the amount of atmospheric inorganic carbon ( 750 Gt C) (Siegenthaler and Sarmiento 1993; Jiao et al., 2010). DOM plays diverse important ecological and environmental roles both on local ecosystem and globally. Locally, it serves as energy source for heterotrophic bacteria and thus fuels the microbial loop, acts as a natural 
sunlight attenuator and $\mathrm{pH}$ buffer for aquatic ecosystems. Furthermore, it is a carrier for organic and inorganic xenobiotics, so the dynamics of DOM can impact the transport and fate of environmentally significant pollutants. Globally, as one of the largest and mobile carbon pools on Earth, the biogeochemical cycling of DOM is intricately associated with nutrient and element cycling and as well climate change (Findlay and Sinsabaugh 2003; Hansell and Carlson 2002).

Degradation and transformation processes of DOM have been a fundamental question and a topic of particular interest to both ecologists and biogeochemists for decades. So far, photo- and bio-degradation are regarded as two major processes, working in parallel, in competition, and in concert, to transform and mineralize DOM (Obernosterer and Benner 2004; Hansell and Carlson 2002 and references therein). Heterotrophic microorganisms have long been known as DOM decomposers, and have a proven ability to uptake labile molecules (e.g., free amino acids and carbohydrates) readily and cleave certain biopolymers via exoenzymes (Benner and Kaiser 2010; Arnosti 2003). Microorganisms were also observed to synthesize refractory DOM out of simple small molecules (Ogawa et al., 2001). While the role of microorganisms in DOM degradation has long been recognized, the importance of solar irradiation was only recognized 1-2 decades ago, and triggered an intensified research on the DOM photo-degradation (Moran and Zepp, 2000; Moran and Covert, 2003; Scully et al., 2004; Spencer et al., 2009; Gonsior et al., 2009; Ortega-Retuerta et al., 2010; Shank et al., 2010; Stubbins et al., 2010; Benner and Kaiser 2010). To date, studies have found solar radiation can cause photominerization (produce $\mathrm{CO}_{2}, \mathrm{CO}$, 
carbonyl sulfide, etc.), photoamonification (produce $\mathrm{NH}_{4}^{-}$), photobleaching of CDOM, photohumification, photoproduction of new DOM, and photoformation of reactive oxygen species (ROS: ${ }^{1} \mathrm{O}_{2}$, HO•, etc.) (Moran and Zepp 2000; Stedmon et al., 2007; Housari et al., 2010; Clark et al., 2004). It has been observed that photoalterations can increase, decrease, or have no net effect on biodegradability of DOM depending on different DOM sources (Tranvik and Bertilson 2001; Moran and Zepp 2000). However, there is a general consensus that sunlight has "priming effect" for bacterial uptake on old terrestrial-derived DOM as opposite to the negative effects on fresh algae-derived DOM (Moran and Covert 2003).

Photo- and bio-reactivity of DOM have been observed to be linked to its inherent structure (Opsahl and Benner 1995; Benner and Kaiser 2010), and compositional differences and structural features of DOM have been reported as playing critical roles in controlling its reactivity. Detailed structure determinations by nuclear magnetic resonance (NMR) and mass spectroscopy (FT-ICR/MS and others), have provided evidence for this (Mopper et al., 2007; Koch et al., 2008; Abdulla et al., 2010a; Abdulla et al., 2010b; Gonsior et al., 2011). The compositional variability of the DOM might therefore result in carbon pools of varying reactivity. As such, Davis and Benner (2007) quantified the concentrations of three pools of DOM, i.e., labile, semi-labile, and refractory, DOM on the basis of bio-reactivity of carbonnormalized yields of combined amino acids. They defined labile, semi-labile, and refractory DOM based on the timescales of biological utilization of hours-weeks, months-decades, and centuries-millennia, respectively. While biomolecules such as 
amino acids and neutral sugars have been related to bioavailability of DOM (Davis et al., 2009), Benner and Kaiser (2010) proposed using carbon-normalized amino acids and lignin phenols as indicators of DOM bio- and photo-lability respectively. Recently, the percent of protein-like components of DOM, as defined by their excitation emission matrix (EEM) fluorescence, have been found to show a close correlation with the bioavailable dissolved organic carbon (BDOC) pool (Balcarczyk et al., 2009; Fellman et al., 2008, 2009a, and 2009b). Meanwhile, external factors have also been found to play various roles in DOM turnover rates. Physical, chemical, and biological conditions, such as microbial community structure and physiological status, temperature, availability of oxygen, sunlight, presence of photosensitizers (e.g. dissolved $\mathrm{Fe}, \mathrm{NO}_{3}^{-}, \mathrm{NO}_{2}^{-}$) or inhibitors, $\mathrm{pH}$, ionic strength and salinity, have been observed to be involved in affecting DOM transformation and rate (Schmitt-Kopplin et al., 1998; Minor et al., 2006; Marschnera and Kalbitz 2003). The underlying degradation pathways and mechanisms of DOM however, remain elusive although there are multiple proposed processes such as exoenzymatic cleavage and bacterial reworking, bond cleavage by UV, ring opening and/or photo-Fenton reactions and free radical chain reaction caused by reactive oxygen species (ROS) (Boreen et al., 2008; Southworth and Voelker 2003).

Because of their easy use and sensitivity, optical techniques have shown significant potential to trace the source, transformation and fate of organic matter in various environments (Jaffé et el., 2008; Fellman et al., 2010). Fluorescence spectroscopy has been successfully used to study the dynamics of DOM 
over the past decades and opens new windows into DOM dynamics in aquatic ecosystems (Fellman et al., 2010; Jaffé et al., 2008; Yamashita et al., 2010). By decomposing the EEM data statistically into different fluorescent components, EEM-PARAFAC has been successfully applied in DOM studies, including the photodegradation and biodegradation studies (Stedmon and Markager 2005), in diverse environments over the past years (Stedmon et al., 2003; Cory and McKnight 2005; Ohno and Bro 2006; Yamashita and Jaffé 2008; Fellman et al., 2009a, 2009b).

The Florida coastal Everglades (FCE) is one of the largest wetlands in the world and it is undergoing a historic restoration which aims to restore the quality, quantity, timing, and distribution of water flow (http://www.evergladesplan.org/). DOM in this P-limited oligotrophic subtropical wetland is primarily autochthonous and originates from the vegetation, algae, and peat and marl soil. Biomass leaching and soil diffusion have been demonstrated to be important sources of DOM in this ecosystem (Maie et al., 2006c; Scully et al., 2004; Davis et al., 2006). The majority of nitrogen $(\mathrm{N})$ and phosphorous $(\mathrm{P})$ in the Everglades are in organic forms and therefore associated with the DOM (Boyer et al., 1997; Boyer 2006). Therefore, the processes driving DOM transformation and turnover in the FCE are critical in driving local nutrient cycling. However, little is known about DOM reactivity and associated cycling in this ecosystem.

The goal of this study was to determine the photo- and bio-reactivity of DOM in the FCE qualitatively and quantitatively through an EEM-PARAFAC approach. The objectives were three-fold: (i) to assess the photo- versus bio- versus sequential 
(photo + bio) degradation processes of DOM; (ii) to determine DOM degradation rates using EEM-PARAFAC components by comparing photo- and bio-reactivity of DOM derived from different sources such as biomass, soils and surface waters and (iii) to semi-quantitatively determine pool sizes of labile, semi-labile and refractory DOM (defined based on local water residence times), with the objective to assess the potential impact of restoration-based enhanced water delivery on DOM dynamics in the FCE.

\subsection{Sampling and experimental methods}

\subsubsection{Sampling}

Senescent plant materials from Cladium jamaicense (sawgrass), Elocharis cellulosa (spikerush), Rhizophora mangle (red mangrove), fresh shoots of Thalassia testudinidum (seagrass), floating and epiphytic periphyton, top soils (including peat soil, marl soil, mangrove mud, and Florida Bay sediment), and surface water samples from different sub-environments were collected in the Florida Coastal Everglades. These biomass and soils are believed to be dominant sources of DOM in the FCE (Maie et al., 2006c; Yamashita et al., 2010a) in addition to direct inputs from agricultural areas (Yamashita et al., 2010). Table 3.1 summarizes the information of the sample characteristics and sampling stations, while Fig. 3.1 displays the locations of the sampling sites. The five biomass materials and corresponding surface water samples were obtained in July 2007 (wet season) and the four soil samples and corresponding surface water samples were collected in February 2008 (dry season). 
Biomass samples were hand-picked using pre-cleaned powder-free latex gloves (Fisher). Top soils/sediments were collected with a pre-cleaned small shovel. Before collecting the surface water samples, the bottles were rinsed three times with surface water. The samples were placed into pre-cleaned zip lock bags (Lab Safety Supply), pre-combusted glass jars (I-CHEM), and pre-cleaned acid-washed brown high-density polyethylene bottles (Nalgene) for biomass, soil, and surface water, respectively.

Table 3.1. Summary of sampling sites and sample descriptions.

\begin{tabular}{|c|c|c|}
\hline sample name & species/type & sample description \\
\hline \multicolumn{3}{|l|}{ biomass } \\
\hline & Cladium & \\
\hline sawgrass (TS/Ph2) & jamaicense & above water senescencent leaves \\
\hline spikerush(SRS3) & Elocharis cellulosa & above water senescencent stems \\
\hline periphyton(TS/Ph2) & $\begin{array}{c}\text { floating and } \\
\text { epiphytic }\end{array}$ & entangled with utricularia \\
\hline & Rhizophora & \\
\hline mangrove(SRS5) & mangle & yellow leaves picked from trees \\
\hline seagrass(TS/Ph11) & $\begin{array}{c}\text { Thalassia } \\
\text { testudinidum }\end{array}$ & whole shoots \\
\hline \multicolumn{3}{|l|}{ soil/sediment } \\
\hline SRS3 soil & wetland peat & dark and fine \\
\hline SRS5 soil & wetland peat & dark color with fine capillary roots \\
\hline $\mathrm{TS} / \mathrm{Ph} 2$ soil & wetland marly peat & light color \\
\hline $\mathrm{TS} / \mathrm{Ph} 11$ soil & calcitic marl & white and coarse \\
\hline
\end{tabular}

All samples were stored on ice immediately after collection, transported to the laboratory within 12 hours, and stored under refrigeration until further processing. 
Surface water was sequentially filtered through pre-combusted $0.7 \mu \mathrm{m} \mathrm{GF} / \mathrm{F}$ to remove larger particles, followed by $0.22 \mu \mathrm{m}$ filters (Durapore, Millipore) to remove the majority of bacteria, and then stored in refrigerator for further use within 3 days. Plants samples were rinsed with Milli-Q water upon arrival in the lab. Biomass and soil samples were stored refrigerated until leaching experiments were performed (within 2 days) to ensure proper preservation and minimize microbial growth (e.g., seagrass).

\subsubsection{Leaching experiments:}

Since ionic strength is an important factor affecting DOM leaching and reactivity (Minor et al., 2006; Grebel et al., 2009), natural surface water from each corresponding site was used for the leaching experiments to better mimic the chemical conditions of the natural environment. The background DOM of these water was reduced using a pre-cleaned activated carbon filtration with Carbon-cap 150 (Whatman) cartridges. The activated carbon column was extensively pre-washed with large amount of $0.01 \mathrm{M}$ hydrochloric acid (certified A.C.S. plus, Fisher) and then followed by large amount of Mill-Q water ( $\sim 80 \mathrm{~L})$, until the background DOC from the column effluent was below $0.2 \mathrm{mg} / \mathrm{L}$. TP, TN, and EEM were also monitored to ensure no potential sources of contamination or fertilization of the incubations. Three dead volumes of column effluent were discarded before collecting the water for leaching purpose. The DOM-reduced water was sequentially filtered with $0.7 \mu \mathrm{m}$ $\mathrm{GF} / \mathrm{F}$ and $0.22 \mu \mathrm{m}$ sterile filters. The carbon column was replaced after every $8 \mathrm{~L}$ of 
water to ensure maximum absorption efficiency. After completion of the leaching process, the remaining background DOC from the original surface water was $<5 \%$ (DOC remaining in background / $\mathrm{DOC}$ initially in sample $\mathrm{X} 100 \%$ ), except for $\mathrm{TS} / \mathrm{Ph} 2$ soil leachate which was $\sim 10 \%$.

Previous studies dealing with Everglades biomass leaching have shown that this process was fast for senescent leaves (Maie et al., 2006c; Davis et al., 2006; Scully et al., 2004). Therefore, all substrates studied here were leached for a 24 hours period. Biomass and soil (about $20 \mathrm{~g} / \mathrm{L}, 50 \mathrm{~g} / \mathrm{L}$, and $380 \mathrm{~g} / \mathrm{L}$ wet weight for higher plants, periphyton, and soil, respectively) were submerged into pre-combusted $4 \mathrm{~L}$ Erlenmeyer flasks containing $2 \mathrm{~L}$ of DOM-reduced reference water. Sawgrass and spikerush leaves were cut into small pieces $(\sim 3$ inches $)$ to facilitate leaching. Flasks were covered and wrapped with aluminum foil to avoid photo-degradation during the leaching process. The flasks were placed onto a shaker for soil leaching to enhance desorption and diffusion while they were static for the biomass (the biomass samples were loose in texture and light compared to soil and sediments which were heavy and deposited on the bottom of the flask. Thus, the latter needed the shaker to enhance contact time). Room temperature during the 1-day leaching experiments was about $21^{\circ} \mathrm{C}$. Chemicals commonly used to control bacterial activity were not added during the leaching experiments considering the relative short leaching time as well as the potential interfering effects on DOM optical properties. The leachates were sequentially filtered through $0.7 \mu \mathrm{m} \mathrm{GF} / \mathrm{F}$ and $0.22 \mu \mathrm{m}$ sterile filters and further diluted with background DOM-reduced surface water to the average UV-Vis absorbance of 


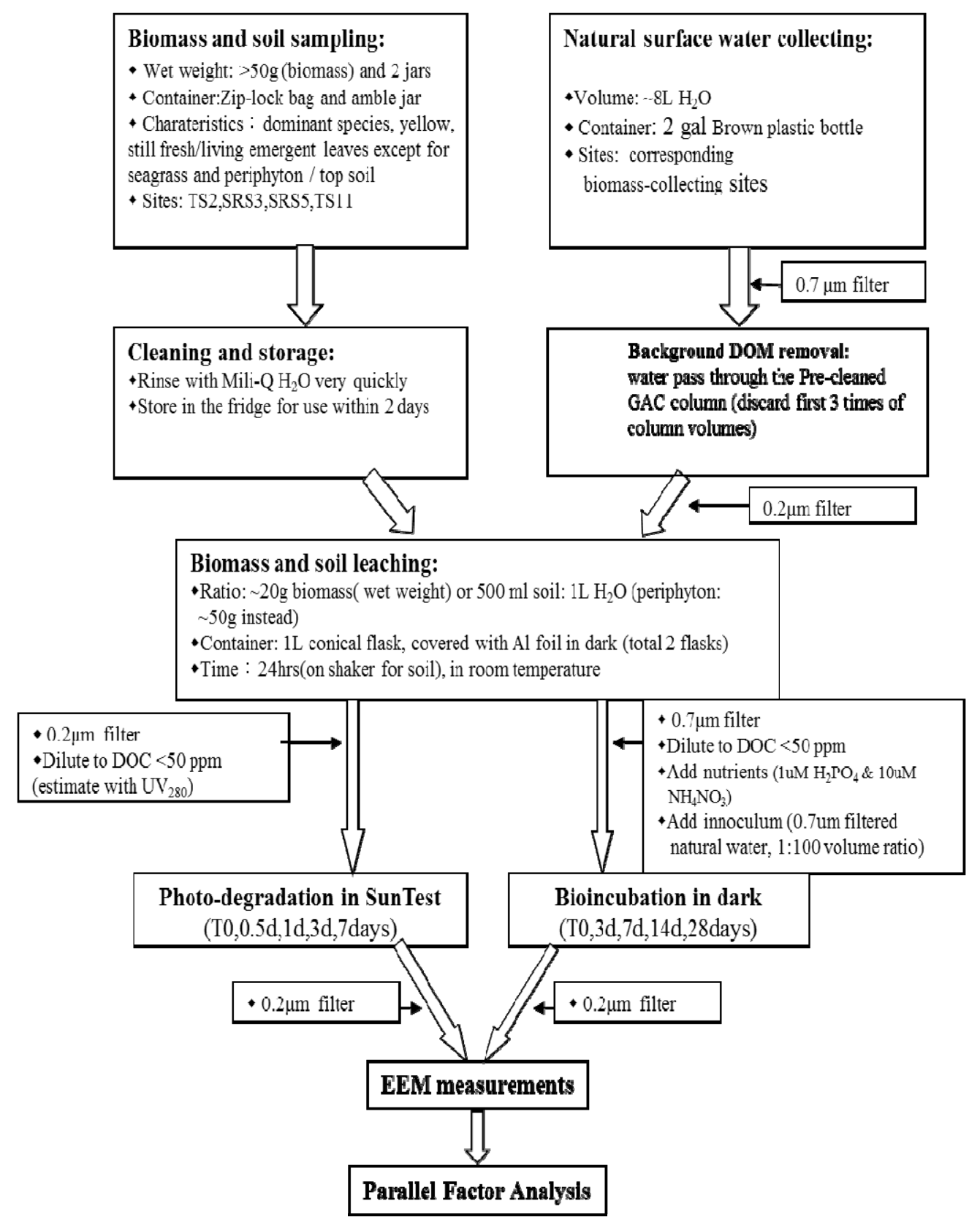

Fig.3.1 Flow chart of leaching and photo- and bio-degradation experiments. 
typical FCE surface water $\left(\sim 0.2-0.5 \mathrm{~cm}^{-1}\right.$ at $\left.\lambda=280 \mathrm{~nm}\right)$. The obtained leached DOM samples were split into 2 aliquots, and the photo- and biodegradation experiments started on the same day.

\subsubsection{Photo-degradation experiments:}

A bench top SunTest XLS (ATLAS) solar simulator was used for the photo-degradation experiments. The SunTest emits a full-spectrum between 300-800 $\mathrm{nm}$ via a xenon lamp on top of the exposure chamber. The light intensity was measured with a spectrophotometer (Ocean Optics) on a daily basis and the lamp performance was found to be stable throughout the time of the experiments. The SunTest intensity was $765 \mathrm{~W} / \mathrm{m}^{2}$ equivalents to mid-day sunlight on a sunny summer day in South Florida. One day of SunTest treatment was estimated as equivalent to about a 4-day sunlight dose in the FCE environment during summer. For the photochemical exposure experiments, the leachates were split into eighteen $150 \mathrm{ml}$ pre-combusted beakers and covered with pre-combusted quarts covers. Three beakers were wrapped with layers of aluminum foil as dark controls. Fifteen sample-containing beakers together with three blanks were put into the water bath of the exposure chamber of the SunTest. The water bath was circulated pumping cool water to stabilize the water bath temperature $\left(\sim 23-26^{\circ} \mathrm{C}\right)$ during the 7-day irradiation. Samples were not filtered during the 7-day irradiation period considering that the sample volume in each beaker was shallow ( $\sim 0.5$ inch) and the intense irradiation was expected to inhibit bacterial activity. Triplicate aliquots were removed from the 
SunTest chamber periodically on day $0,0.5,1,3$, and 7 . Samples were filtered with $0.22 \mu \mathrm{m}$ filters and measurements of optical properties were performed.

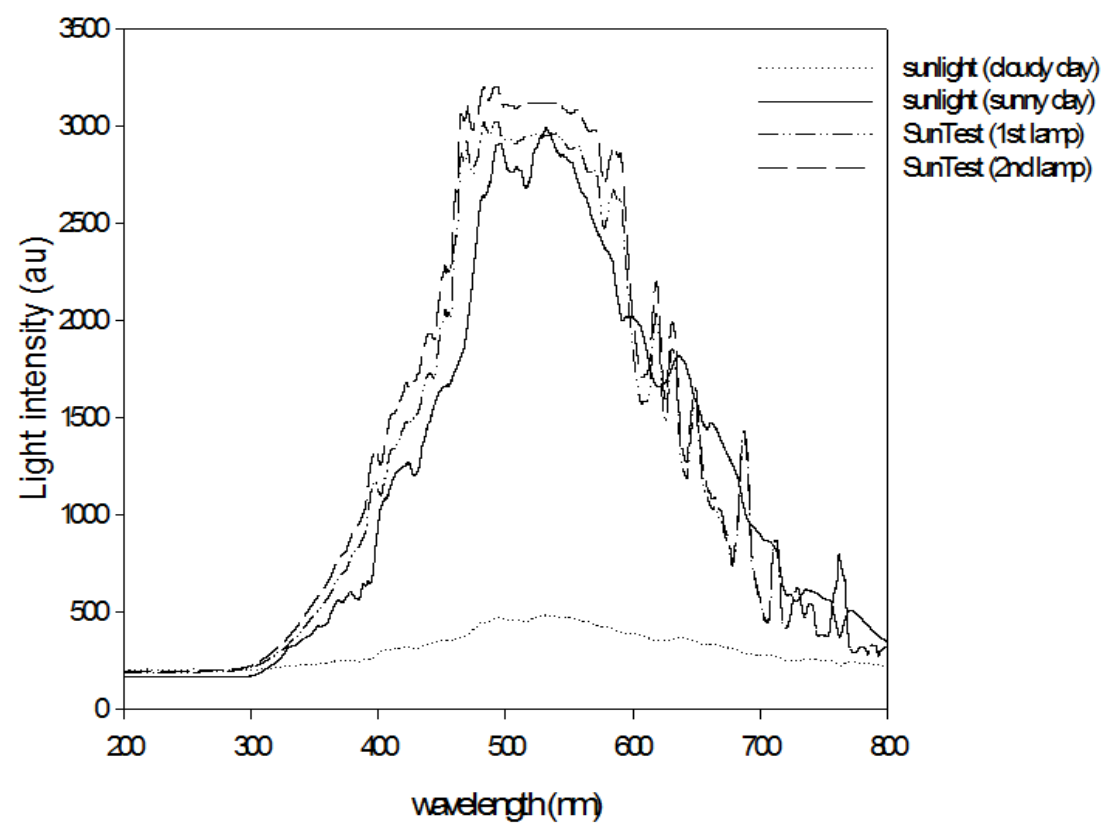

Fig.3.2 Comparison of SunTest irradiation intensity with natural sunlight in South Florida.

\subsubsection{Biodegradation experiments:}

Leachate as inoculums from each site were added to the $0.7 \mu \mathrm{m}$ filtered surface water samples at a ratio of $1: 100$, in addition to final concentrations of $10 \mu \mathrm{M}$

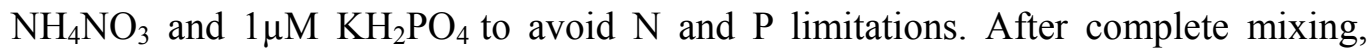
leachates were split into 15 pre-combusted glass jars, which were wrapped with aluminum foil and then incubated in the dark for up to 28 days. Jars were opened every other day to aerate, and large headspaces were left to ensure enough oxygen for 
bioincubation. Triplicate aliquots were removed periodically on days $0,3,7,14$, and 28. Samples were filtered with $0.22 \mu \mathrm{m}$ filters prior to DOC, UV-Vis, and EEM measurements.

\subsubsection{Sequential photo- and biodegradation experiments:}

Triplicate samples removed after the 7-day photo-incubation in the SunTest were filtered with $0.22 \mu \mathrm{m}$ sterile filters, spiked with an inoculum and $10 \mu \mathrm{M}$ $\mathrm{NH}_{4} \mathrm{NO}_{3}$ and $1 \mu \mathrm{M} \mathrm{KH} \mathrm{KO}_{4}$ as described above. After complete mixing, the samples were put into pre-combusted glass jars, which were wrapped with aluminum foil and then incubated in the dark for up to 28 days. The experiment was treated exactly like the direct bio-incubations. After 28 days, samples were filtered with $0.22 \mu \mathrm{m}$ filters prior to DOC, UV-Vis, and EEM measurements.

\subsubsection{Analytical measurements:}

DOC determinations, UV-Vis and EEM fluorescence spectra were determined for each sample. The UV-Vis absorbance was determined using a Varian Cary 50 bio spectrophotometer with a $1 \mathrm{~cm}$ quartz cuvette scanning from $240 \mathrm{~nm}$ to $800 \mathrm{~nm}$. The

EEMs were measured using a Horiba Jovin Yvon SPEX Fluoromax-3 spectrofluorometer equipped with a $150 \mathrm{~W}$ continuous output Xe arc lamp. Slits were set at $5.7 \mathrm{~nm}$ for excitation and $2 \mathrm{~nm}$ for emission. Forty-four emissions scans were acquired at excitation wavelength $\left(\lambda_{\mathrm{ex}}\right)$ between 240 and $455 \mathrm{~nm}$ at $5 \mathrm{~nm}$ steps. The emission wavelengths were scanned from $\lambda_{\mathrm{ex}}+10 \mathrm{~nm}$ to $\lambda_{\mathrm{ex}}+250 \mathrm{~nm}$ (i.e., between 
250 and $705 \mathrm{~nm}$ ) in $2 \mathrm{~nm}$ steps (Maie et al., 2006b). Fluorescence signals were acquired in signal over reference ratio mode $(\mathrm{S} / \mathrm{R})$ to eliminate potential fluctuation of the Xe lamp. More detailed information of post-acquisition steps for correction and standardization can be found elsewhere (Chen et al., 2010). The DOC concentrations were measured using the high-temperature catalytic combustion method with a Shimadzu TOC-V total organic carbon analyzer.

\subsubsection{PARAFAC model fitting and residue components validation:}

PARAFAC is a statistical tool based on an alternating least square (ALS) algorithm. It can statistically decompose EEMs into fluorescent groups (components). The mathematical equation is shown as follows (Eq.1).

$$
\begin{aligned}
& \mathrm{x}_{\mathrm{ijk}}=\sum_{c=1}^{C} \mathrm{a}_{\mathrm{ic}} \mathrm{b}_{\mathrm{jc}} \mathrm{c}_{\mathrm{kc}}+\mathrm{R}_{\mathrm{ijk}} \\
& \mathrm{i}=1, \ldots, \mathrm{I} ; \mathrm{j}=1, \ldots, \mathrm{J} ; \mathrm{k}=1, \ldots, \mathrm{K}
\end{aligned}
$$

where $\mathrm{x}_{\mathrm{ijk}}$ is the fluorescence intensity of the ith sample at emission wavelength $\mathrm{j}$ and excitation wavelength $\mathrm{k}$. The variable $\mathrm{c}$ defines the number of components for the model and $\mathrm{R}_{\mathrm{ijk}}$ is the residue that represents the residue remained after modeling or fitting. $\mathrm{a}_{\text {ic }}$ is proportional to the concentration of the cth component in the ith sample (i.e. "scores"); $\mathrm{b}_{\mathrm{jc}}$ and $\mathrm{c}_{\mathrm{kc}}$ are "loadings" of the emission and excitation spectra for the cth component, which are linearly related to the fluorescence quantum efficiency 
at emission wavelength $\mathrm{j}$ and specific absorption coefficient at excitation wavelength $\mathrm{k}$, respectively.

There are two ways to apply PARAFAC modeling, i.e., either by creating and validating the model using the complete dataset of EEMs (e.g., Stedmon et al., 2003; Ohno and Bro, 2006) or by fitting the EEMs to an already established PARAFAC model (e.g., Yamashita and Jaffé, 2008a). Here all biomass and soil leachates and surface water EEMs were fitted to an existing Everglades/Florida Bay surface water PARAFAC model which had been well established using 1394 surface water samples. The PARAFAC component spectral characteristics and split-half validation data can be seen in Chen et al. (2010). The analysis was carried out in MATLAB 7.0.4 (Mathworks, Natick, MA) with the DOMFluor toolbox (Stedmon and Bro, 2008). Residues or residual components obtained by subtracting the modeled EEMs from the original EEMs, were picked out through "peak-picking" for biomass and soil leachate. A residue was considered as a PARAFAC component if it featured actual spectroscopic patterns and further validated only if its signal was at least three times the background noise as follows (2):

$$
\text { Residue peak signal } \%>3 \times \text { noise } \%
$$

where noise \% was calculated using the average residue values for the FCE surface water which represents the average normal noise residue. 


\subsubsection{Multi- and single-pool kinetics modeling and PCA statistics:}

A multi-pool decay model is superior to a simple exponential decay model considering a heterogeneous nature of DOM (Hopkinson et al., 2002). Another study on soil organic matter bio-degradation also successfully applied a multi-pool decay model (Feng and Simpson 2008). This model was applied in the present study, where two non-linear regression models, including a four - parameter and a five - parameter model, were tested and the four-parameter first order decay kinetics model was found to best fit the data generated during the DOM decomposition experiments (Eq.3).

$$
\mathrm{C}_{\mathrm{t}}=\mathrm{a}^{*} \mathrm{e}^{-\mathrm{k}}{ }_{1}^{\mathrm{t}}+\mathrm{b} * \mathrm{e}_{2}^{-\mathrm{k}}{ }^{\mathrm{t}}
$$

where $\mathrm{C}_{\mathrm{t}}$ is the total DOM concentration or fluorescence intensity at time $\mathrm{t}$, $\mathrm{a}$ and $\mathrm{b}$ are two constants related to relative sizes of pool 1 (labile or semi-labile) and pool 2 (semi-labile or refractory) pools. $\mathrm{k}_{1}$ and $\mathrm{k}_{2}$ are two decay rates of pool 1 and pool 2 , respectively. This two pool (labile and refractory) model can either be used directly as is, or customized to specific environmental conditions. As such, by substituting time $t$ with defined time ranges of what is specifically defined as labile and refractory fractions, the sizes of labile DOM (L-DOM) and refractory DOM (R-DOM) can be obtained. The size of a semi-labile (S-DOM) fraction can then be obtained by subtracting the \% L-DOM and \% R-DOM from total DOM. This approach was used here and described later in the text. The fitting was conducted with a non-linear least-squares fitting (SigmaPlot 2001). All fittings passed the constant variance test 
with $p<0.05$ and commonly showed almost prefect $r^{2}$ values, suggesting that this model was ideally suited for this data set.

Half-lives were calculated through the following equation for first-order decay (Eq.4):

$$
\mathrm{t}_{1 / 2}=\operatorname{In} 2 / \mathrm{k}
$$

where $t_{1 / 2}$ represents half-life and $\mathrm{k}$ stands for decay rate.

In contrast to the decomposition process, a single pool first order production kinetic model was found to better fit the production process of the EEM-PARAFAC components. The equation is as follows (Eq.5):

$$
\mathrm{C}_{\mathrm{t}}=\mathrm{a} * \mathrm{e}^{\mathrm{kt}}
$$

where $C_{t}$ is the total DOM concentration or fluorescence intensity at time $t$, a is a constant and $\mathrm{k}$ is the growth rate. The non-linear growth fittings had also passed the constant variance test with $\mathrm{p}<0.05$.

Principal component analysis (PCA) statistics were carried out using a JMP program (SAS) with correlation mode. 


\subsection{Results and discussions}

\subsubsection{EEM-PARAFAC modeling results}

The EEM data obtained from the biomass and soil leachate and surface water degradation studies were fitted into a previously established 8-component PARAFAC model for FCE surface water (Chen et al., 2010) as shown in Table 3.2. This approach can facilitate the comparison among surface water, biomass leachate, and soil leachate to an already existing PARAFAC model. The 8 components were assigned as six humic-like and two protein-like based on the comparison of spectral characteristics with previous studies (Yamashita and Jaffé 2008a; Cory and McKnight 2005; Stedmon et al., 2003). While the humic-like components C1, C5, and C7 were found to be ubiquitous to all the samples from different sources, the remaining five components were absent in some source materials (Fig.3.3). The most noticeable absence was that of $\mathrm{C} 2$, which is a humic-like component believed to be photoproduct and/or photorefractory (Chen et al., 2010), and has been found in high abundance in DOM derived from agricultural soils (Yamashita et al., 2010a). C2 was absent in all the initial biomass leachates and also initial marly soil leachates, suggesting that it is not produced from biomass sources but possibly form organic rich wetland soils in addition to the already established oxidation of agricultural soils or drained peat environments from the EAA. The next noticeable absence is that of $\mathrm{C} 3$, which is also a humic-like component and was not found in initial mangrove, periphyton, and marly soil leachates. C4, a traditionally termed marine humic-like component, was absent in the initial seagrass and mangrove leachates, 
Table 3.2 Major sources and reactivity of EEM-PARAFAC components.

\begin{tabular}{|c|c|c|}
\hline component & $\mathrm{Ex} / \mathrm{Em} \max (\mathrm{nm})$ & Summary of nature,sources, and reactivity \\
\hline \multirow[t]{3}{*}{$\mathrm{C} 1$} & $<260(345) / 462$ & humic-like. \\
\hline & & ubiquitous component; abundant in soil, SW, and biomass \\
\hline & & photoreactive; biorefractory for soil leachate and SW \\
\hline \multirow[t]{3}{*}{$\mathrm{C} 2$} & $<260 / 454$ & humic-like \\
\hline & & absent in the 4 higher plants; \\
\hline & & photoproduction \& photodecay \\
\hline \multirow[t]{3}{*}{$\mathrm{C} 3$} & $<260(305) / 416$ & humic-like \\
\hline & & biomass, soil, and photoproduction from mangrove leacahte \\
\hline & & photoproduction \& photodecay \\
\hline \multirow[t]{4}{*}{$\mathrm{C} 4$} & $<260(305) / 376$ & humic-like \\
\hline & & abundant in spikerush leachate, soil leachate, and surface \\
\hline & & water \\
\hline & & photoreactive \\
\hline \multirow[t]{3}{*}{$\mathrm{C} 5$} & $<260(405) />500$ & humic-like. \\
\hline & & ubiquitous component; rich in soil and SW \\
\hline & & photoreactive; biorefractory for soil leachate and SW \\
\hline \multirow[t]{3}{*}{ C6 } & $<260(325) / 406$ & humic-like \\
\hline & & abundant in soil leachate, seagrass, and groundwater \\
\hline & & very photoreactive; $\mathrm{C} 6 \%$ tended to go up during bioincubation \\
\hline \multirow[t]{3}{*}{$\mathrm{C} 7$} & $275 / 326$ & protein-like \\
\hline & & abundant in seagrass \\
\hline & & photoreative; bioreactive for biomass leachate and SW \\
\hline \multirow[t]{3}{*}{$\mathrm{C} 8$} & $300 / 342$ & protein-like \\
\hline & & abundanat in periphyton; bioproduction \\
\hline & & photoreactive. less bio-reactive \\
\hline $\mathrm{R} 1-\mathrm{P}$ & $275 / 305$ & protein-like; more abundant in biomass leachate; very reactive \\
\hline $\mathrm{R} 2-\mathrm{P}$ & $310 / 440$ & protein-like? more abundant in biomass leachate; very reactive \\
\hline $\mathrm{R} 3-\mathrm{P} / \mathrm{S}$ & $410 / 468$ & humic-like; in both biomss and soil leachate; very reactive \\
\hline $\mathrm{R} 1-\mathrm{S}$ & $370 / 468$ & humic-like; abundant in FB sediement leachate; very reactive \\
\hline $\mathrm{R} 2-\mathrm{S}$ & $<260 / 468$ & humic-like; more abundant in soil leacahte; very reactive \\
\hline
\end{tabular}

while the protein-like $\mathrm{C} 8$ was absent in initial sawgrass, seagrass, and mangrove leachates. 

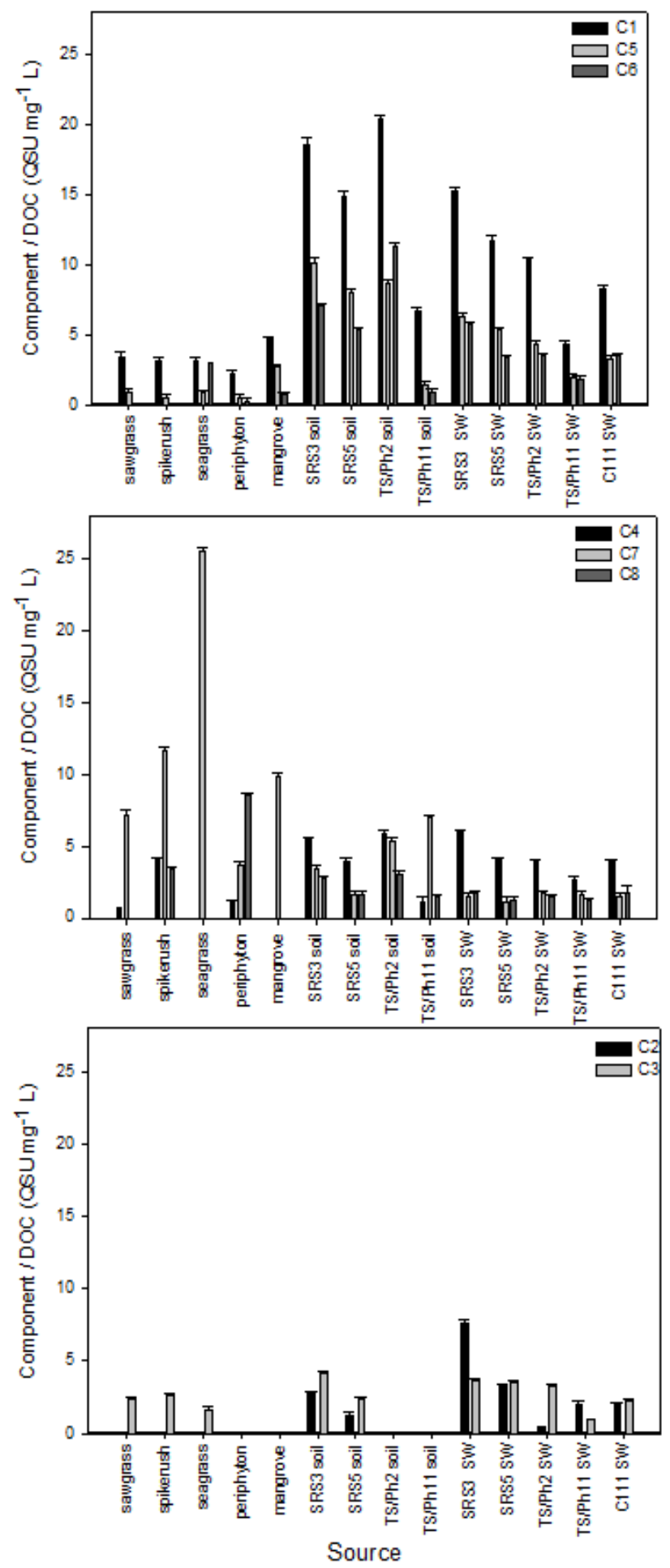

Fig.3.3 Comparison of relative EEM-PARAFAC composition of DOM from different source materials (biomass leachates, soil leachates and surface waters). 
In addition to these eight components, established from a surface water DOM database, three residue peaks (residual PARAFAC components) were identified and validated as described above for biomass leachate and another three for soil leachate. The characteristics of all the components were summarized in Table 3.2.

Since the residues were not observed in surface water samples, they are suggested to be highly labile and do not accumulate in the natural environment. Therefore, the focus of discussion will be placed on the 8 commonly observed and environmentally more stable PARAFAC components.

\subsubsection{Qualitative assessment of DOM photo- and bio-reactivity}

In an attempt to compare the different effects of photo-, bio- and sequential degradation processes using EEM-PARAFAC data, a principal component analysis (PCA) approach was utilized to include the wide array of data from different sources and during different degradation processes. The relative abundance of EEM-PARAFAC data, including the residual PARAFAC components (R), for initial, 7-day photo-degradation, 28-day biodegradation, and sequential 7-day photofollowed by 28 -day biodegradation were loaded into principal components analysis for both the biomass leachates and the soil leachates (Figs.3.4a and 3.4b respectively). Typical surface water PARAFAC distributions for both freshwater (Everglades) and marine (Florida Bay) FCE environments were also included. The two PCA graphs displayed different clusters but similar trends, suggesting that DOM origins and composition control the diagenetic status and degradation process. For biomass 
leachate vs. surface water graphs (Fig. 3.4a), principal component 1 (PC1) explained $46.8 \%$ of the variance, whereas principal component 2 (PC2), accounted for a further $20.8 \%$ of the variance. For soil leachate vs. surface water graphs (Fig. 3.4b), PC1 explained $50.6 \%$ of the variance, whereas PC2, accounted for a further $20.6 \%$ of the variance. For both biomass and soil leachate graphs, a similar transformation patterns were observed.

Principal component 1 (PC1) was controlled by DOM source where humic-like components dominated surface water composition and positively correlate with PC1, while the labile residual components and $\mathrm{C} 7$ dominated the leachates' composition and correlate negatively with PC1. PC2 seems indicative of diagenetic effects resulting from both photo- and bio-degradation. C3 is located on the PCA graph suggestive of a role of a photo-degradation intermediate, while $\mathrm{C} 6$ and $\mathrm{C} 8$ seem to act as biodegradation intermediates. Periphyton behaved differently from the other biomass samples, which is not surprising considering is an assemblage of algae, microbes, and detritus rather than vascular plants like sawgrass, spikerush, mangrove, and seagrass, and presented the least significant photo- or bio-degradation changes based on the PCA plot. Sequential photo- and bio-degradation proved to be most effective in changing the leachates' DOM fluorescence characteristics into EEMs more similar to those of the natural surface water DOM. This was typified by the seagrass leachate clustering closely with Florida Bay surface water after sequential degradation. This is consistent with previous findings that sunlight has "priming effect" for bacterial uptake on terrestrial-derived DOM (Tranvik and Bertilson 2001; Qualls 

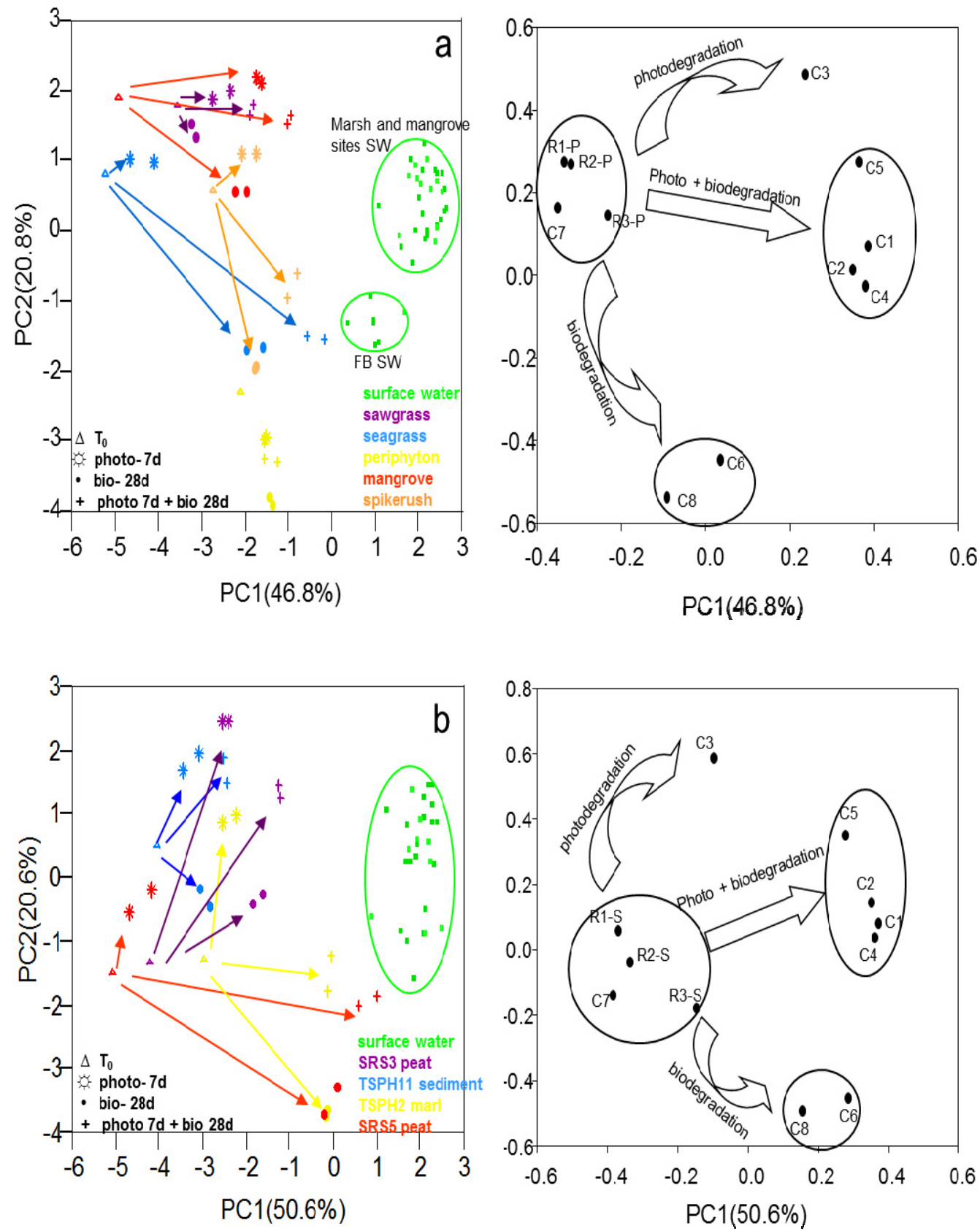

Fig. 3.4 Principal components analysis of biomass leachate vs. surface water (a) and soil leachate vs. surface water (b) during photo-, bio- and sequential photo plus bio degradation based on EEM-PARAFAC data. Score plots are on the left and loading plots are on the right; $C=$ EEM-PARAFAC components; $R=$ EEM-PARAFAC residues; FB SW = Florida Bay surface water. Arrows indicate the directions of transformations. 
and Richardson 2003; Moran and Covert 2003). An interesting result from this study is the general indication that $\mathrm{C} 3$ may serve as a proxy for a photo-degradation intermediate while C6 and C8 could serve that function for the bio-degradation process.

\subsubsection{Quantitative assessment of DOM photo- and bio-reactivity:}

A multi-pool model was used by Hopkinson et al., 2002 to determine the reactivity of different fractions of DOM (i.e., labile and refractory fractions). This approach was superior to a simple exponential decay model assuming a homogeneous nature of DOM. Similar modeling approaches have been used for soil organic matter (Feng and Simpson 2008). In this study, a four-parameter multi-pool first order decay kinetic equation (Eq. 3; Feng and Simpson 2008) and a single pool first order growth kinetic equation (Eq.5) were found to produce the best fit for the data and therefore were used to quantify the kinetics of decay or production during both photo- and biodegradation. Figures 3.5A, 3.5B, 3.5C, and 3.5D show some representative examples of the modeling trends for the photo- and biodegradation data of UV absorbance at $254 \mathrm{~nm}$ (A254) and eight EEM-PARAFAC components. Data for half-lives of labile (pool-1) and semi-labile (pool-2) fractions for each A254 and EEM-PARAFAC components of all the samples can be found in Table 3.3A.

The two organic matter pools model provided to be an excellent fit for the decay data observed in this study. However, there were a variety of different behavioral patterns observed between the photo- and bio-degradation kinetics, 

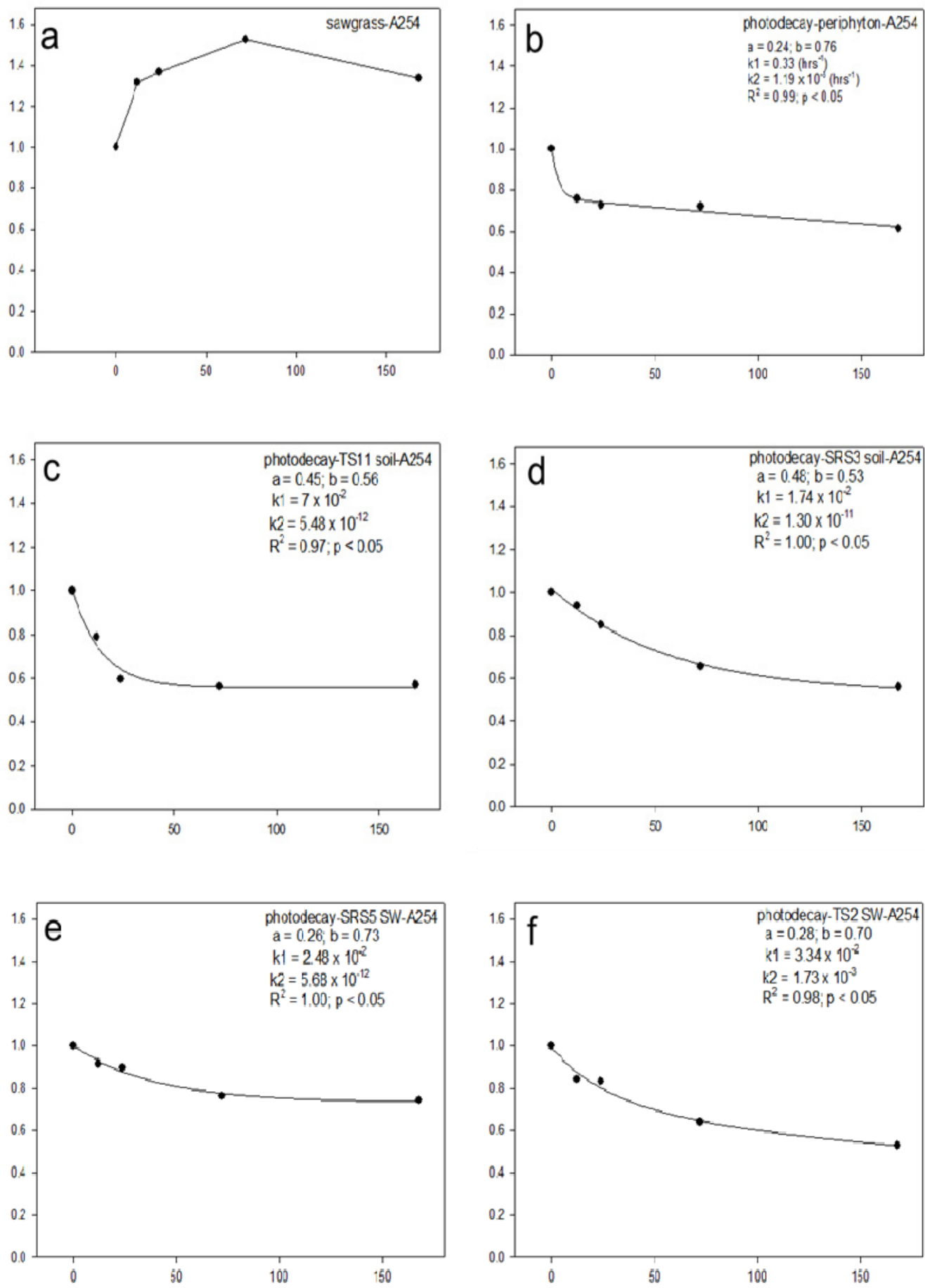

Fig. 3.5A Examples of absorbance at $254 \mathrm{~nm}$ (A254) photo-degradation patterns and kinetics data fitted into a multi-pool first-order decay model. $\mathrm{SW}=$ surface water. 
between different samples and sample types, and between different PARAFAC components, significantly complicating the data presentation and interpretation. Reaction kinetics showed profiles for exponential decay and increase followed by decrease for A254, and exponential decay, exponential generation, no observable change through time or variable decreases and increments for EEM-PARAFAC components throughout the incubation periods. This high degree of variability, not only in time dependent patterns but also quantitatively regarding variations in rate constants (or half-lives) for the same PARAFAC components depending on sample type, was an intriguing finding, and will be discussed in more detail below. In general, decay curves for the photo-degradation kinetics most commonly resulted in significantly higher rate constants for the degradation of pool-1, the presumably more labile DOM pool compared to those obtained for pool-2, the more refractory pool. However, the pool size, although variable, was usually higher for the more labile pool (pool-1; 58\% on average) compared to the more refractory pool-2 for fluorescent DOM (FDOM).However, the opposite was observed for the chromophoric DOM (CDOM) as evidenced by the A254 trends (pool-2; 68\% on average), implying a larger fraction of FDOM is photo-labile compared to the CDOM. Similar observations were true for the bio-degradation kinetics, although for the most part the half-lives were much longer for this degradation process (see below) and decay kinetics were less common that for photo-degradation. For the bio-degradation process, patterns showing no significant change over time were more common compared to decay patterns. While photo-degradation half-lives were on the order of $10^{1}$ hours for 
Table 3.3A Photo- and bio-degradation trends and kinetics data of UV absorbance at $254 \mathrm{~nm}(\mathrm{~A} 254 \mathrm{~nm})$.

\begin{tabular}{|c|c|c|c|c|c|c|}
\hline $\mathrm{A} 254 \mathrm{~nm}$ & trend & $\mathrm{t}_{1 / 2,1}(\mathrm{hrs})$ & $\mathrm{t}_{1 / 2,2}(\mathrm{hrs})$ & pool1\% & pool $2 \%$ & $\mathrm{R}^{2}$ \\
\hline photodegradation & & & & & & \\
\hline sawgrass & $\uparrow$ & & & & & \\
\hline spikerush & $\uparrow \quad \downarrow$ & & & & & \\
\hline periphyton & $\downarrow$ & $2.1 \mathrm{E}+00$ & $5.8 \mathrm{E}+02$ & 24 & 76 & 1.0 \\
\hline mangrove & $\uparrow \quad \downarrow$ & & & & & \\
\hline seagrass & $\uparrow \quad \downarrow$ & & & & & \\
\hline SRS3 soil & $\downarrow$ & $4.0 \mathrm{E}+01$ & $5.3 \mathrm{E}+10$ & 48 & 52 & 1.0 \\
\hline SRS5 soil & $\downarrow$ & $2.4 \mathrm{E}+01$ & $2.3 \mathrm{E}+11$ & 38 & 62 & 1.0 \\
\hline $\mathrm{TS} / \mathrm{Ph} 2$ soil & $\downarrow$ & $1.8 \mathrm{E}+01$ & $8.1 \mathrm{E}+02$ & 36 & 64 & 1.0 \\
\hline TS/Ph11 soil & $\downarrow$ & $9.9 \mathrm{E}+00$ & $1.3 \mathrm{E}+11$ & 45 & 55 & 1.0 \\
\hline SRS3-SW & $\downarrow$ & $2.4 \mathrm{E}+01$ & $3.5 \mathrm{E}+02$ & 15 & 85 & 1.0 \\
\hline SRS5-SW & $\downarrow$ & $2.8 \mathrm{E}+01$ & $1.2 \mathrm{E}+11$ & 27 & 73 & 1.0 \\
\hline TS/Ph2-SW & $\downarrow$ & $2.1 \mathrm{E}+01$ & $4.0 \mathrm{E}+02$ & 29 & 71 & 1.0 \\
\hline TS/Ph11-SW & $\downarrow$ & $3.0 \mathrm{E}+01$ & $5.4 \mathrm{E}+10$ & 40 & 60 & 1.0 \\
\hline C111-SW & $\downarrow$ & $3.1 \mathrm{E}+01$ & $1.6 \mathrm{E}+11$ & 23 & 77 & 1.0 \\
\hline Average-A254 & & $2.3 \mathrm{E}+01$ & $7.5 \mathrm{E}+10$ & 32 & 68 & 1.0 \\
\hline biodegradation & & & & & & \\
\hline sawgrass & $\uparrow \quad \downarrow$ & & & & & \\
\hline spikerush & $\uparrow \quad \downarrow$ & & & & & \\
\hline periphyton & $\downarrow$ & $1.5 \mathrm{E}+03$ & $1.8 \mathrm{E}+03$ & 46 & 54 & 1.0 \\
\hline mangrove & $\uparrow \quad \downarrow$ & & & & & \\
\hline seagrass & $\uparrow \quad \downarrow$ & & & & & \\
\hline SRS3 soil & $\rightarrow$ & & & & & \\
\hline SRS5 soil & $\rightarrow$ & & & & & \\
\hline $\mathrm{TS} / \mathrm{Ph} 2$ soil & $\downarrow$ & $1.4 \mathrm{E}+01$ & $3.9 \mathrm{E}+03$ & 13 & 87 & 1.0 \\
\hline TS/Ph11 soil & $\downarrow$ & $3.4 \mathrm{E}+01$ & $1.3 \mathrm{E}+04$ & 36 & 64 & 1.0 \\
\hline SRS3-SW & $\rightarrow$ & & & & & \\
\hline SRS5-SW & $\rightarrow$ & & & & & \\
\hline TS/Ph2-SW & $\rightarrow$ & & & & & \\
\hline TS/Ph11-SW & $\rightarrow$ & & & & & \\
\hline C111-SW & $\rightarrow$ & & & & & \\
\hline Average-A254 & & $5.1 \mathrm{E}+02$ & $6.1 \mathrm{E}+03$ & 32 & 68 & 1.0 \\
\hline Note: & $\begin{array}{l}\text { ase; } \downarrow= \\
\text { ire rate }\end{array}$ & $\begin{array}{l}\text { crease; } \\
\text { nstant k (hr }\end{array}$ & $\begin{array}{l}\text { no obvious } \\
\text { 1) instead o }\end{array}$ & $\begin{array}{l}\text { hange; } \\
\text { half-life }\end{array}$ & & \\
\hline
\end{tabular}


pool-1, those for pool-2 were as high as $10^{11} \mathrm{hrs}$. Differences in photo-degradation half-lives for pool-1 corresponding to different PARAFAC components ranged from not significantly different to about a factor of 10 higher for the soil and SW samples. Differences between biomass leachates, soil leachates and surface waters, but for pool-2 were harder to assess as these were highly variable ranging from $10^{1}$ to $10^{11}$ across the different sample types. Specifically, trends and tendencies for A254 and different PARAFAC components were as follows.

A254: While exponential photo-bleaching were observed for all the surface water, soil leachates, and periphyton leachate, the four vascular plants leachate displayed photo-humification first followed by photo-bleaching. Photo-humification was previously reported in literature at UV absorbance $325 \mathrm{~nm}$ for Antarctic Ocean water (Ortega-Retuerta et al., 2010). Half-lives of photo-degradation for pool-1 were quite similar for soil leachate and surface water sample types, with an average of $2.3 \times 10^{1}$ hours, and $7.5 \times 10^{10}$ for pool-2. Periphyton leachate has relative short half-lives of 2.1 hours for pool-1 and $5.8 \times 10^{2}$ hours for pool-2 as compared to the higher plants leachates. For biodegradation, vascular plants' leachates showed a pattern similar to the photo-degradation pattern of initially increase followed by a decrease, possibly caused by biopolymerization as observed in another study (Jee et al., 2010). Most bio-degradation data showed no change over the incubation period except for a few samples with half-lives for pool-1 on the order of $10^{1}$ to $10^{3}$ hours and pool-2 at $10^{3}-10^{4}$ hours. Generally, A254 data showed approximately $32 \%$ of the CDOM as 
photo-reactive on an order of $10^{1}$ hours, while ca. $68 \%$ was more refractory with half-lives on an order of $10^{2}$ hours for periphyton and TS2 soil leachates and TS2 surface water, and an order of $10^{10}-10^{11}$ hours for the rest soil leachates and surface water.

C1: Half-lives for pool-1 were quite similar for the three sample types with an average of $1.2 \times 10^{1}$ hours, and $1.9 \times 10^{2}$ for pool-2. Two samples, namely mangrove leaf leachate and the mangrove soil leachate had half-lives on the order of $10^{10}$ for pool-2 suggesting that these materials are highly refractory on the basis of the experimental procedures used here. Most bio-degradation data showed no change over the incubation period except for a few samples with half-lives for pool-1 on the order of $10^{1}$ to $10^{2}$ hours and pool-2 at $10^{3}-10^{11}$ hours suggesting a high degree of refractory character of $\mathrm{C} 1$ to biodegradation processes. Generally, $\mathrm{C} 1$ has been observed as the most abundant PARAFAC component throughout the Everglades (Yamashita et al., 2010a) suggesting it's ubiquitous in the Everglades and of a refractory character.

C2: Data for C2 are extremely variable. Photo-degradation data showed mainly no change throughout the photo-exposure period since this component was absent in most of the biomass samples. C2 was observed to increase with time of exposure for the periphyton leachate, and the soil/sediment leachates of TS2 and TS11. Photo-decay was observed only for SRS5 and TS11 SW samples. Biodegradation of C2 was only observed for the SRS5 soil sample at half-lives of $5.9 \times 10^{1}$ and $3.5 \times 10^{3}$ 

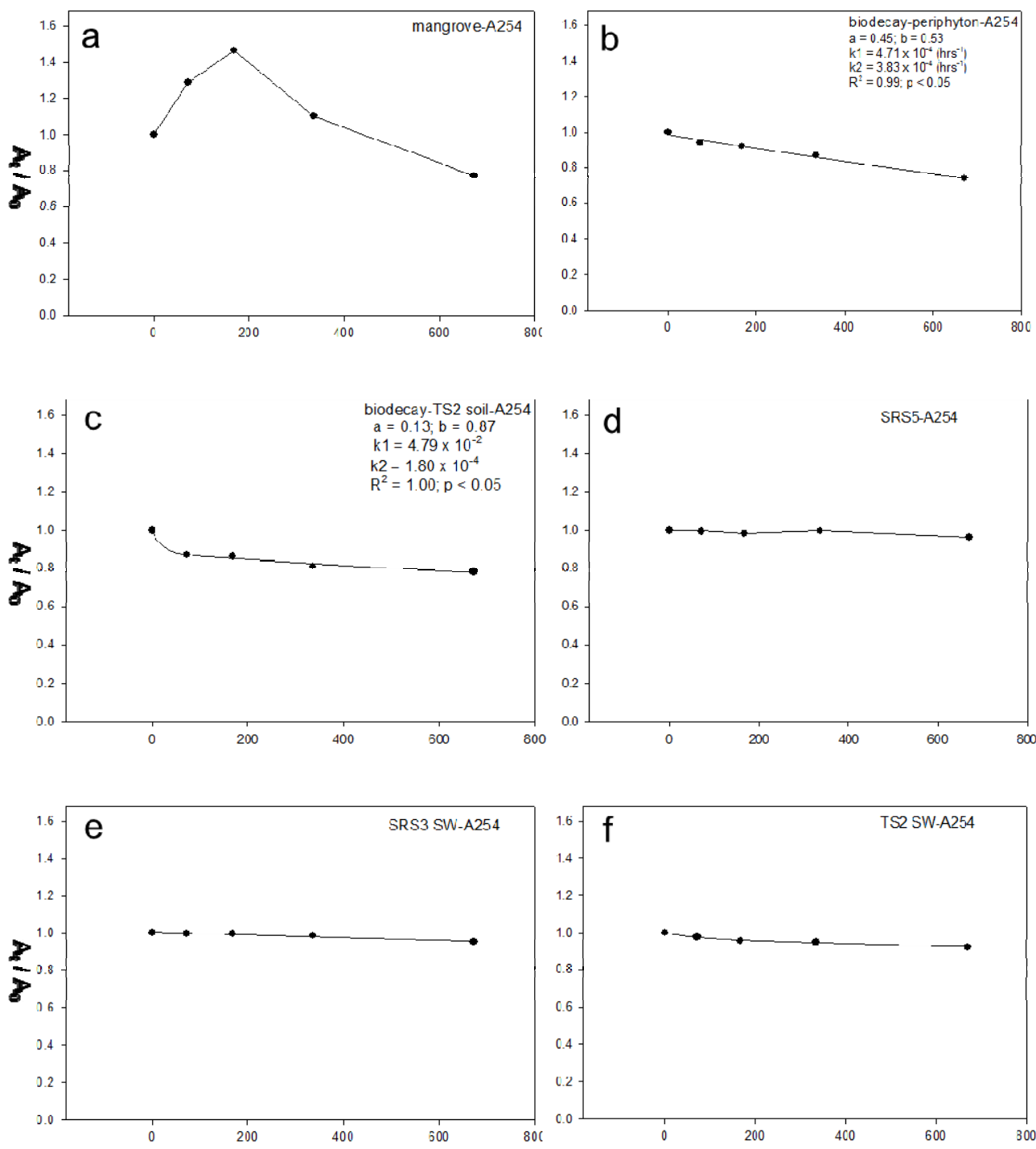

Fig. 3.5B Examples of absorbance at $254 \mathrm{~nm}$ (A254) biodegradation patterns and kinetics. $\mathrm{SW}=$ surface water.

hours for pool-1 and pool-2 respectively. While $\mathrm{C} 2$ has been suggested to be a photoproduct or a photorefractory component (Chen et al., 2010) it has also been observed in high abundance in DOM exported from agricultural areas (Yamashita et al., 2010a). Our data seems to confirm that its source is more likely from soils than 
biomass and that with a few exceptions it seems quite resistant to degradation processes.

C3: This humic-like component was observed to be mainly following exponential decay patterns when exposed to sunlight. Again, half-lives for the labile pool were significantly lower compared to the more refractory pool-2. A generation of this compound was observed only for the mangrove leaf leachate showing half-lives of $3.3 \times 10^{1}$ and $2.6 \times 10^{10}$ hours for pool- 1 and pool-2 respectively. The significantly larger half-lives of pool-2 suggest that this pool would accumulate in the Everglades environment, and in fact $\mathrm{C} 3$ is very commonly observed throughout this ecosystem. This tendency to accumulate during photo-degradation (based on the refractory character of pool-2) may explain the location of $\mathrm{C} 3$ in the PCA plot of figure 3.4. Regarding bio-degradation the data obtained does not provide any consistent patterns. Decay curves were only observed for spikerush and SRS5 soil leachates, showing only a labile pool for the spikerush leachate at $9.4 \times 10^{1}$ hours half live and $4.0 \times 10^{1}$ and $3.0 \times 10^{11}$ for pools 1 and 2 for SRS5 soil respectively.

C4: This component has been assigned a microbial/marine humic-like character. It presents mainly exponential decay patterns when exposed to sunlight with significantly longer half-lives for pool-2 compared to pool- 1 at $5.9 \times 10^{9}$ and $1.8 \times 10^{1}$ hours respectively. Similar to the other components shown above, the biodegradation data seemed quite inconsistent and no clear patterns could be determined. Decay curves were only observed for spikerush and periphyton leachates with half-lives of 

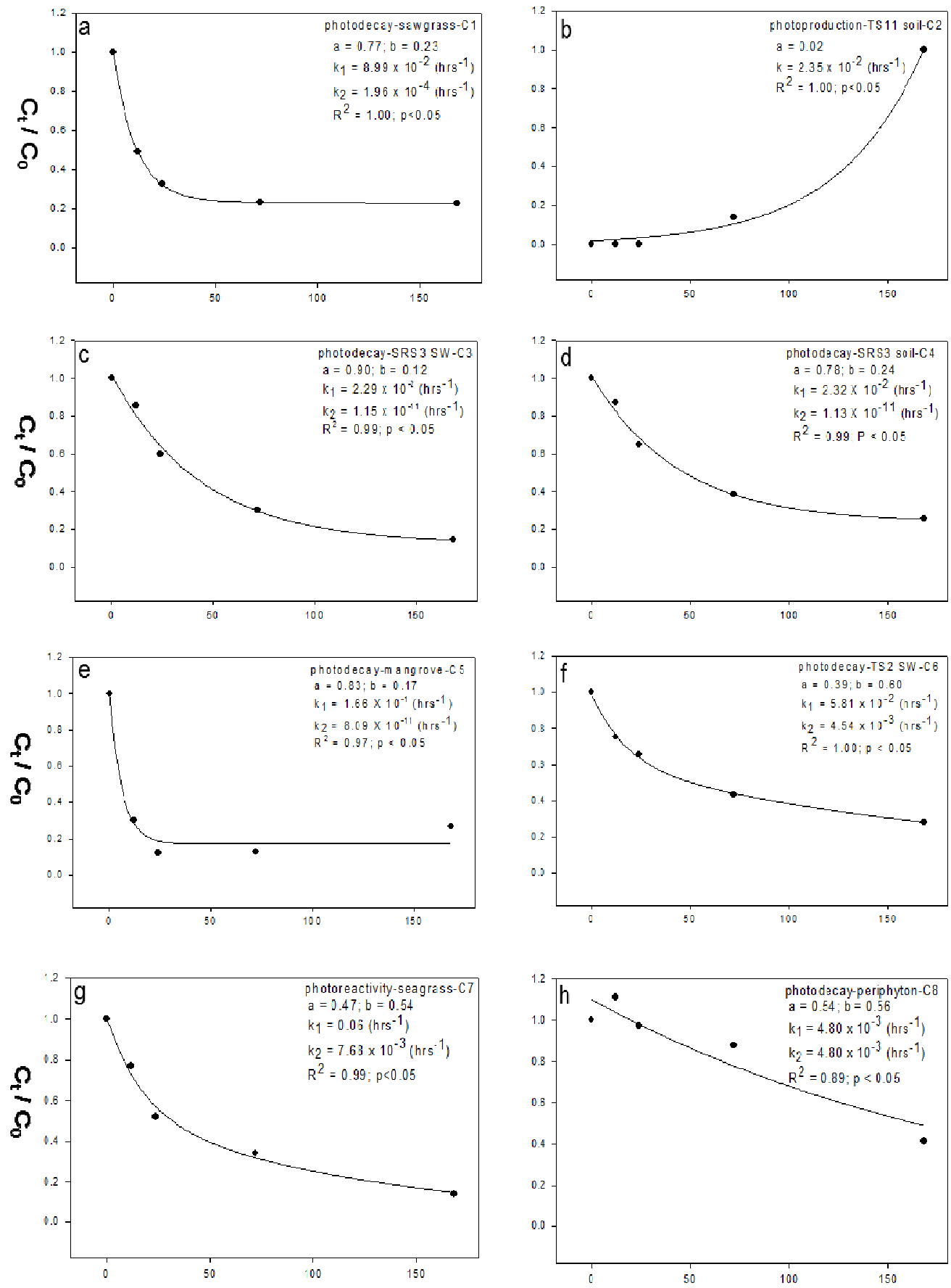

Fig. 3.5C Examples of EEM-PARAFAC components photo-degradation patterns and kinetics data (average of triplicate) fitted into a multi-pool first-order decay model $C t=a * e^{-k}{ }_{1}^{t}+b^{*} e^{-k}{ }_{2}^{t}(a$ and $c-h)$; and a single pool first-order growth kinetic model $\mathrm{Ct}=\mathrm{a} * \mathrm{e}^{\mathrm{kt}}(\mathrm{b}) . \mathrm{SW}=$ surface water. 
$9.7 \times 10^{1}$ and $2.4 \times 10^{10}$ hours for pool-1 and pool-2, respectively.

C5: This humic-like component has a very similar behavior to that observed for $\mathrm{C} 1$ and $\mathrm{C} 3$ in that it presented mainly exponential decay curves for the photo-degradation experiment with half-lives for pool-2 being much higher than for pool-1 and on the order of $10^{10}$ hours. Only two samples, namely sawgrass and mangrove leachates showed any degree of biodegradation with half-lives of ca. $2.6 \times 10^{1}$ for pool-1 and $7.7 \times 10^{11}$ and $5.1 \times 10^{2}$ for pool-2 from sawgrass and mangrove leachate respectively. C6: This component has been assigned a microbial humic-like character, and has been reported as photosensitive (Chen et al., 2010). The photo-degradation patterns of C6 were quite consistent with decay patterns resulting in an average half-life of $3.8 \times 10^{1}$ hours for pool-1 and significantly larger values ranging from $10^{2}$ to $10^{11}$ hours for pool-2. The highest photo-degradation rate was observed for seagrass $(95 \%$ with a half live of $8.3 \times 10^{-6}$ hours) and mangrove leachates with only one, labile pool represented (half live 16 hours). Bio-degradation profiles resulted mostly in increases in the abundance of C6 during the incubation or in some instances not much change over time, suggesting a high degree of microbial generation of this component. The abundance of C6 is therefore likely a reflection of the source strengths with regards to the competing photo-exposure. This is in agreement with the fact that C6 was reported as enriched in groundwater compared to surface water in the Everglades (Chen et al., 2010).

C7: This component has been assigned a protein-like character, and as such is expected to present some sensitivity to exposure to sunlight. In fact, $\mathrm{C} 7$ was observed 
to decrease exponentially in abundance when exposed to sunlight resulting in an average half-life of $3.2 \times 10^{1}$ hours for pool- 1 and a range from $10^{1}$ to $10^{11}$ hours for pool-2. Biodegradation patterns were surprising as protein-like components in surface waters are commonly observed to be quite bioavailable (Fellman 2008, 2009a, 2009b). Here, only the biomass leachates and two of the soil leachates, namely those from TS2 and TS11, the two most microbially influences locations, showed clear decay patterns during bio-incubation, while the other soil leachates and the SW samples showed no significant change over the time of incubation. The biomass leachate samples presenting half-lives of $2.6 \times 10^{2}$ and $1.9 \times 10^{3}$ hours for pool-1 and pool-2 respectively. This suggests that the bioavailability of $\mathrm{C} 7$ is quite variable and DOM source dependent. As such, the abundance of C7 as a proxy for bioavailability needs to be considered with care (see below).

C8: Similar to $\mathrm{C} 7$ this component has also been assigned a protein-like character, and its response to photo- and bio-degradation was in many aspects similar to that of $\mathrm{C} 7$. While the photo-degradation showed the expected decay curves for 8 out of 13 samples, with half-lives of $3.9 \times 10^{1}$ hours for pool- 1 and $1.3 \times 10^{10}$ hours for pool-2, similar to $\mathrm{C} 7$, the bio-degradation patterns were quite different. Unlike the common exponential decay patterns observed for $\mathrm{C} 7$ for the biomass leachates, $\mathrm{C} 8$ showed in most cases a combination of decreases and increases throughout the degradation process, suggesting that competing degradation and generation processes control the abundance of this component in the environment. Similar suggestions have previously been reported in the literature based on field data (Yamashita et al., 2008b, 2010b) and 
C8 may in fact have a net accumulation in the environment after photo- or bio-degradation of DOM. As such it seems to justify its location on the PCA plot shown in figure 3.4 .

It was reported that the decay half-lives of plant leachate in Everglades ranged from about 4 to 347 days for bulk DOC with 28-day dark bio-degradation (Scully et al., 2004). In another study for more specific type of compounds, half-lives of $\sim 10-20$ hours for most humic peaks and refractory characters for most protein peaks were found during photo-degradation experiments for Southern California coastal water (Clark et al., 2008).

Recently, Shank et al. (2010) reported a photo-bleaching rate of $\sim 60-90$ hours for CDOM (absorption coefficient at $305 \mathrm{~nm} \mathrm{a} \mathrm{a}_{305}$ ) produced from yellow and orange mangrove leaves. In contrast, half-lives for the refractory FDOM pool estimated here are orders of magnitude longer than ${ }^{14} \mathrm{C}$ - based average age of $\sim 4000$ to 6000 years for deep ocean refractory DOC (Williams and Druffel 1987; Bauer et al., 1992). However, considering that $14 \mathrm{C}$-dating provides an average age for the sampled DOC pool, the actual half-lives may cover a much larger range. DOM is an assemblage of mixtures of compounds, comprising supramolecular assemblages which have not been clearly identified with regards to their actual structure (Sutton and Sposito 2005). Such variety in the molecular speciation of DOM may result in highly variable reactivity, which could span the whole gamut of the time continuum. Little is known about this subject, but it would explain why individual PARAFAC components from different sources feature such different degradation patterns and degradation kinetics. 
Table 3.3B Examples of degradation trends and kinetics data.

\begin{tabular}{|c|c|c|c|c|c|c|c|c|c|c|c|c|}
\hline \multirow[t]{2}{*}{ items } & \multicolumn{4}{|c|}{ photodegradation } & \multirow[b]{2}{*}{ pool $2 \%$} & \multirow[b]{2}{*}{$\mathrm{R}^{2}$} & \multirow[b]{2}{*}{ trend } & \multicolumn{3}{|c|}{ biodegradation } & \multirow[b]{2}{*}{ pool $2 \%$} & \multirow[b]{2}{*}{$\mathrm{R}^{2}$} \\
\hline & trend & $\mathrm{t}_{1 / 2,1}(\mathrm{hrs})$ & $t_{1 / 2,2}(h r s)$ & pool $1 \%$ & & & & $\mathrm{t}_{1 / 2,1}$ (hrs) & $\mathrm{t}_{1 / 2,2}$ (hrs) & pool1\% & & \\
\hline \multicolumn{13}{|l|}{ EEM-PARAFAC } \\
\hline C5-saw grass & $\downarrow$ & $1.2 \mathrm{E}+01$ & 4.4E+10 & 46 & 54 & 1.0 & $\downarrow$ & $2.4 \mathrm{E}+01$ & 7.7E+11 & 22 & 78 & 1.0 \\
\hline C5-spikerush & $\downarrow$ & $7.9 \mathrm{E}+00$ & $1.4 \mathrm{E}+11$ & 33 & 67 & 0.9 & $\uparrow \downarrow$ & & & & & \\
\hline C5-periphyton & $\downarrow$ & 1.7E+02 & $1.7 \mathrm{E}+02$ & 49 & 51 & 0.9 & $\uparrow \downarrow$ & & & & & \\
\hline C5-mangrove & $\downarrow$ & $4.2 \mathrm{E}+00$ & $8.6 \mathrm{E}+09$ & 83 & 17 & 1.0 & $\downarrow$ & $2.8 \mathrm{E}+01$ & $5.1 \mathrm{E}+02$ & 70 & 30 & 1.0 \\
\hline C5-seagrass & $\downarrow$ & $1.5 \mathrm{E}-04$ & $3.4 \mathrm{E}+10$ & 44 & 56 & 0.9 & $\uparrow \downarrow$ & & & & & \\
\hline C5-SRS3 soil & $\downarrow$ & $1.9 \mathrm{E}+01$ & $3.9 \mathrm{E}+02$ & 67 & 33 & 1.0 & $\rightarrow$ & & & & & \\
\hline C5-SRS5 soil & $\downarrow$ & $1.7 \mathrm{E}+01$ & $2.1 \mathrm{E}+10$ & 70 & 30 & 1.0 & $\rightarrow$ & & & & & \\
\hline C5-TS/Ph2 soil & $\downarrow$ & $5.9 \mathrm{E}+00$ & $1.5 \mathrm{E}+02$ & 51 & 49 & 1.0 & $\rightarrow$ & & & & & \\
\hline C5-TS/Ph11 soil & $\downarrow$ & $4.5 \mathrm{E}+00$ & $3.7 \mathrm{E}+02$ & 72 & 28 & 1.0 & $\rightarrow$ & & & & & \\
\hline C5-SRS3-SW & $\downarrow$ & $5.0 \mathrm{E}+00$ & $1.0 \mathrm{E}+02$ & 41 & 59 & 1.0 & $\rightarrow$ & & & & & \\
\hline C5-SRS5-SW & $\downarrow$ & $5.4 \mathrm{E}+00$ & $1.4 \mathrm{E}+02$ & 69 & 31 & 1.0 & $\rightarrow$ & & & & & \\
\hline C5-TS/Ph2-SW & $\downarrow$ & $2.0 \mathrm{E}+01$ & $3.5 \mathrm{E}+02$ & 54 & 46 & 1.0 & $\rightarrow$ & & & & & \\
\hline C5-TS/Ph11-SW & $\downarrow$ & $7.5 \mathrm{E}+01$ & $4.1 \mathrm{E}+10$ & 60 & 40 & 1.0 & $\rightarrow$ & & & & & \\
\hline C5-C111-SW & $\downarrow$ & $1.8 \mathrm{E}+01$ & $3.3 E+02$ & 33 & 67 & 1.0 & $\rightarrow$ & & & & & \\
\hline Average-C5 & & $2.6 \mathrm{E}+01$ & $2.0 \mathrm{E}+10$ & 55 & 45 & 1.0 & & $2.6 \mathrm{E}+01$ & $3.9 \mathrm{E}+11$ & 46 & 54 & 1.0 \\
\hline C6-saw grass & $\downarrow$ & $8.8 \mathrm{E}+00$ & $8.8 \mathrm{E}+00$ & 49 & 51 & 1.0 & $\uparrow$ & k: $7.1 \mathrm{E}-04$ & & & & 0.9 \\
\hline C6-spikerush & zero & & & & & & $\uparrow$ & k: $1.9 \mathrm{E}-03$ & & & & 0.6 \\
\hline C6-periphyton & $\downarrow$ & $1.3 \mathrm{E}+02$ & $1.3 \mathrm{E}+02$ & 50 & 50 & 0.9 & $\uparrow$ & $\mathrm{k}: 1.4 \mathrm{E}-03$ & & & & 0.6 \\
\hline C6-mangrove & $\downarrow$ & $1.6 \mathrm{E}+01$ & $1.6 \mathrm{E}+01$ & 58 & 42 & 0.8 & $\uparrow \downarrow$ & & & & & \\
\hline C6-seagrass & $\downarrow$ & 8.3E-06 & $4.8 \mathrm{E}+09$ & 95 & 5 & 1.0 & $\downarrow$ & 1.3E-04 & $3.5 \mathrm{E}+11$ & 52 & 48 & 1.0 \\
\hline C6-SRS3 soil & $\downarrow$ & $2.1 \mathrm{E}+01$ & 4.7E+02 & 75 & 25 & 1.0 & $\rightarrow$ & & & & & \\
\hline C6-SRS5 soil & $\downarrow$ & $1.2 \mathrm{E}+01$ & $2.0 \mathrm{E}+10$ & 75 & 25 & 1.0 & $\rightarrow$ & & & & & \\
\hline C6-TS/Ph2 soil & $\downarrow$ & $5.7 \mathrm{E}+00$ & $1.3 \mathrm{E}+02$ & 62 & 38 & 1.0 & $\uparrow$ & $\mathrm{k}: 1.2 \mathrm{E}-04$ & & & & 0.4 \\
\hline C6-TS/Ph11 soil & $\downarrow$ & $5.6 \mathrm{E}+00$ & $3.0 \mathrm{E}+02$ & 34 & 66 & 1.0 & $\uparrow$ & k: $5.4 \mathrm{E}-04$ & & & & 0.9 \\
\hline C6-SRS3-SW & $\downarrow$ & $3.6 \mathrm{E}+00$ & $9.2 \mathrm{E}+01$ & 40 & 60 & 1.0 & $\rightarrow$ & & & & & \\
\hline C6-SRS5-SW & $\downarrow$ & $6.5 \mathrm{E}+00$ & 4.1E+02 & 41 & 59 & 1.0 & $\rightarrow$ & & & & & \\
\hline C6-TS/Ph2-SW & $\downarrow$ & $1.2 \mathrm{E}+01$ & $1.5 \mathrm{E}+02$ & 39 & 61 & 1.0 & $\rightarrow$ & & & & & \\
\hline C6-TS/Ph11-SW & $\downarrow$ & $2.5 \mathrm{E}+02$ & $2.5 \mathrm{E}+02$ & 54 & 46 & 1.0 & $\uparrow$ & $k: 3.6 \mathrm{E}-04$ & & & & 0.9 \\
\hline C6-C111-SW & $\downarrow$ & $2.0 \mathrm{E}+01$ & $1.7 \mathrm{E}+02$ & 30 & 70 & 1.0 & $\rightarrow$ & & & & & \\
\hline Average-C6 & & $3.8 \mathrm{E}+01$ & $1.9 \mathrm{E}+09$ & 54 & 46 & 1.0 & & 1.3E-04 & $3.5 \mathrm{E}+11$ & 52 & 48 & 1.0 \\
\hline C7-saw grass & $\downarrow$ & $3.5 \mathrm{E}+00$ & $1.2 \mathrm{E}+02$ & 45 & 55 & 1.0 & $\downarrow$ & 3.1E-02 & 2.7E+04 & 38 & 62 & 1.0 \\
\hline C7-spikerush & $\downarrow$ & $1.6 \mathrm{E}+01$ & $8.9 \mathrm{E}+01$ & 61 & 39 & 1.0 & $\downarrow$ & $1.3 \mathrm{E}+02$ & $5.3 \mathrm{E}+09$ & 86 & 14 & 0.9 \\
\hline C7-periphyton & $\downarrow$ & $9.4 \mathrm{E}+00$ & $1.0 \mathrm{E}+02$ & 56 & 44 & 1.0 & $\downarrow$ & $9.6 \mathrm{E}+00$ & $3.1 \mathrm{E}+02$ & 30 & 70 & 1.0 \\
\hline C7-mangrove & $\downarrow$ & $5.1 \mathrm{E}+00$ & $1.5 \mathrm{E}+02$ & 65 & 35 & 1.0 & $\downarrow$ & $2.6 \mathrm{E}+01$ & $3.3 E+02$ & 64 & 36 & 1.0 \\
\hline C7-seagrass & $\downarrow$ & $1.2 \mathrm{E}+01$ & $9.0 \mathrm{E}+01$ & 47 & 53 & 1.0 & $\downarrow$ & 5.6E-03 & $3.3 E+02$ & 79 & 21 & 1.0 \\
\hline C7-SRS3 soil & $\downarrow$ & $3.1 \mathrm{E}+01$ & $2.8 \mathrm{E}+09$ & 72 & 28 & 1.0 & $\rightarrow$ & & & & & \\
\hline C7-SRS5 soil & $\downarrow$ & 1.7E+02 & $1.7 \mathrm{E}+02$ & 50 & 50 & 0.8 & $\rightarrow$ & & & & & \\
\hline C7-TS/Ph2 soil & $\downarrow$ & $2.7 \mathrm{E}+01$ & $4.5 E+09$ & 55 & 45 & 0.8 & $\downarrow$ & $1.2 \mathrm{E}+03$ & $1.2 \mathrm{E}+03$ & 48 & 52 & 0.9 \\
\hline C7-TS/Ph11 soil & $\downarrow$ & $8.4 \mathrm{E}+00$ & $2.8 \mathrm{E}+02$ & 84 & 16 & 1.0 & $\downarrow$ & $3.1 \mathrm{E}+01$ & $1.1 \mathrm{E}+03$ & 50 & 50 & 1.0 \\
\hline C7-SRS3-SW & $\downarrow$ & $3.3 \mathrm{E}+01$ & $2.1 \mathrm{E}+10$ & 66 & 34 & 1.0 & $\rightarrow$ & & & & & \\
\hline C7-SRS5-SW & $\downarrow$ & $3.9 \mathrm{E}+01$ & $2.6 \mathrm{E}+10$ & 49 & 51 & 1.0 & $\rightarrow$ & & & & & \\
\hline C7-TS/Ph2-SW & $\downarrow$ & $4.5 \mathrm{E}+01$ & $1.0 \mathrm{E}+11$ & 37 & 63 & 0.5 & $\rightarrow$ & & & & & \\
\hline C7-TS/Ph11-SW & $\downarrow$ & $3.2 \mathrm{E}+01$ & $7.3 E+10$ & 42 & 58 & 1.0 & $\rightarrow$ & & & & & \\
\hline C7-C111-SW & $\downarrow$ & $1.5 \mathrm{E}+01$ & $2.1 \mathrm{E}+10$ & 32 & 68 & 0.8 & $\downarrow$ & $1.2 \mathrm{E}-02$ & $6.7 \mathrm{E}+03$ & 27 & 73 & 1.0 \\
\hline Average-C7 & & $3.2 \mathrm{E}+01$ & $1.8 \mathrm{E}+10$ & 54 & 46 & 0.9 & & $1.8 \mathrm{E}+02$ & $6.6 \mathrm{E}+08$ & 53 & 47 & 1.0 \\
\hline \multirow[t]{2}{*}{ Note: } & \multicolumn{6}{|c|}{$\uparrow=$ increase $; \downarrow=$ decrease; $\rightarrow$ =no obvious change; } & & & & & & \\
\hline & \multicolumn{8}{|c|}{ values are rate constant k (hrs-1) instead of half-life in case of increase. } & & & & \\
\hline
\end{tabular}


This study used not only the bulk CDOM (A254) but also PARAFAC to decompose EEMs into different components so as to better characterize the detailed reactivity for multiple "types" of DOM. In addition, multi-pool degradation modeling divided the fluorophores in each component into three lability-based pools. Quantification of photo- and bio-reactivity for each pool of each EEM-PARAFAC component originated from different sources provided more detailed reactivity information than quantifying bulk parameters such as DOC. Furthermore, different half-lives (orders of multitude) were observed for even a same component from different sources, suggesting the mixture nature of the fluorophores in each component, most likely the result of different structures, speciation and conformation, and molecular weights. This call for a cautious approach when direct comparisons between EEM-PARAFAC components in different ecosystems are performed as components with similar fluorescence characteristics can actually present very different photo- and bio-reactivity due to different structural features or speciation states.

\subsubsection{Reactivity comparison of biomass leachate, soil leachate, and surface water}

The EEM-PARAFAC components of FCE DOM were further sub-classified into 3 reactivity categories according to the half-lives calculated based on the maximum estimated residence time of a conservative tracer about 2 months for Everglades National Park as follows: The DOM pools were classified as labile (L-DOM) by replacing the term t (time) in equation 3 for 4 days; semi-labile 

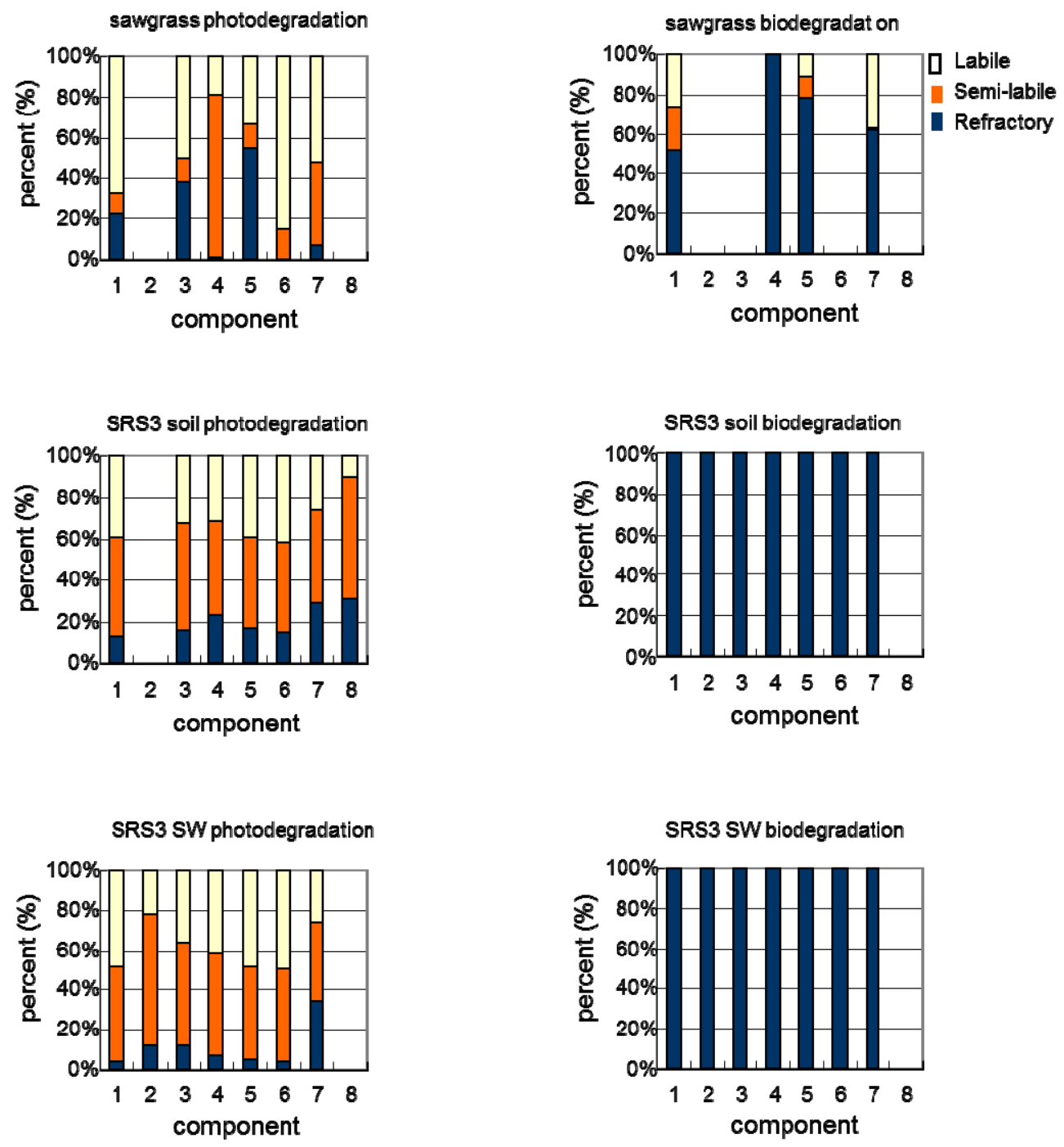

Fig.3.6 Examples of comparison of photo- (7 days) and bio-reactivity ( 28 days) of EEM-PARAFAC components for biomass leachate, soil leachate, and surface water in FCE. (Labile: $t_{1 / 2}<4$ days; semi-labile: $t_{1 / 2}$ between 4-60 days; and refractory: $t_{1 / 2}>60$ days).

(SL-DOM) for residence times between 4-60 days and the refractory pool (R-DOM) for above 60 days. The days above are "equivalent" days and 1 SunTest day was estimated to be equivalent to 4 days in natural environment. \% L-DOM and \% 
R-DOM were calculated by substituting the time t with 4 and 60 equivalent days, respectively, and \% SL-DOM was obtained by subtracting the sum of $\%$ L-DOM and $\%$ R-DOM from a total $100 \%$. Since the actual photo-degradation were 28 equivalent days and bio-incubation were 28 actual days, the calculations here were estimations based on the assumption that the exponential decay trends will continue extrapolating to longer time scales. Fig.3.6 shows some representative examples of biomass, soil and surface water comparison of \% L-DOM, \% SL-DOM, and \% R-DOM during photo- and biodegradation. Additional data are presented in Appendix. The results show that solar irradiation alone was very powerful in degrading fluorescent DOM as opposite to bio-incubation alone, which only displayed some effects on the biomass leachates. This is consistent with the finding in northern Everglades that microbial degradation of DOM was very slow (Qualls and Richardson 2003). The EEM-PRAFAC components featured a wide range of half-lives and general degradation trends were not readily observable in this large dataset. In order to facilitate data interpretation, PCA analyses were performed after loading the \% L-DOM, \% SL-DOM, and \% R-DOM of the EEM-PARAFAC components. To simplify the analyses, the humic-like $\mathrm{C} 1$ and protein-like $\mathrm{C} 7$ only were selected for the PCA as representatives of the potentially photo-reactive humic-like fractions and the potentially bio-labile protein-like fractions and were also present in all the samples as stated before. Using this approach, general trends became clear as illustrated in Fig.3.7. Principal component 1 (PC1), which represents the reactivity scale with the labile fraction on the right-hand side and the refractory fraction on the left, accounted 

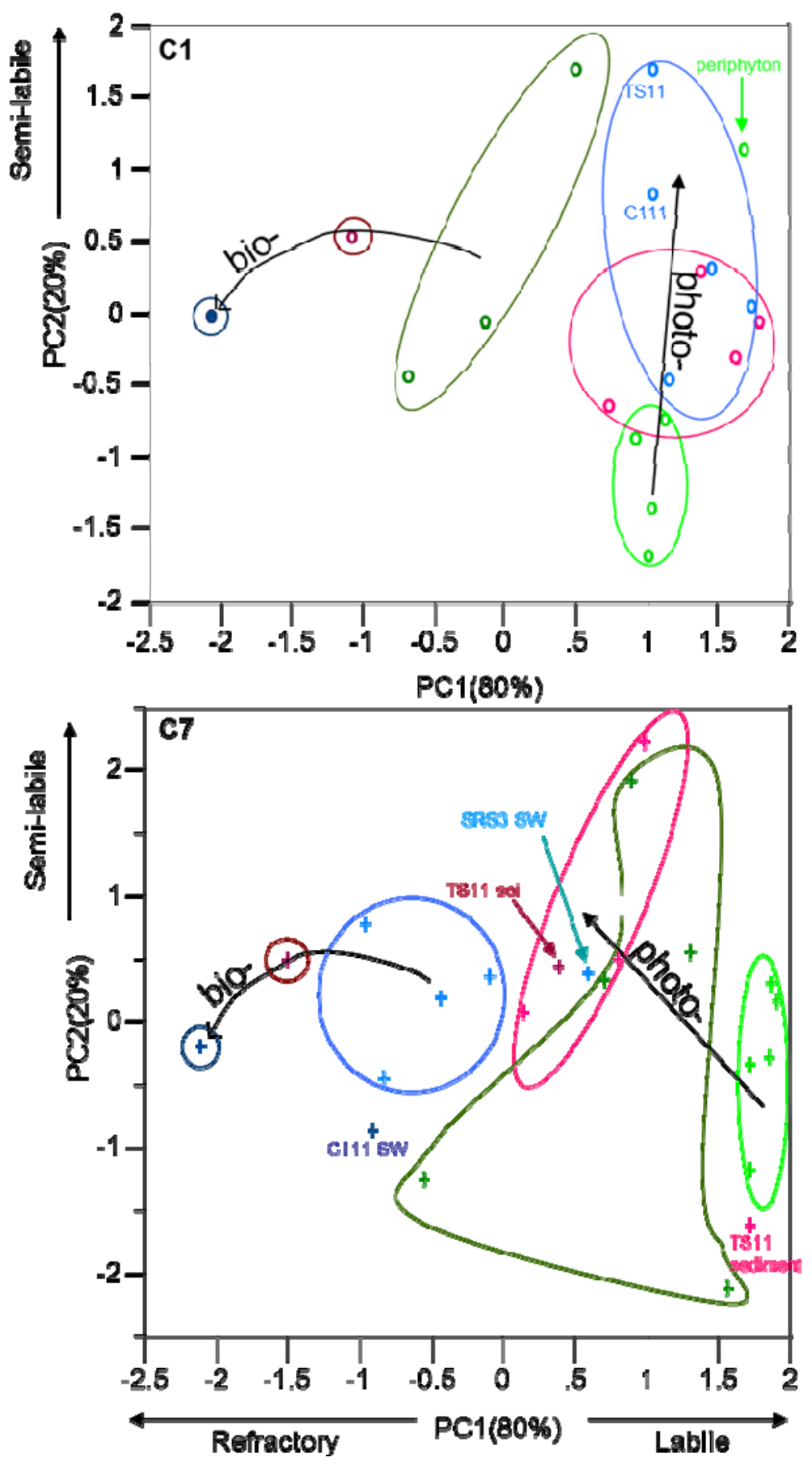

Fig.3.7 PCA comparison of photo- and bio-reactivity of humic-like C1 and protein-like $\mathrm{C} 7$ among three sources (biomass leachate, soil leachate, and surface water) based on relative abundance of the labile, semi-labile, and refractory pools. (Color code for photodegradation: biomass; soil leachate; SW; color code for biodegradation: biomass; soil leachate; SW; SW = surface water. 
for $80 \%$ of the variability, while PC2, representing the semi-labile fraction vertically, accounted for $20 \%$ of the variability. Both components showed a more positive correlation with $\mathrm{PC} 1$ for the photo-degradation data compared to the biodegradation data, suggesting a higher propensity to photo-degradation than bio-degradation. Patterns observed for $\mathrm{C} 1$ showed a general reactivity trend of biomass $>$ soil $>\mathrm{SW}$ (excluding the periphyton leachates which don't seem very photo-reactive), and a significant overlap between the data for the soil and SW samples. C7 also showed a general similar trend to that of $\mathrm{C} 1$, except for TS11 sediment, which showed a high degree of labile character similar to the biomass leachates. In general, the trends in photo-degradation were mostly from labile to semi-labile for the $\mathrm{C} 1$ (positive correlation with PC2) while a slight shift to a more refractory character was observed for $\mathrm{C} 7$ (both positive correlation with PC2 and negative correlation with PC1). With regards to bio-reactivity, both $\mathrm{C} 1$ and $\mathrm{C} 7$ had similar trends with a shift from semi-labile to labile (negative correlation with PC1) along the biomass to soil to surface water reactivity gradient.

\subsubsection{Correlation of biodegradable DOC versus protein-like components:}

Yamashita and Tanoue (2003) observed good correlations between protein-like EEM-PARAFAC components and aromatic amino acids, and proposed that protein-like components could be useful indicators as not only aromatic amino acids but of the total hydrolysable amino acids (THAA) in bulk DOM. In this respect, other authors have suggested that some optical properties such as the protein-like 

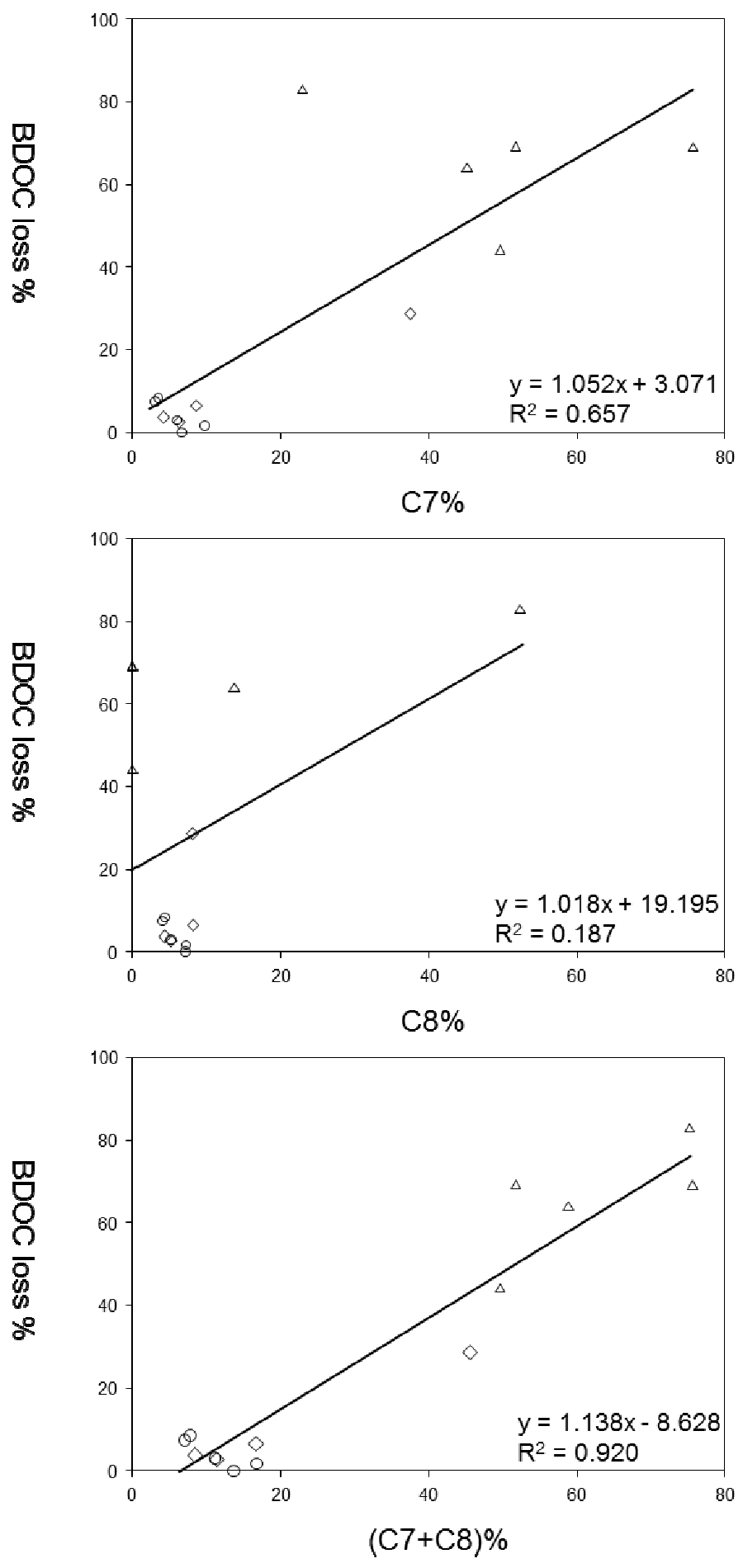

Fig.3.8 Correlation of \% BDOC loss versus each and the sum of two protein-like EEM-PARAFAC components. Symbols represent: $\Delta$ biomass leachate; $\Delta$ soil leachate; $O$ surface water. 
fluorescence, could be used as proxies for the biodegradable DOC fraction (BDOC) (Fellman et al., 2008, 2009a, and 2009b; Balcarczyk et al., 2009). In the present study the correlation between \% BDOC loss and \% C7 alone, \% C8 alone, and the sum of the two protein-like components $\%(C 7+C 8)$, showed that while protein-like components $\mathrm{C} 7$ and $\mathrm{C} 8$ were found to be reasonably well and not correlated with \% BDOC loss respectively $\left(\mathrm{R}^{2}=0.66\right.$ and 0.19 , for $\mathrm{C} 7 \%$ and $\mathrm{C} 8 \%$, respectively), the sum of $\mathrm{C} 7 \%$ and $\mathrm{C} 8 \%$ showed the best correlation $\left(\mathrm{R}^{2}=0.92\right.$; Fig. 3.8). Similar linear correlations have been reported for biodegradation of DOM in surface waters (Balcarczyk et al., 2009). However, in this case the correlation represents a range of samples from biomass leachates, soil leachates and surface waters. In this correlation the surface water samples were clustered on the lower part of the line, but did not show any linear correlation among them. While the correlation shown in Figure 3.8 suggests that the $\% \mathrm{C} 7+\mathrm{C} 8$ can be used as a proxy for BDOC over a wide range of DOM sources, its direct application as a proxy for surface waters of the Everglades seems unlikely and may be controlled by local environmental dynamics. This lack of correlation seems to be consistent with the observation by Maie et al. (2007) in Everglades that a protein-like peak-T (excitation/emission maximum at 280/325 nm) can be a mixture of protein-like and polyphenol-like fluorescence, in which case the application of this parameter as a bioavailability proxy has severe limitations. Alternatively, in ecosystem like the Everglades where terrestrial DOM is dominant, protein-like structures might be encapsulated and thus "shielded" in the three dimensional structure of the DOM (Yamashita and Jaffe, 2008a) and consequently are 
less available for bacterial uptake. In addition, relatively high amounts of dissolved black carbon in Everglades DOM (up to $25 \% \mathrm{C}$; Jaffé unpublished) can also serve as a means of reducing DOM bioavailability.

\subsection{Conclusions and Environmental implications:}

(1) Qualitative assessment of DOM reactivity: An interesting result from this study is the general indication that C3 may serve as an indicator of the degree of photo-degradation, as it becomes enriched during this process. Similarly, C6 and C8 could serve that function for the bio-degradation process. Sequential photo- followed by bio-degradation proved to be most effective in changing the leachates' DOM fluorescence characteristics into EEMs more similar to those of the natural surface water DOM. This is consistent with previous findings that sunlight has "priming effect" for bacterial uptake on terrestrial-derived DOM (Tranvik and Bertilson 2001; Qualls and Richardson 2003; Moran and Covert 2003).

(2) Quantitative assessment of DOM reactivity: The two organic matter pool model provided to be an excellent fit for the decay data observed in this study. A variety of different behavioral patterns were observed between the photo- and bio-degradation kinetics, between different samples and sample types, and between different PARAFAC components. Reaction kinetics showed profiles for exponential decay and increase followed by decrease for $a_{254}$, and exponential decay, exponential generation, no observable change through time or variable decreases and increments for EEM-PARAFAC components throughout the incubation periods. It is intriguing 
that observe this high degree of variability in degradation patterns and associated rate constants (or half-lives) even for the same PARAFAC components depending on sample type and source. This suggests that the mixture nature of the fluorophores in each component, most likely the result of different structures, speciation and conformation, and molecular weights is causing this effect. This calls for a cautious approach when direct comparisons between EEM-PARAFAC components in different ecosystems are performed as components with similar fluorescence characteristics can actually present very different photo- and bio-reactivity due to different structural features or speciation states.

In general, decay curves for the photo-degradation kinetics most commonly resulted in significantly higher rate constants for the degradation of the more labile pool-1 compared to those obtained for the more refractory pool-2. However, the pool size was usually higher for pool-1 compared to pool-2 for fluorescent DOM (FDOM), but just the opposite for chromophoric DOM (CDOM) as evidenced by $a_{254}$ trends, implying that a larger fraction of the FDOM is photo-reactive compared to CDOM. Similar observations were true for the bio-degradation kinetics, although for the most part the half-lives were much longer for this degradation process where decay kinetics were less common that for photo-degradation, and patterns showing no significant change over time were more common. While photo-degradation half-lives were on the order of $10^{1}$ hours for pool-1, those for pool-2 were as high as $10^{11} \mathrm{hrs}$. Differences in photo-degradation half-lives for pool-1 corresponding to different PARAFAC components ranged from not significantly different to about a factor of 10 higher for 
the soil and SW samples. Differences between biomass leachates, soil leachates and surface waters for pool-2 were harder to assess as these were highly variable ranging from $10^{1}$ to $10^{11}$ across the different sample types, again suggesting a highly heterogeneous character regarding reactivity of the FCE DOM

(3) DOM reactivity comparison among sources: By further sub-classifying the EEM-PARAFAC components of FCE DOM into 3 reactivity categories according to the half-lives calculated based on the maximum estimated water residence time of about 2 months for FCE, patterns observed for the humic-like components (C1) showed a general reactivity trend of biomass $>$ soil $>\mathrm{SW}$, excluding the periphyton leachate, and a heavy overlap between soil and SW samples. Protein-like components (C7) also showed a general similar trend to that of C1, except for TS11 sediment. These general trends are not unexpected as biomass leachate DOM can be expected to have more reactive components compared to those in surface waters, who have already been actively exposed to environmental conditions. As such, soil leachates serve as intermediates in this reactivity continuum. The important implication of this finding is its application in carbon cycling modeling once source strengths (biomass versus soils) for FCE DOM can be quantitatively estimated.

(4) Correlation of BDOC with EEM-PARAFAC components: The correlation between \% BDOC loss and \% $\mathrm{C} 7$ alone, \% $\mathrm{C} 8$ alone, or the two protein-like components $\%(\mathrm{C} 7+\mathrm{C} 8)$, showed that the latter had a good correlation with it $\left(\mathrm{R}^{2}=\right.$ 0.92; Fig. 3.8). However, in this case the correlation represents a range of samples from biomass leachates, soil leachates and surface waters. The surface water samples 
were clustered on the lower part of the line, but did not show any linear correlation among them. While similar correlations for surface water DOM have clearly shown the application of the protein-like fluorescence in BDOM assessments, this does not seem to apply to the FCE DOM. It is likely that differences in DOM speciation (i.e. formation of supramolecular associations, molecular stacking and 3D structures of the DOM) may control the bio-availability of the protein-like carbon compounds to the microbial community (e.g. Yamashita and Jaffe, 2008).

(5) Implications for FCE wetland restoration: The results obtained through this study have environmental implications both for local Florida Everglades and for the global environment. Based on the reactivity study the FDOM in the FCE seems mainly controlled by its photo-reactivity and to a much lesser extent to the bio-reactivity. It is important to mention that this applies for the FDOM in general, and is not necessarily transferable to the DOC. While the latter was observed to decrease by $0.0-68.2 \%$ over the 28 day incubation, much of this decrease may be caused by the respiration on non-FDOM components such as carbohydrates (see Fig.A-2). However, other studies agree that the BDOM in the FCE is quite limited. Half-lives determined for both photo- and bio-degradation of the FDOM fraction suggest that at least the biodegradation process is limited by the elevated fraction of refractory FDOM based on present day water residence times in Everglades National Park. While the Everglades are undergoing an unprecedented historic restoration which aims to enhance among others the water flow throughout the system, such enhanced water delivery is expected to result in higher water depth, longer 
hydroperiod and shorter water residence times in the freshwater marsh and mangrove forest area, and more water delivery into Florida Bay and Gulf of Mexico coastal area. As sunlight penetration will be attenuated with water depth, DOM in deeper water and soil will be less exposed to UV irradiation. Similarly, shorter water residence time will reduce the time for degradation of the DOM further. The combined effects of higher water depth and shorter water residence time are expected to deliver not only more terrestrial-derived but also less refractory DOM into coastal area. While the potential effects of this enhanced reactivity character of the allochthonous DOM in coastal regions including Florida Bay remain unknown, the difference with present day conditions is difficult to assess as the magnitude of enhanced water delivery remains difficult to estimate at this time in the restoration process.

(6) General implications for PARAFAC applications: The significant differences and observed variability in DOM photo- and bio-reactivity from different sources is a reminder that cautions should be taken when comparing EEM-PARAFAC data in different ecosystems, as components with very similar fluorescence spectra may actually feature significantly different speciation and structures potentially resulting in vastly different photo- and bio-reactivity. More research in this area is needed to better constrain the limitations of this technique in comparative ecosystem studies and in particular for the application of EEM-PARAFAC based reactivity proxies. 


\section{Chapter 4}

Study of dissolved organic matter from groundwater and surface water in the Florida coastal Everglades 


\subsection{Abstract}

Dissolved organic matter (DOM) in groundwater and surface water samples from the Florida coastal Everglades (FCE) were studied using Excitation Emission Matrix fluorescence modeled through Parallel Factor Analysis (EEM-PARAFAC). DOM in both surface and groundwater from the eastern Everglades S332 basin reflected a terrestrial-derived fingerprint through dominantly higher abundances of humic-like PARAFAC components. In contrast, surface water DOM from northeastern Florida Bay featured a microbial-derived DOM signature on the basis of the higher abundance of microbial humic-like and protein-like components consistent with its marine source. Surprisingly, groundwater DOM from northeastern Florida Bay reflected terrestrial-derived source except for samples from the Nest Key (NK) well, which mirrored a combination of terrestrial and marine end-member origin. Furthermore, surface water and groundwater displayed effects of different degradation pathways such as photo-degradation and bio-degradation as exemplified by two PARAFAC components seemingly indicative of such degradation processes. Finally, Principal Component Analysis (PCA) of the EEM-PARAFAC data was able to distinguish and classify most of the samples according to DOM origins and degradation processes experienced, except for a small overlap of S332 surface water and groundwater, implying rather active surface-to-ground water interaction in some sites particularly during the rainy season. This study highlights that EEM-PARAFAC could be used successfully to trace and differentiate DOM from diverse sources across both horizontal and vertical flow profiles, and as such could be a convenient and 
useful tool for the better understanding of hydrological interactions and carbon biogeochemical cycling.

\subsection{Introduction}

Dissolved organic matter (DOM) is an assemblage of heterogeneous organic molecules that is ubiquitous in aquatic ecosystems and plays diverse biogeochemical and ecological roles (Findlay and Sinasbaugh 2003). As such, DOM has been shown to be a driver in microbial loop dynamics and a controlling factor in light availability to aquatic organisms, it can negatively impact water treatment processes and serve as a media for the transport of trace metals and organic pollutants, among others (Lu \& Jaffé 2001; Cai et al.,, 2000; Findlay \& Sinsabaugh 2003; Yamashita \& Jaffé 2008).

DOM is derived primarily from the decaying of organisms such as plants or algae. It is often classified into humic substances and biochemically defined non-humic substances such as proteins, carbohydrates and lipids. Generally speaking, DOM from marine and aquatic sources is more enriched in aliphatic structures while DOM from terrestrial/higher plant sources features more conjugated structure and higher aromaticity (e.g., Maie et al., 2005). While aliphatic structures in DOM tend to affect fluorescence spectra through a blue-shift, highly conjugated structures tend to be characterized by more red-shifted spectra (Coble 1996). These characteristics have successfully been used to differentiate terrestrial/higher plant derived DOM from marine/microbial sources (e.g., Coble, 1996; McKnight et al., 2001). 


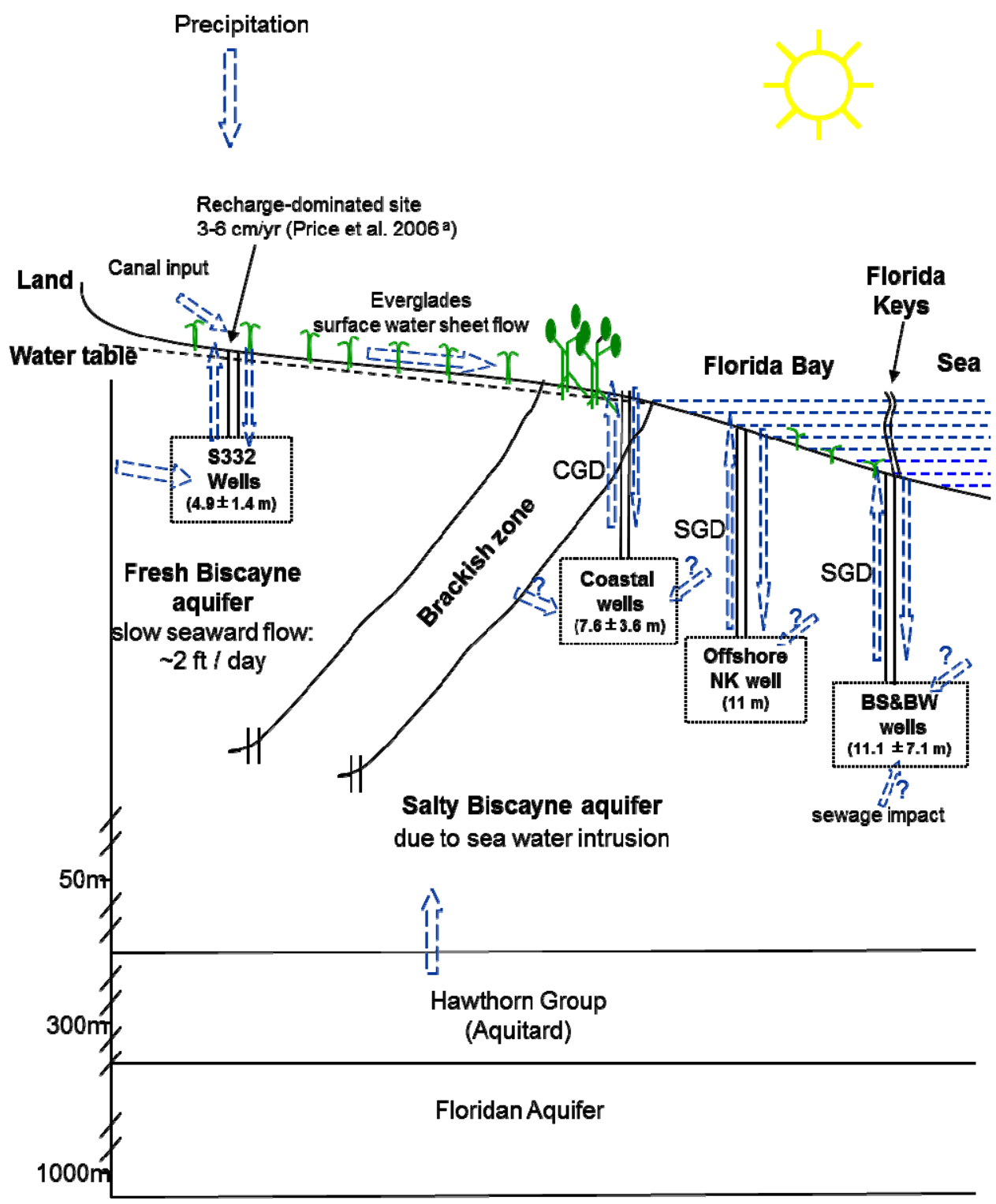

Fig.4.1 Conceptual diagram depicting sources of DOM in FCE ground water and surface water. $C G D=$ coastal groundwater discharge; SGD=submarine groundwater discharge. Arrow sizes are not proportional to flux size.

Diagenetic processes, such as photodegradtion and biodegradation, can also alter DOM structure and composition (Obernosterer \& Benner 2004; Zhang et al., 2009). Suboxic or anoxic environments, often typical for groundwater, favor 
microorganism-catalyzed reactions which can alter the nature of DOM through redox reactions. Humic substances in DOM can be directly or indirectly involved in microorganism-catalyzed redox reactions, either as electron shuttles or in some cases as terminal electron acceptors (Scott et al., 1998; Peretyazhko \& Sposito, 2006; Ratasuk et al., 2007; Jiang \& Klapper, 2008). Cory \& McKnight (2005) reported a reduced form of quinone and several partly reduced semiquinone fluorophores in reducing lake environments. They also found that the increase of a reduced form of quinone was concurrent with a decrease of an oxidized counterpart below the oxycline. Such studies have been possible thanks to the application of excitation-emission matrix with parallel factor analysis (EEM-PARAFAC) modeling. As such, this technique has ample potential to aid in the better understanding of DOM dynamics in groundwater and associated surface-to-groundwater exchange. However, only few reports have appeared in the literature regarding the use of fluorescent DOM as a natural tracer of groundwater sources, flow, and effects of pollution or land use (Baker \& Genty, 1999; Baker, 2001; Baker, 2002; Lapworth et al., 2008). The main objective of this study was to apply EEM-PARAFAC to the assessment of DOM dynamics in groundwater from the Florida coastal Everglades (FCE) ecosystem.

The FCE is one of the largest wetlands in the world and is undergoing an unprecedented ecological restoration aiming at restoring its historic quality, quantity, and timing of water flow (see http://www.evergladesplan.org/). A salinity gradient extends along FCE from freshwater marshes in the north, across a mangrove fringe along the coast, to the estuarine environments of Florida Bay and the Gulf of Mexico 
to the south. Environmental deterioration of this ecosystem due to changes in water quality and water delivery poses increasing urgency for biogeochemical and hydrological research. Most of the nitrogen and phosphorus in the Everglades are in an organic form (Boyer et al., 1997; Boyer, 2006), and thus associated with DOM. The objectives of the Comprehensive Everglades Restoration Plan (CERP) are to store large amounts of water underground (see http://www.evergladesplan.org/). Yet little information is available regarding DOM dynamics in ground waters of the greater Everglades ecosystem, although active recharge-discharge interactions have been shown to exist (Aiken \& McKnight et al., 1985; Corbett et al., 1999; Corbett et al., 2000; Price et al., 2006a; Price et al., 2006b; Harvey et al., 2006).

The sources of DOM to surface water in the FCE include: (1) autochthonous production by organisms such as emergent, floating, and submerged vegetation and periphyton; (2) oxidation of soil organic matter; (3) precipitation; (4) exchange with underlying ground water; and, (5) canal inputs. Possible inputs of DOM to groundwater include: (1) recharge from the overlying surface water; (2) groundwater flow from upstream of the FCE (3) desorption from the soils/sediments en route of percolating waters to the aquifer; (4) upward diffusion from deeper aquifers (Reese \& Cunningham 2000); and (5) possible input from the ocean side due to sea water intrusion. To better assess these surface-to-ground water dynamics for DOM, .we applied EEM-PARAFAC in an attempt to discriminate DOM sources and quality among surface water and groundwater from different locations in the Florida coastal Everglades, and in the process, trace the hydrological interactions between surface 
and groundwater. These are the first data of their kind for the greater Everglades ecosystem.

\subsection{Sampling and experimental methods}

\subsubsection{Sites description}

The eastern border of Everglades National Park and the north-east section of Florida Bay were selected as the study sites for this project (Fig.4.2). The region is immediately underlain by the Biscayne Aquifer, one of the most permeable karst aquifers in the world (Parker et al., 1955). The aquifer extends from Palm Beach County in the north to under Florida Bay and the Florida Keys in the south, and forms a wedge-shaped with a thin edge along its western boarder and thickening in and southeast direction to over $65 \mathrm{~m}$ along the coastline (Fish and Stewart, 1991; Bradner et al., 2005; Parker et al., 1955). The geology of the Biscayne aquifer is dominantly marine and freshwater carbonates deposited during the Pleistocene, overlain by recent deposits of peat and marl (Cunningham et al., 2006), The inorganic water chemistry of the Biscayne Aquifer beneath the FCE is dominantly calcium-bicarbonate typical for groundwater in contact with limestone, except for along the coastline where seawater intrudes into the aquifer and shifts the groundwater chemistry to a sodium-chloride-type of water (Harvey and McCormick, 2009; Price et al., 2006a). The shallow groundwater $(<30 \mathrm{~m})$ in the Biscayne Aquifer beneath the FCE has been dated using tritium/helium age dating techniques to be less than 30 years (Price et al., 
2003). The ${ }^{14} \mathrm{C}$-derived age of humic material isolated from groundwater from the Biscayne aquifer was found to be an average $683( \pm 50)$ years (Thurman, 1985).

The study sites include the S332 $\left(25.422^{\circ} \mathrm{N}, 80.590^{\circ} \mathrm{W}\right)$ basin area of ENP in the north and Florida Bay in the south. The S332 basin area was historically a part of the natural wetlands of the Everglades, but was farmed for a time, and has since been incorporated into a water treatment basin. Most surface water flow in the basin is controlled through pumps that transfer water from the adjacent L31 canal. This water is allowed to drain slowly from the basin into the headwaters of Taylor Slough, the natural surface water flow-way in the region, or to infiltrate into the groundwater table.

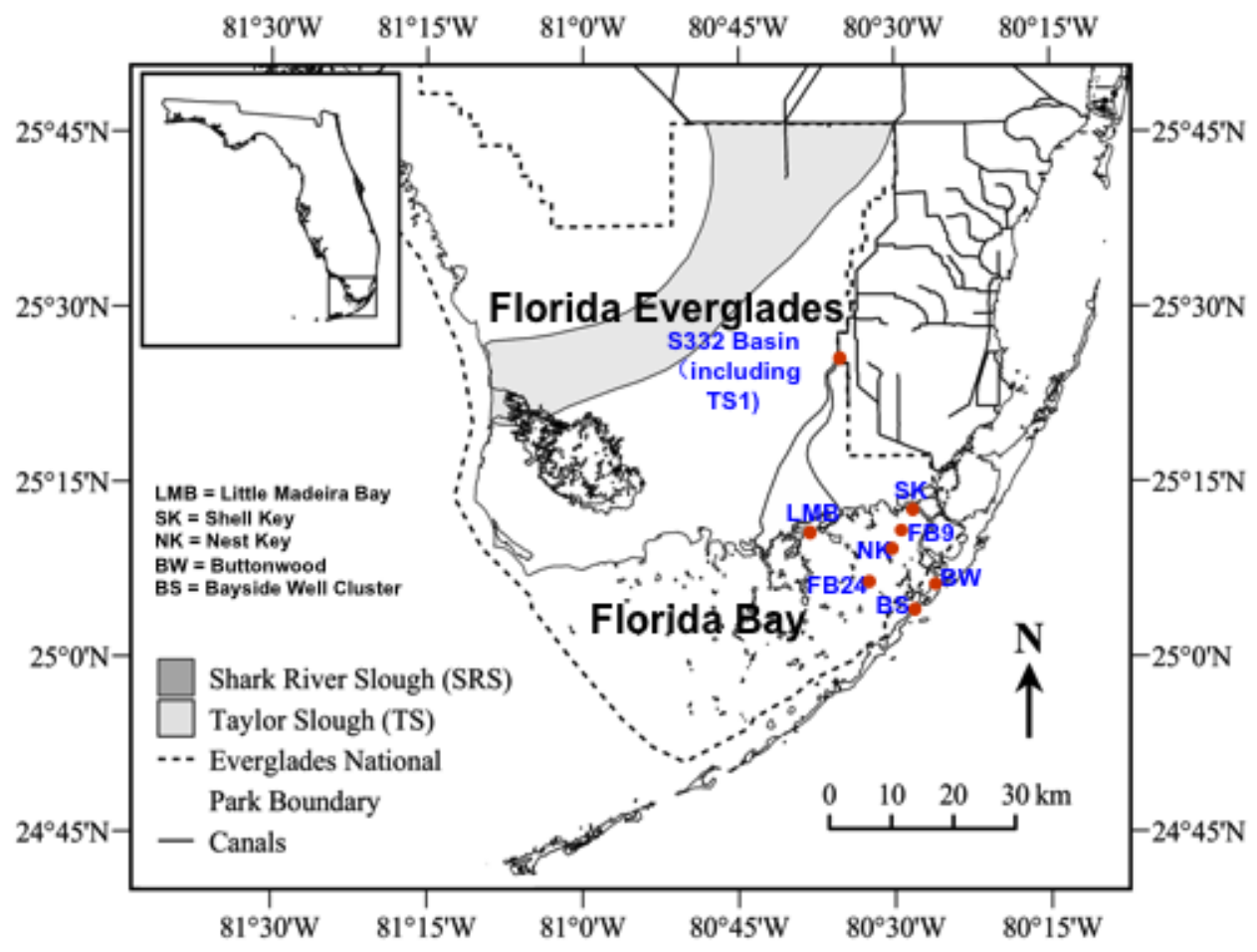

Fig.4.2 Sampling sites in Florida coastal Everglades (FCE). Groundwater and surface water were collected from S332 basin area and Northeastern FL Bay. 
The purpose of the basin is to retain nutrients (phosphorus and nitrogen) that may be in the canal water prior to its release to Taylor Slough.

Florida Bay is a coastal lagoon lying between the southern tip of the Florida mainland and the Florida Keys (Fourqurean and Robblee, 1999). Here several sites were studied including Little Madeira Bay (LMB; adjacent to the outflow of the Taylor River) and Shell Key (SK), located on the coastal side of Florida Bay, where fringe mangrove forests are the dominant vegetation. Offshore sites include Nest Key (NK), FB9, and FB24, sites covered by a thin layer of calcitic marl underling a blanket of seagrass. Two sites were located along the Florida Keys, namely the Buttonwood (BW) and Bay Side (BS) sites, both are in proximity of mangrove and urban environments.

\subsubsection{Sampling}

Groundwater from more than 20 wells (3.6 to $10.2 \mathrm{~m}$ in depth) in S332 basin was collected quarterly between September 2006 and September 2007. In addition, groundwater from 12 wells at five sites, scattered throughout northeastern Florida Bay

(Fig.4.1), were collected in September 2007. At four of the sites, groundwater samples were pumped from both shallow $($ depth $=4.6-6.1 \mathrm{~m})$ and deep $($ depth $=8.2-19.8 \mathrm{~m})$ wells (LMB, SK, BS, BW) while at NK groundwater was collected from a deep $($ depth $=11 \mathrm{~m})$ well only. Prior to sampling of each well, they were purged of at least 3 well volumes using a high flow pump. During purging, specific water quality data, such as salinity, $\mathrm{pH}$, and dissolved oxygen, were monitored until stable readings using 
an Orion meter (Table 1). Samples were pumped using a low flow peristaltic pump and filtered through a $0.45 \mu \mathrm{m}$ filter (HDPE, MilliPore groundwater sampling capsule) in situ. A syringe was attached to the end of the filter, and water samples were collected in glass Vacutainer tubes which were first pre-cleaned in dilute $(10 \%) \mathrm{HCl}$, flushed with helium and then evacuated with a vacuum pump in an attempt to remove $\mathrm{O}_{2}$. Collected samples were stored in a cooler with ice, transported to the lab on the same day, and then stored in a refrigerator for measurements within 3 days.

Surface water samples were collected monthly between October 2004 and September 2008 for TS1 (in S332 basin) and FB9 sites and from October 2004 to September 2006 for the FB24 site. The TS1 site became dry during dry season (typically between January to May) so samples were primarily collected during the wet season. The FB9 and FB24 sites were selected since they are close to the groundwater sites and representative of marine surface water. Samples were collected in pre-cleaned, acid-washed, brown high density polyethylene bottles (Nalgene). Containers were rinsed three times before sample collection. All surface water samples were filtered in the lab with pre-combusted $0.7 \mu \mathrm{m} \mathrm{GF} / \mathrm{F}$ filters and stored in a refrigerator until analyses within one week of collection.

\subsubsection{Analytical measurements}

The DOC concentrations were measured using the high-temperature catalytic combustion method with a Shimadzu TOC-V total organic carbon analyzer. Samples were acidified to $\mathrm{pH}<2$ with $3 \mathrm{~N}$ hydrochloric acid and were purged with $\mathrm{CO}_{2}$ free air 
to remove inorganic carbon before measurements. DOC data were used to calculate the specific ultraviolet absorbance, $a(254)^{*}$, which is an indicator of DOM aromaticity and defined as UV absorption coefficient $a(254)$ in inverse meters normalized to DOC concentration in $\mathrm{mg} / \mathrm{L}$ (Hansell \& Carlson, 2002, Weishaar et al., 2003). Due to very low levels of dissolved Fe in South Florida waters $a(254)^{*}$ values were not corrected for Fe interference (Weishaar et al., 2003). The $a$ (254) was determined using a Varian Cary 50 bio spectrophotometer with a $1 \mathrm{~cm}$ quartz cuvette scanning from $240 \mathrm{~nm}$ to $800 \mathrm{~nm}$. The UV-Vis spectra were also used for inner filter correction for the EEMs according to McKnight et al. (2001) and to determine the slope ratio $\left(\mathrm{S}_{\mathrm{R}}\right)$ of $275-295 \mathrm{~nm}$ to $350-400 \mathrm{~nm}$, as a proxy for the molecular weight distribution of DOM (Helms et al., 2008).

The EEMs were measured using a Horiba Jovin Yvon SPEX Fluoromax-3 spectrofluorometer equipped with a $150 \mathrm{~W}$ continuous output xenon arc lamp. Slits were set at $5.7 \mathrm{~nm}$ for excitation and $2 \mathrm{~nm}$ for emission. Forty-four emissions scans were acquired at excitation wavelength $\left(\lambda_{\text {ex }}\right)$ between $240-455 \mathrm{~nm}$ at every $5 \mathrm{~nm}$ steps. The emission wavelengths were scanned from $\lambda_{\mathrm{ex}}+10 \mathrm{~nm}$ to $\lambda_{\mathrm{ex}}+250 \mathrm{~nm}$ (i.e.: between $250-705 \mathrm{~nm}$ ) at $2 \mathrm{~nm}$ steps (Maie et al., 2006b). The 44 individually scanned spectra were concatenated to form EEMs. All fluorescence signals were acquired in signal over reference ratio mode $(\mathrm{S} / \mathrm{R})$ to eliminate potential fluctuation of the xenon lamp. Several post-acquisition steps were also carried out for correction and standardization: (1) inner filter effect correction using UV-Visible data according to McKnight et al., (2001); (2) instruments biases correction were performed using 
specific excitation and emission correction files provided by the manufacturer; (3) blank subtraction using Milli-Q water was performed; (4) daily fluorescence intensity variations were corrected using the area under the Milli-Q water Raman peak at excitation $350 \mathrm{~nm}$ (Cory \& McKnight 2005); (5) finally, all fluorescence measurements were converted to quinine sulfate units (QSU). The Fluorescence Index (FI) was determined as the ratio of the emission intensity at a wavelength of $470 \mathrm{~nm}$ to that at $520 \mathrm{~nm}$, obtained with an excitation of $370 \mathrm{~nm}$.

For groundwater samples, caution was taken to avoid $\mathrm{O}_{2}$ exposure and possible DOM oxidation before or during EEM measurements. As described above, the samples were collected in vacuumed tubes and transferred to a sealable cuvette in an inert Argon gas box for measurements.

\subsubsection{Parallel Factor Analysis (PARAFAC)}

PARAFAC is a statistic model used to decompose multi-way data into different components. It is derived from an alternating least square (ALS) algorithm. Thus, PARAFAC can statistically decompose EEMs into fluorescent groups (components). There are two ways to apply PARAFAC modeling, i.e., by creating and validating the model using the complete dataset of EEMs (e.g., Stedmon et al., 2003; Ohno and Bro, 2006) or by fitting the EEMs to an already established PARAFAC model (e.g., Yamashita and Jaffé, 2008; Fellman et al., 2009). The groundwater EEMs were fitted to an existing Everglades/Florida Bay surface water PARAFAC model which had been well established using 1394 surface water samples (Fig. 2) (Maie et 
al., personal communication). The analysis was carried out in MATLAB 7.0.4. (Mathworks, Natick, MA) with the DOMFluor toolbox (Stedmon and Bro, 2008). No obvious residues were found after fitting the groundwater EEMs to the established 8 components model, indicating that this model was applicable to groundwater DOM studies and that the fluorophores were similar between groundwater and surface water in the collected samples. The PARAFAC component spectral characteristics and split-half validation data are shown in Figure 2.2.

\subsection{Results \& Discussions}

\subsubsection{Water chemistry and optical parameters}

Both surface water and groundwater from the S3321 area were fresh as indicated by low salinity values (Table 4.1). While both surface water and groundwater from FB had salinity $>30$ (Table 4.1). The $\mathrm{pH}$ measurements ranged from 6.9 to 8.4 for all samples. FB groundwater had generally lower $\mathrm{pH}$ values compared to FB surface water. Dissolved oxygen values for all the groundwater samples were less than $1 \mathrm{mg} / \mathrm{L}$ compared to $6.3( \pm 1.9) \mathrm{mg} / \mathrm{L}$ for surface samples, implying suboxic conditions in the studied wells.

Bulk DOC data showed S332 surface water had a highest average value, followed by S332 groundwater, and FB surface water. DOC values for FB groundwater were not determined due to sample volume limitations, and only TOC (unfiltered samples) data were available for the latter. The TOC values were used as equivalent to DOC for comparison purpose. Under this assumption, FB groundwater 
had the lowest DOC values compared to the other surface and groundwater samples,

indicating possible removal or dilution processes such as absorption by sediments

and/or aquifer materials, bio-degradation processes, or dilution by low DOC water

from underneath. DOC for the S332 surface water showed a much larger range

Table 4.1 Summary of water chemistry and optical parameters.

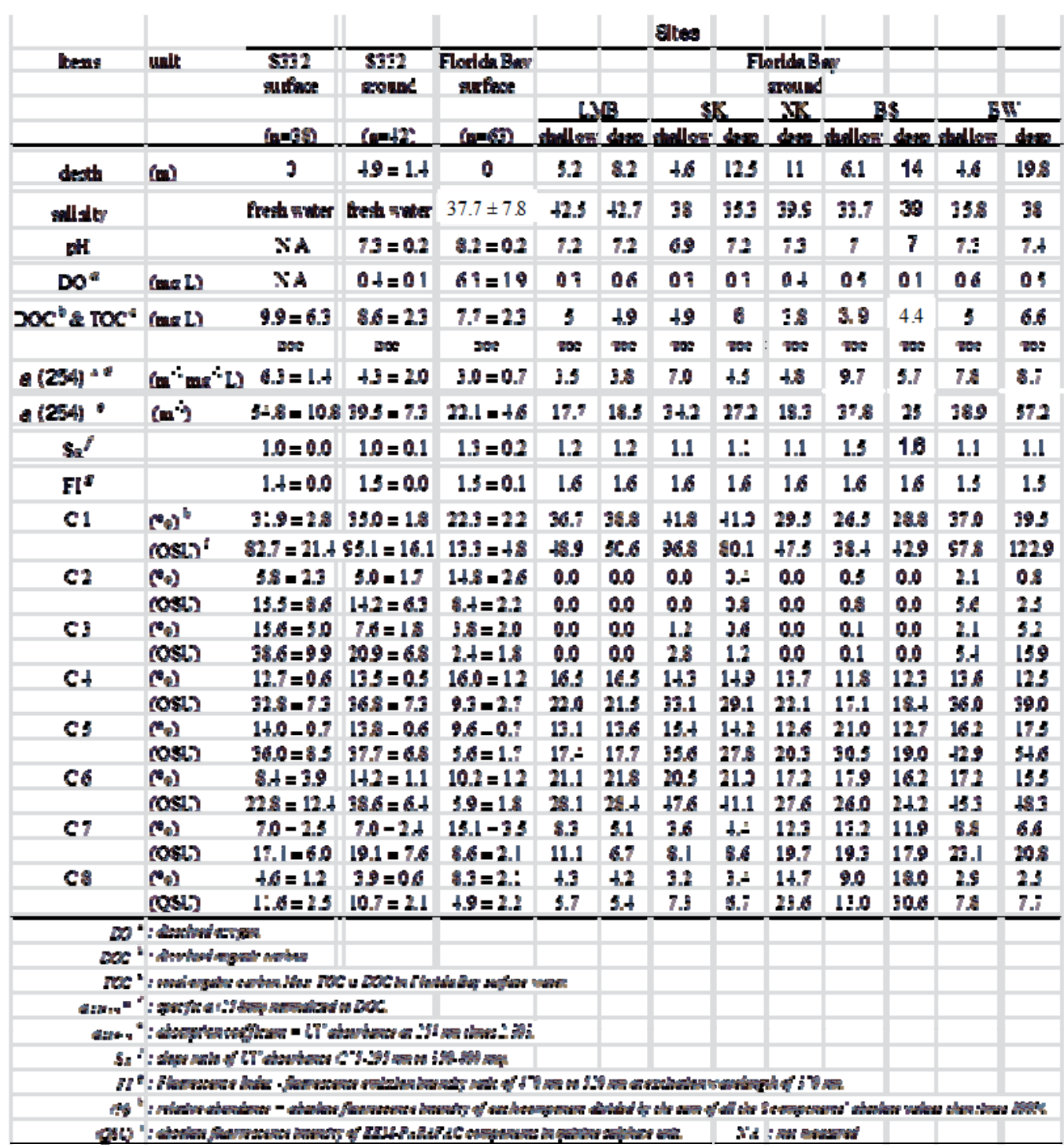


$(9.9 \pm 6.3 \mathrm{mg} / \mathrm{L})$ than at the other sites, suggesting a bigger seasonal change for this site than groundwater and also FB surface water.

The $a(254)^{*}$ data confirm previous reports (Maie et al., 2005; Maie et al., 2006a) that Florida Bay surface water DOM is characterized by low aromaticity, in accordance with its microbial DOM origin and potential degradation effects due to intense solar radiation on the shallow waters of the Bay. The S332 surface water DOM showed the highest absorption coefficient $a(254)$ values and several FB groundwater sites such as the BW site also displayed comparably elevated values. BS groundwater samples were observed having the highest slope ratio $S_{R}$ value of 1.5 for the shallow well $(6.1 \mathrm{~m})$ and 1.6 for the deep well $(13.7 \mathrm{~m})$, as compared with 1.0-1.3 for all the other samples, indicative of smaller molecular weight for DOM in this site. The FI values ranged from 1.4 to 1.6 , with S332 surface water samples having the lowest values, consistent with their terrestrial (higher plant/soil) origin.

\subsubsection{Classification of water samples via PCA}

The EEM data were fitted to a previously established 8-component PARAFAC model for Florida Everglades surface water DOM ( $\mathrm{n}=1394)$. The advantage of using this model is that it can facilitate the direct comparison between FCE groundwater and surface water. No obvious residues were obtained from this model for this dataset. The spectral characteristics and contours of the modeled PARAFAC components are presented in Figure 2.2. From the comparison of spectral characteristics of each component (Fig.2.2) with those reported in previous studies (e.g., Stedmon and 
Markager, 2005; Cory and McKnight, 2005; Yamashita et al., 2008; Murphy et al., 2008; Santín et al., 2009), components 1, 2, 3, 5, and 6 were assigned as terrestrial humic-like components. Component 4 was assigned as a microbial (marine) humic-like component while C7 and C8 were protein-like components with the former tyrosine-like (and/or blue-shifted tryptophan-like) and the latter tryptophan-like. The trends in the absolute and relative abundance of EEM-PARAFAC data across a terrestrial to marine gradient will be discussed in detail later (see Fig. 4.4 below).

In an attempt to use the PARAFAC data as a fingerprinting tool for DOM source and quality, the relative abundance of all the EEM-PARAFAC components for all groundwater and surface water samples studied here (see Table 4.1 for definitions and calculations), were used for Principal Component Analysis (PCA). The PCA graph

display (Fig.4.3) produced different clusters, suggesting that samples could be classified according to DOM origins and different environmental conditions. Principal component 1 explained $66 \%$ of the variance, whereas principal component 2 , accounted for a further $18 \%$ of the variance. The differences among these clusters are likely controlled by a variety of factors including DOM source strength, degree of diagenetic degradation, hydrological conditions and redox state.

\subsubsection{Effects of DOM sources and precursor types}

Potential sources of DOM in groundwater and surface water in the FCE have been discussed earlier, and should play a central role in the PCA classification of the 
samples. From the loading plots of Fig.4.3 (B), S332 surface water, S332 groundwater, and most FB groundwater (except for NK site) seemed mostly controlled by the loadings of the terrestrial humic-like components ( $\mathrm{C} 1$ and $\mathrm{C} 5)$, while Florida Bay surface water samples displayed more marine/microbial humic-like and protein-like signatures $(\mathrm{C} 4, \mathrm{C} 7$, and $\mathrm{C} 8)$. The $\mathrm{PC} 1$ of $\mathrm{NK}$ site from $\mathrm{FB}$ fell in the middle between the terrestrial and marine end-members, suggesting combined effects from both
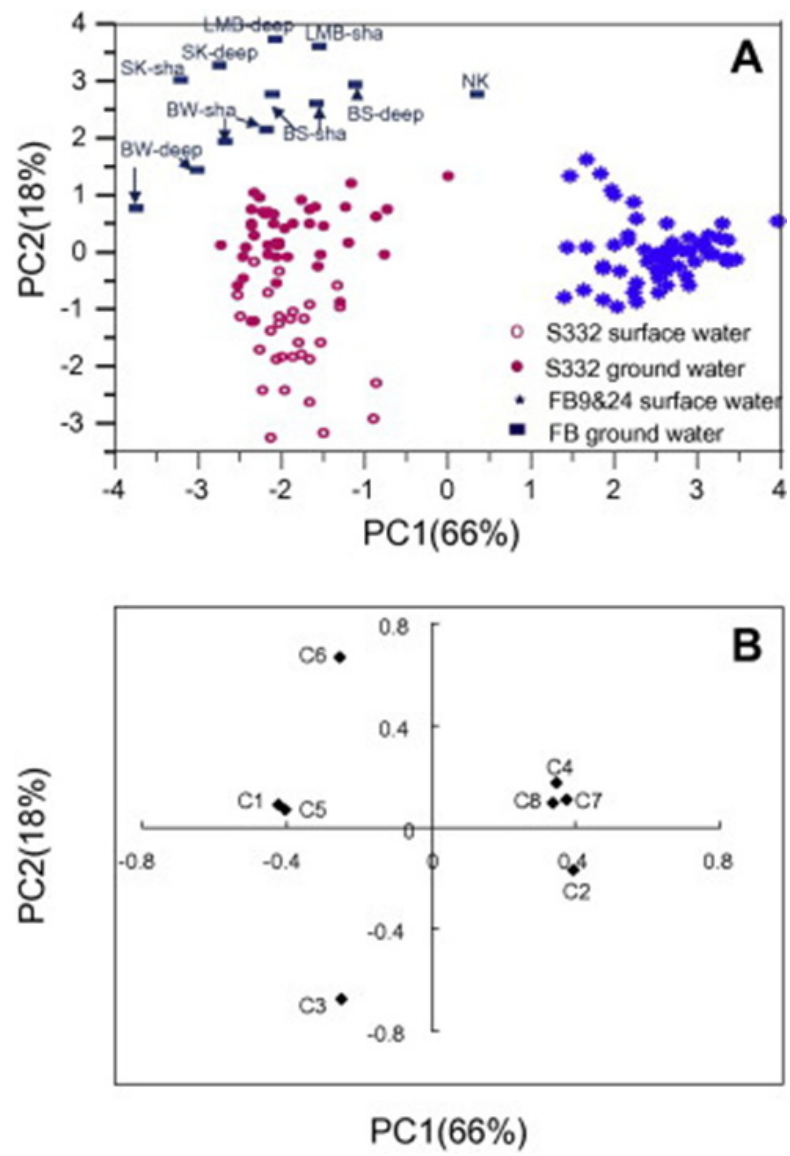

Fig.4.3 PCA for EEM-PARAFAC results of all the surface and ground water samples. (A) Score plot (B) loading plot. sha $=$ shallow. 
sources. Thus, PC1 seems to control the clustering based on DOM source. In contrast, for PC2 surface water samples seemed more controlled by the loadings of components $\mathrm{C} 2$ and $\mathrm{C} 3$ while the groundwater samples were more dependent on the component C6. FB groundwater featured either extremely low levels or absence of components C2 or C3, with the exception of the BW site. Thus, PC2 seems dependent on both photo- and bio-degradation of DOM as described below.

Most samples types clustered separately on the PCA plot of the EEM-PARAFAC data (Fig. 4.3), and as such were distinguishable based on their fluorescence characteristics. The exceptions were several surface freshwater samples from June, July, and August, and several groundwater samples from the S332 basin which were overlapping at the freshwater surface to groundwater clusters. This would not be surprising considering that the Biscayne aquifer is shallow and highly permeable, and the sources of groundwater recharge in the S332 basin are primarily from the overlying surface water in the wet season and from interactions with canals that penetrate the Biscayne Aquifer in the dry season (Price et al., 2006a; Genereux and Slater, 1999). Harvey et al. (2006) found that surface water and groundwater 'actively exchanged' in the central Everglades, and estimated the storage depth of interactive groundwater as $3.1 \mathrm{~m}$ after adjustment for the porosity of different soil types. This was consistent with our observations that the DOM samples from wells at depths of around $3.1 \mathrm{~m}$ were more similar in their optical properties to surface water than those of most of the deeper wells. Some deeper well samples also fell within this region, probably due to specific site characteristics such as sinkholes and conduits of 
higher porosity allowing for pathways of preferential flow (Cunningham et al., 2006). Geochemical evidence of surface water interactions with deeper wells in the vicinity of the S332 basin was also reported by Price et al. (2003) and Wilcox et al. (2004), and explained by vertical and horizontal conduits in the karst limestone allowing for rapid infiltration of surface water or rainwater to deeper depths.

\subsubsection{Diagenetic effects by photo- and biodegradation}

As stated above, photo-induced transformations of biomass and soil derived DOM from Florida coastal Everglades may be an important degradation pathway (Scully et al., 2004; Maie et al., 2008), and could be significant on a relatively short timescale. In contrast to the intense sunlight exposure to surface waters, especially in FB, light is not available in the subsurface. Hence, the groundwater DOM is expected to be less photo-degraded than the surface water. This may explain why the relative abundance of $\mathrm{C} 2$, which has been considered to be a photoproduct or a photorefractory component (Chen unpublished data; Stedmon et al., 2007), was sparse in groundwater but more abundant in surface water as seen from Fig.4.4. Therefore, the distribution of samples along PC2 may in part be controlled by the loadings of the photo-produced component C2.

On the other hand, in addition to photo-exposure, DOM is also subjected to microbial degradation. Maie et al. (submitted) found the inverse relationship between relative abundance of $\mathrm{C} 3$ and $\mathrm{C} 6$ in the $\mathrm{FB}$ and suggested that $\mathrm{C} 6$ might be a degradation product of $\mathrm{C} 3$. Based on the data shown in Figure 3.3, and assuming that 
component $\mathrm{C} 6$ is in fact a microbial degradation product, it seems that groundwater DOM is more prone to biodegradation than that of surface waters, and in fact Analysis of Variance (ANOVA) showed that the C6 was significantly higher in groundwater than in surface water $(\mathrm{P}<0.0001$, see box plot in Fig. 4.4). Consequently, the spread of the clusters as determined by PC2 seems to be controlled by DOM degradation/modification processes.

\subsubsection{Trends of DOC, $a(254)$, and EEM-PARAFAC components}

Sample locations were grouped into six groups along the terrestrial to marine (N-S) transect. They are: S332 surface water (S332-SW), S332 groundwater (S332-GW), coastal FB groundwater from LMB-GW and SK-GW (FB-Coastal-GW), Florida Bay surface water (FB-SW), central-east FB groundwater from the NK station (FB-Central-GW), and the Florida Keys groundwater sites from stations BS-GW and BW-GW (FB-Keys-GW). The DOC, $a(254)$, and absolute and relative abundance of selected EEM-PARAFAC components were plotted and compared among these six groups (Fig. 4.4).

As seen in Figure 4.4A, both DOC and $a(254)$ values were significantly higher in the S332-SW compared to FB-SW, and initially decreased gradually across the N-S transect to increase again for Florida Keys groundwater sites. This trend suggests a dilution of terrestrial DOM along the N-S transect, but additional DOM sources in groundwater adjacent to the Florida Keys. FB-SW had rather high DOC but low $a(254)$, suggesting that non-aromatic DOM such as carbohydrates make up an 
important fraction of the DOM in this region (Maie et al., 2005; Maie et al., 2006a). Surface waters from FB had significantly higher levels of DOC compared to the GW samples from FB-coastal and FB-central, although the $a(254)$ were quite similar.

Absolute and relative abundance of terrestrial humic-like (C1, C2, C3, C5) and protein-like (C7, C8) EEM-PARAFAC components are shown in Figure 4.4B and C respectively, and mimic each other in their distribution. Marine humic-like component C4 and microbial-modified component C6 had different patterns as discussed below, and thus were not included for comparison here. Basically, fluorescence intensity values for individual components showed similar pattern as for DOC and $a(254)$ although some components had higher fluorescence readings in the GW samples compared to the SW samples. The four different terrestrial humic-like components did not show the same behavior, with $\mathrm{C} 1$ and $\mathrm{C} 5$ being more enriched at all $\mathrm{GW}$ sites, whereas the abundance of humic-like components $\mathrm{C} 2$ and $\mathrm{C} 3$ very much lower or even non-detectable in most of the Florida Bay GW. This suggests that the composition of SW and GW samples, particularly in FB are quite different possibly due to DOM source changes and more likely to differences in DOM processing. While C2 has been suggested as a photo-product and/or photo-refractory fraction of DOM (Chen et al., unpublished data; Stedmon et al., 2007) and thus is more abundant in SW than GW, C3 may be a more biodegradable humic-like component (possibly leading to the formation of $\mathrm{C} 6$ ), have higher absorption capacities to aquifer materials and/or precipitate out at high salinities and thus have a low tendency to accumulate in GW (Chen and Jaffe, unpublished). 
With respect to the protein-like components (C7 and C8), these were mostly enriched in FB samples, particularly FB-SW, and with $\mathrm{C} 7$ being more prominent compared to $\mathrm{C} 8$ in most samples except for FB-NK-GW and FB-Keys-GW. The tryptophan-like C8 has been reported to be more biodegradable, while the tyrosine-like (or blue-shifted tryptophan-like) C7 has been suggested as more refractory in natural aquatic environments (Yamashita \& Tanoue 2003; Yamashita \& Tanoue 2004; Maie et al., 2006b). However, it is possible that C8 preferentially accumulates as DOM in GW ages, and it may be more abundant at the FB-Keys-GW locations due to inputs from septic tanks. The marine environment adjacent to the Florida Keys is affected by anthropogenic activities such as wastewater disposal and runoff, and most houses in the Florida Keys are still on septic tanks. High EEM protein-like fluorescence intensities have previously been reported as typical of sewage impacted waters (Baker, 2001; Lamont- Black et al., 2005; Lapworth et al., 2008).

Lastly, a box plot comparison of $\mathrm{C} 2 \%$ and $\mathrm{C} 6 \%$ between surface water and groundwater from both $\mathrm{S} 332$ and FB sites (Fig.4.4), shows that GW samples had a much lower relative abundance of C2 compared to SW samples, while the opposite was true for C6. This would make sense if the abovementioned suggestion that $\mathrm{C} 2$ is a photo-product or a photo-resistant degradation byproduct was correct. As for C6, another humic-like component that has previously been reported as being exported from catchments with high agricultural use (Stedmon and Markager, 2005), its enrichment in GW samples may be indicative of its high photo-reactivity or 
its nature as a microbial degradation product. This component gave an inverse correlation with $\mathrm{C} 3$ in a long-term SW study of DOM from FB $(\mathrm{R}=-0.73$; Maie et al. personal communication) and thus, might be a degradation product of $\mathrm{C} 3$.

The combination of a terrestrial CDOM fingerprint and high salinity $(38.6 \pm$ 3.7) for FB coastal and the Florida Keys GW samples provides evidence of the importance of vertical surface water recharge, possibly in combination with horizontal GW exchange. The dominant source of DOM should be from surface recharge water
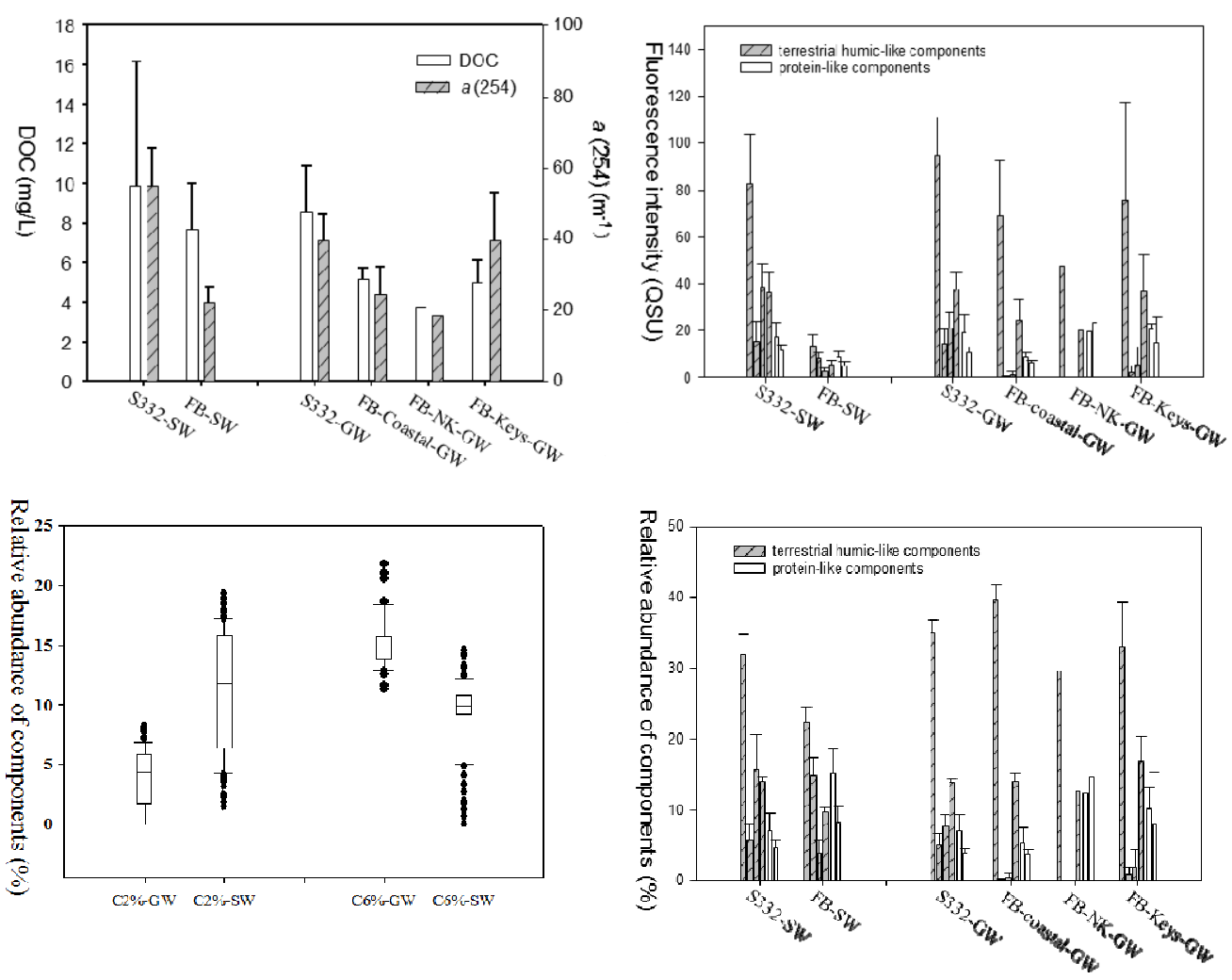

Fig. 4.4 Trends in UV absorption coefficient at $254 \mathrm{~nm}$, and DOC, along with absolute (fluorescence intensity) and relative (out of the total of 8 components) abundance of EEM-PARAFAC terrestrial humic-like (C1, C2, C3, C5) and protein-like (C7 and $\mathrm{C8}$ ) components. $\mathrm{SW}=$ surface water; $\mathbf{G W}=$ groundwater; $\mathrm{FB}=$ Florida Bay. 
which were both saline and contain high levels of terrestrial/higher plant (mangrove) derived DOM. In addition, GW DOM in this system has been suggested to be 'old' based on ${ }^{14} \mathrm{C}$ dating (Aiken \& McKnight, 1985) and consequently may have been accumulating for long periods of time and/or be derived from oxidation of soils. Vertical recharge through sinkholes or vertical conduits often found in karst geography is another reasonable scenario for these cases since both are adjacent to fringe mangrove areas which serve as significant sources of DOM (Jaffe et al., 2004). However, even for the FB-central-GW (site NK) there was a significant difference in DOM fluorescence characteristics compared to FB-SW, suggesting that horizontal recharge from the terrestrial end-members and possibly from mangrove islands in FB is important in controlling FB-GW DOM composition.

\subsection{Conclusions and environmental implications}

In summary, this study shows that the application of EEM fluorescence combined with PARAFAC modeling can provided insightful information regarding the sources, diagenetic status, and hydrological interactions of groundwater and surface water in coastal wetlands and estuaries. Subsequent PCA statistics of the PARAFAC data allowed for a plausible differentiation among the different DOM sources and their diagenetic state for the selected sample set based on both the source strength of terrestrial vs. marine sources and the susceptibility of the DOM to microbial and/or photochemical degradation. Furthermore, the combination of bulk DOC, UV-Vis and EEM-PARAFAC data provided clues regarding the influence of 
horizontal vs. vertical water recharge to some of the studied well sites. As hydrology and water delivery to FB are among the main ecological drivers in the Everglades, this technique has a great potential in tracing hydrological flow and interaction, such as surface water recharge, submarine groundwater discharge, and salt water intrusions. 


\section{Chapter 5}

Molecular Size Based Characterization of Dissolved

Organic Matter Using Size Exclusion Chromatography

and Excitation-Emission Matrix and Parallel Factor Analysis 


\subsection{Abstract:}

The fluorescence composition of size fractionated dissolved organic matter (DOM) was characterized through size exclusion chromatography (SEC) combined with Excitation-Emission Matrix (EEM) fluorescence coupled with parallel factor analysis (PARAFAC). Eight size factions of surface water from two sites in Florida Everglades freshwater marsh and one canal were studied. Interestingly, most of the eight components obtained from PARAFAC modeling were broadly distributed across the DOM molecular weight range, suggesting a fairly homogeneous composition of the fluorescent DOM (FDOM) along the molecular weight continuum. Furthermore, while six of the PARAFAC components were present all the eight molecular weight fractions, some, such as components 2 (C2) and 3 (C3), showed narrower molecular ranges and dominated in fractions 2 to 5 . In addition, protein-like components 7 (C7) an 8 (C8) were relatively enriched in the highest and lowest MW fractions, implying that protein-like fluorescence received contributions from presumably macromolecular proteins and/or small peptides and amino acids respectively. This study suggests that different fluorophores from DOM are speciated along the molecular weight continuum most likely in the form of supramolecular associations, fact that may have important implications in our understanding of the environmental dynamics of FDOM. 


\subsection{Introduction:}

Dissolved organic matter (DOM) is not only one of the largest reservoirs of carbon on the Earth, but as well one of the most complex mixtures in nature. It consists of myriads of organic compounds which play diverse pivotal ecological and biogeochemical roles in the environment. For example, it fuels the microbial loop by providing the heterotrophic microorganisms with an energy source. It can also be oxidized into inorganic carbon and thus affect the global elemental biogeochemical cycling and atmospheric inorganic carbon balance. In addition, DOM can associate with various metals and organic pollutants and thus affect the toxicity, bioavailability, and transport of environmentally important xenobiotics (Findlay and Sinsabaugh 2003; Hansell and Carlson 2002).

. The molecular weight (MW) distribution of DOM plays a crucial role in its bioavailability, photo- and bio-reactivity, and fate in aquatic ecosystems. To date, while some literature reported that low molecular weight (LMW: <1000 Daltons) DOM, such as amino acids and sugar monomers are more readily available to microorganisms (Kujawinski 2011), a sizereactivity continuum model suggests that the bulk of high molecular weight (HMW: >1000 Daltons) DOM is more bio-reactive as compared with its LMW counterpart (Amon and Benner 1994; Amon and Benner 1996; Kaiser and Benner 2009). HMW DOM has also been found to be more readily photo-degraded compared to LMW DOM and UV irradiation has been reported to decrease the MW of DOM in a quasi-exponential manner 
(Lepane et al. 2003; Lou and Xie 2006). In addition, the size distribution characteristics of DOM are also believed to affect the mobility, bioavailability, and toxicity of its associated pollutants (Cabaniss et al. 2000; Chin and Aiken 1997). As such, the understanding of the size distribution of DOM and the composition of these size fractions is of particular ecological, biogeochemical, and environmental interests.

Several techniques exist to fractionate DOM based on size and one of the most commonly used one is size exclusion chromatography (SEC) (Chin et al. 1997; Maie et al. 2007; Woods et al. 2010). HPLC based SEC has the advantage of providing chromatographic peaks of the chromophoric DOM $(\mathrm{CDOM})$ and requires small sample size compared with other techniques such as tangential-flow ultrafiltration (Cai 1999). Due to various practical advantages, including sensitivity and high sample throughput, fluorescence spectroscopic techniques have been widely used to study the dynamics of DOM in various environments over the past decades (Coble et al. 1998; Baker 2001; Jaffe et al., 2008;Fellman et al., 2010). Previous studies have successfully used the combination of SEC followed by techniques such as EEMs (Maie et al. 2007; Her et al. 2003; Lu et al. 2009), NMR (Conte et al.2007), and MS (Persson et al. 2006) to study DOM characteristics. By decomposing the EEM data statistically into different fluorescent components, EEM-PARAFAC has opened a new door to study and assess DOM dynamics in diverse environments during the past years (Stedmon et al. 2003; Cory and McKnight 2005; Jaffé et al. 2008). As such, a previous study used SEC followed 
by EEM-PARAFAC to study DOM in landfill leachate, focusing on the use of a hydrophobic component as a potential tracer of landfill leachate (Lu et. al. 2009). However, despite the importance of better characterizing the fluorescence characteristics of size fractionated DOM, still little is known about this subject.

The purpose of this study is aimed to investigate the size distribution of DOM for Florida Everglades fresh surface water using SEC combined with an EEM-PARAFAC. Specifically, the objectives of this study are to use EEM-PARAFAC to characterize the composition of different DOM size fractions as obtained through SEC fractionation, and compare them among different types of surface waters from this region.

\subsection{Sampling and experimental methods}

\subsubsection{Sampling:}

This study was conducted in the Florida Everglades. Two freshwater marsh Sites from Shark River Slough and Taylor Slough (SRS2 and TS2), located in Everglades National Park (ENP), and a drainage canal (C111) were selected for this study. Their locations are shown in Figure 5.1. The freshwater marsh sites are dominated by sawgrass, interspersed with tree islands, wet prairie and slough communities, and periphyton mats are ubiquitous in the oligotrophic Everglades freshwater environments. Soils from the SRS2 site are peat-based while TS2 site soils are marl-based. The $\mathrm{C} 111$ canal site receives drainage water from the Northern 
Everglades as well as inputs from agricultural areas. Surface water samples were collected in August 2008 from all sites. Samples were collected in pre-cleaned, acid-washed, brown high density polyethylene bottles (Nalgene). Containers were rinsed three times before sample collection. Samples were placed on ice immediately

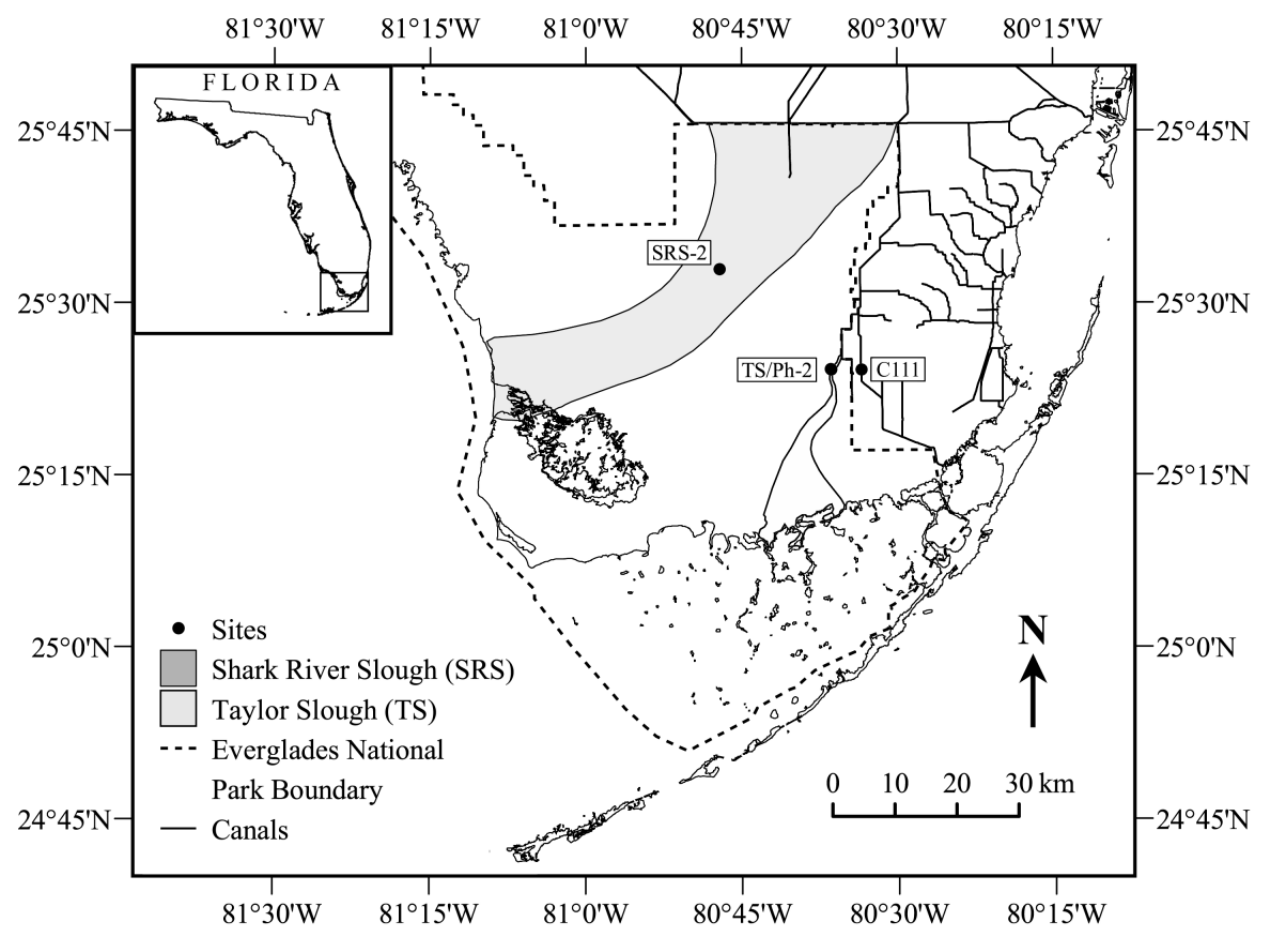

Fig.5.1 Sampling sites (SRS-2, TS-2, and C111) in Florida Everglades

after sampling and were transported to the laboratory the same day. All surface water samples were filtered in the laboratory with pre-rinsed $0.22 \mu \mathrm{m}$ filters (Durapore, Millipore) and stored in a refrigerator until analyses within one week of collection. 


\subsubsection{Molecular size fractionation}

The molecular size fractionation of the DOM was carried out by SEC on a Shimadzu 10A series HPLC equipped with UV-Vis (SPD-10AV) and fluorescence detectors. The elution curve was recorded by measuring UV absorption at $280 \mathrm{~nm}$ and excitation/emission at $350 / 450 \mathrm{~nm}$. Since some DOM components do not absorb at $280 \mathrm{~nm}$, this study was focused on the chromophoric and fluorescent DOM (CDOM and FDOM respectively). A YMC-Pack Diol-120 column (pore size 12nm, I.D. $8.0 \mathrm{~mm} \times$ length $500 \mathrm{~mm}$; YMC Inc) was used for the SEC fractionation. A solution of $0.05 \mathrm{M}$ Tris(hydroxymethyl) aminomethane (THAM) adjusted to $\mathrm{pH}$ at 7.0 with phosphoric acid (Fisher) was prepared as eluent. The injection volume was $150 \mu \mathrm{l}$ and flow rate was $0.7 \mathrm{ml} / \mathrm{min}$ at room temperature $\left(\sim 23{ }^{\circ} \mathrm{C}\right)$. The void volume $\left(\mathrm{V}_{0}\right.$; $12.8 \mathrm{~min})$ and void volume plus inner volume $\left(\mathrm{V}_{0}+\mathrm{V}_{\mathrm{i}} ; 32.3 \mathrm{~min}\right)$ were determined using Blue Dextran 2000 and L-tyrosine, respectively. The column was calibrated with several different MW poly-styrenesulfonic acid sodium salt standards of known MW (Fluka). These had MWs reported as 1400, 4300, 6800, 13000 and 32000 Daltons, respectively. Despite the fact that there is no appropriate calibration standard for DOM, this standard has been found to give reasonable molecular weight estimates (Egeberg and Alberts 2003). However, average weight molecular weight values discussed here are only meant to serve as a guide along the MW continuum and not as actual values (e.g. Scully et al. 2004).

Eight sample size fractions were collected in pre-cleaned pre-combusted amber bottles. The fractions were split according to the elution order of the 8 
observed peaks by the UV detector at 280nm (Fig.5.2). The retention time ranges for the 8 fractions were listed in Table 1 . These retention times are the times after correction of the time lag of eluent traveling the lining between the detector and the receptacle amber bottle. The time lag was estimated with the lining length and the time lag between two detectors. It took 3-5 runs to collect enough sample amounts for each fraction to adequately measure EEMs. The samples were kept refrigerated after collection and the EEMs were determined immediately after SEC fractionation to minimize potential degradation. As mentioned above, the average weight MWs calculated here are apparent MW (AMW) rather than accurate values, due to the absence of an appropriate standard, and some non-size exclusion effects such as “ionic exclusion” and “specific adsorption” (Perminova, 1999).

Table 5.1 Retention time and estimated apparent molecular weight (AMW) for eight fractions.

\begin{tabular}{|c|c|c|}
\hline Fractions & $\begin{array}{c}\text { Retention time } \\
\text { (minutes) }\end{array}$ & $\begin{array}{c}\text { AMW } \\
\text { (daltons) }\end{array}$ \\
\hline 1 & $12.00-15.50$ & $5,176-630,957$ \\
\hline 2 & $15.50-19.50$ & $1,039-5,176$ \\
\hline 3 & $19.50-20.30$ & $750-1,039$ \\
\hline 4 & $20.30-21.40$ & $479-750$ \\
\hline 5 & $21.40-23.10$ & $239-479$ \\
\hline 6 & $23.10-24.10$ & $159-239$ \\
\hline 7 & $24.10-28.00$ & $32-159$ \\
\hline 8 & $28.00-32.00$ & $0-32$ \\
\hline
\end{tabular}




\subsubsection{Analytical measurements and PARAFAC modeling}

UV-Vis was determined using a Varian Cary 50 bio spectrophotometer with a $1 \mathrm{~cm}$ quartz cuvette scanning from $240 \mathrm{~nm}$ to $800 \mathrm{~nm}$. EEMs were measured using a Horiba JovinYvon SPEX Fluoromax-3 spectrofluorometer equipped with a $150 \mathrm{~W}$ continuous output Xe arc lamp. Slits were set at $5.7 \mathrm{~nm}$ for excitation and $2 \mathrm{~nm}$ for emission. Forty-four emissions scans were acquired at excitation wavelength $\left(\lambda_{\mathrm{ex}}\right)$ between 240 and $455 \mathrm{~nm}$ at $5 \mathrm{~nm}$ steps. The emission wavelengths were scanned from $\lambda_{\text {ex }}+10 \mathrm{~nm}$ to $\lambda_{\text {ex }}+250 \mathrm{~nm}$ (i.e., between 250 and $705 \mathrm{~nm}$ ) in $2 \mathrm{~nm}$ steps (Maie et al., 2006b). Fluorescence signals were acquired in signal over reference ratio mode (S/R) to eliminate potential fluctuation of the Xe lamp. More detailed information of post-acquisition steps for correction and standardization can be found elsewhere (Chen et al., 2010). The Fluorescence Index (FI) was determined as the ratio of the emission intensity at a wavelength of $470 \mathrm{~nm}$ to that at $520 \mathrm{~nm}$, obtained at an excitation of $370 \mathrm{~nm}$ (Jaffé et al. 2008). Dissolved organic carbon (DOC) concentrations for each fraction were not measured due to the limited sample amount.

PARAFAC can statistically decompose EEMs into fluorescent groups or components (Stedmon et al., 2003). PARAFAC modeling can be obtained by either creating or validating the model using the complete dataset of EEMs or by fitting the EEMs to an already established PARAFAC model. In this study, the triplicate EEMs of the eight fractions collected from the freshwater water samples from three sites were fitted into a previously established model for Everglades surface water. No residues peaks were observed. The analysis was carried out in MATLAB 7.0.4. 
(Mathworks, Natick, MA) with the DOMFluor toolbox (Stedmon and Bro 2008). The characteristics of the Eight EEM-PARAFAC components were summarized in Table 5.2. PARAFAC component spectral characteristics and split-half validation can be found elsewhere (Chen et al., 2010).

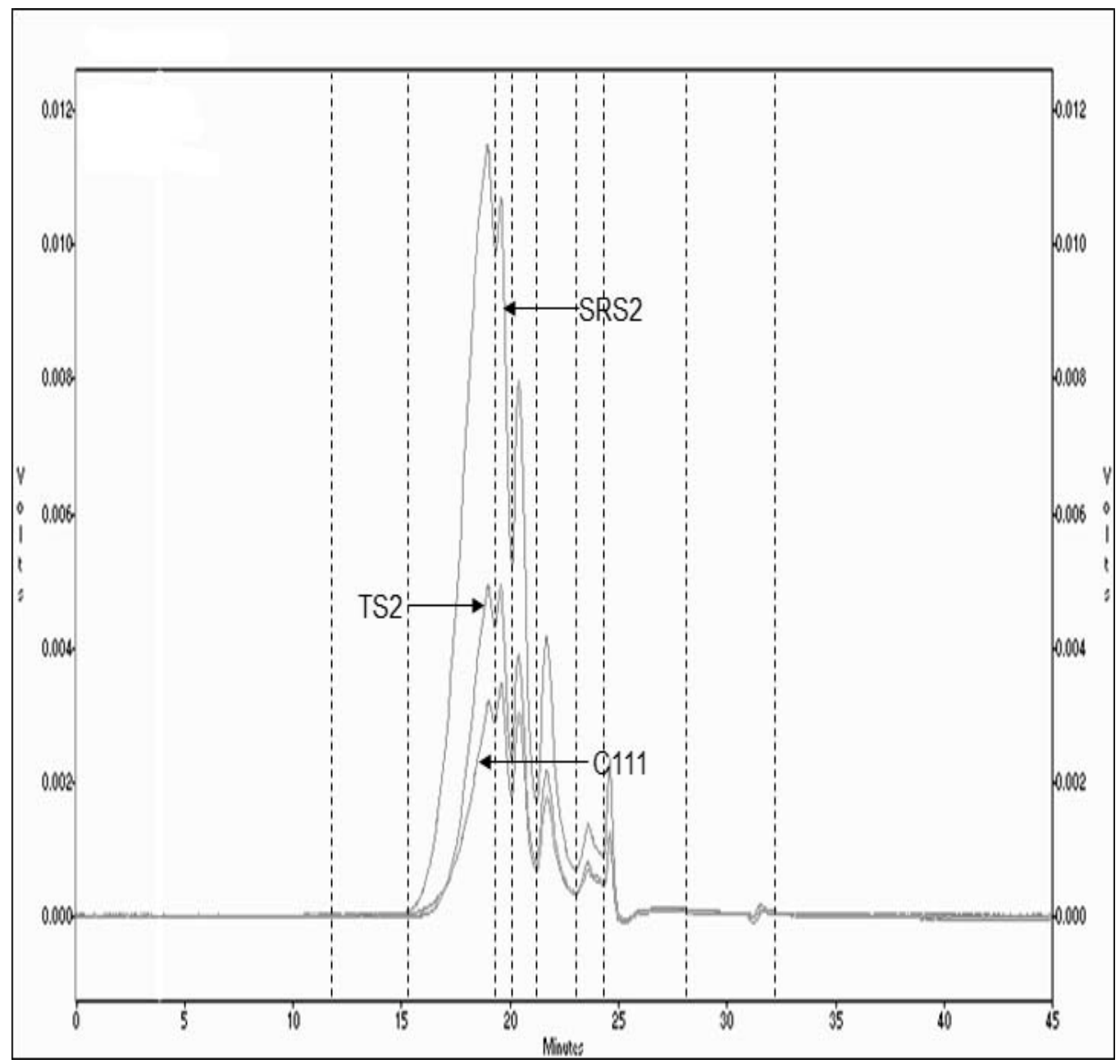

Fig.5.2 SEC chromatograms with UV-Vis detection at $280 \mathrm{~nm}$ for the three samples studied here. Eight fractions were collected as shown by the dotted lines. 


\subsection{Results and discussion}

\subsubsection{Compositional differences and similarities for different MW fractions}

A variety of differences in optical properties were observed for the different size fractions. As shown in Figures 5.2 and 5.3 there is a trend of higher A280 and lower FI for fraction 2, 3, 4, suggesting these fractions were dominated by more aromatic terrestrial-derived DOM. Her et al., 2003 reported that the fraction of AMW around $1000-5000$ Daltons (equivalent primarily to fraction 2 in this study) showed higher aromaticity, which is also consistent with the high A280 values and the low FI value for fraction 2. While the highest FI values were those for the highest and the lower MW fractions (Fig. 5.5 and likely associated with the presence of microbially derived FDOM, there was a clear trend of decreasing aromaticity between fraction 2 and 8.

The EEM-PARAFAC distribution among the eight molecular weight fractions is presented in Figure 5.4for samples from three freshwater sites in the Florida Everglades while Figure 5.4 and Table 5.4 show the relative abundance of all PARAFAC components in each MW fraction. Surprisingly, all eight fractions received contributions to their overall fluorescence signal from at least six out of eight PARAFAC components, where Component 2 and Component 3 were the most common exceptions. This suggests a highly homogeneous distribution of EEM-PARAFAC components along the molecular weight continuum. Component 1 , a humic-like component which is ubiquitous and abundant in aquatic environments, showed the highest abundance of all PARAFAC components (Yamashita et al., 2010) 
Table 5.2 Molecular weight distribution characteristics of components.

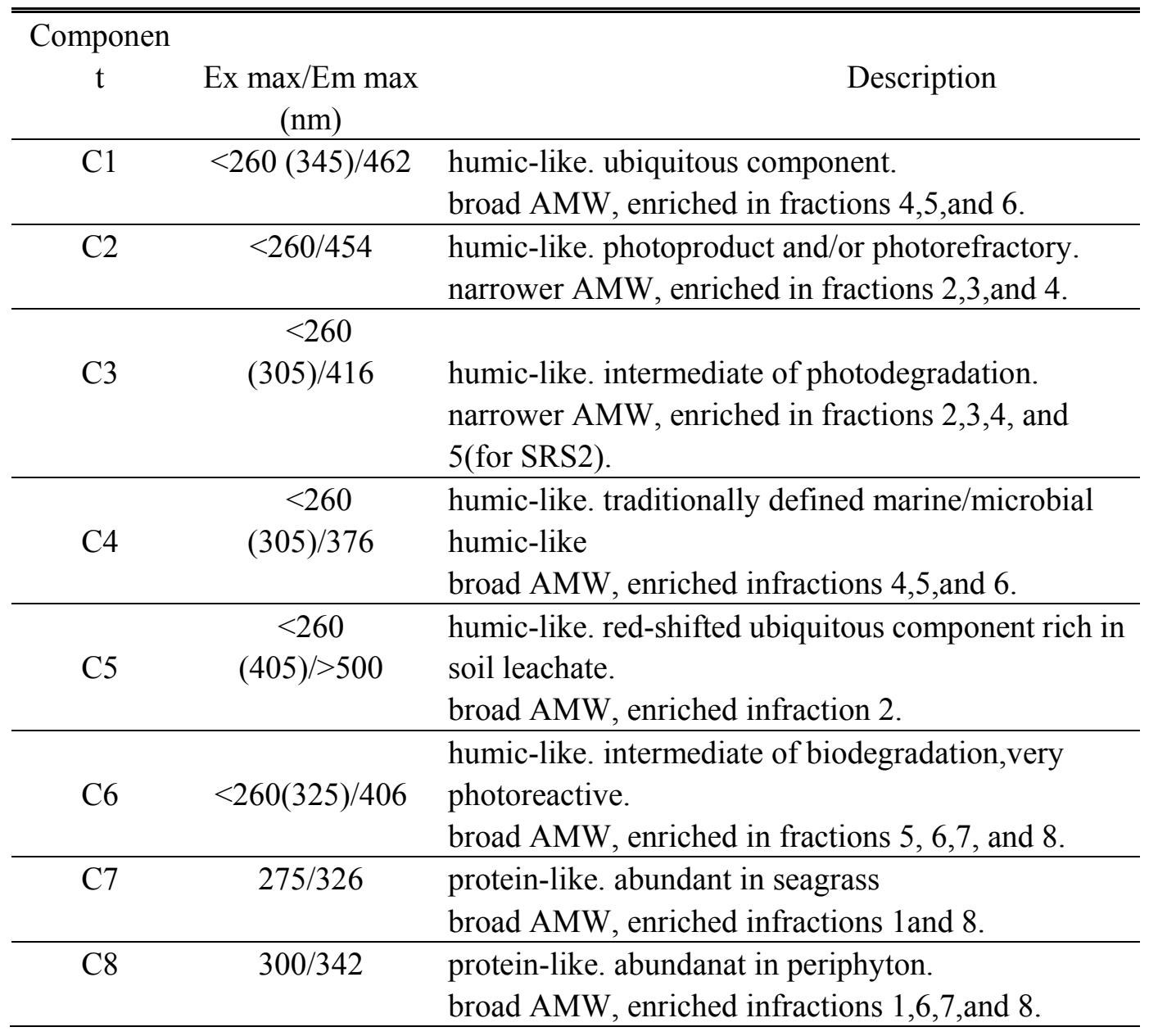

and a relatively uniform contributions in all eight fractions but was slightly more enriched in the mid-size fractions 4, 5, and 6 (AMW: 260 - 771 Daltons). Component 4, a humic-like component which was traditionally termed as marine humic-like (Coble 1996), showed a similar MW distribution pattern to component 1. Namely, it also has relative uniform contribution to all eight fractions and a slightly higher relative abundance in fractions 4,5 , and 6 . Component 5 , believed to be a red-shifted 
humic-like component which is ubiquitous in aquatic ecosystems as well, been previously found closely coupled with component 1 in Everglades ecosystem (Chen, Thesis Chapter 2). It also receives contributions from all eight fractions with broad AMW. Unlike component 1, however, component 5 was commonly more enriched in fraction 2 (AMW: $1.1 \times 10^{3}-5.2 \times 10^{3}$ Daltons), suggesting an association with higher AMW fractions compared to component 1. This is consistent with the finding that a component similar to component 5 , reported to be abundant in estuarine soil and sediment, was relatively enriched in the higher MW humic acid fraction (vs. the lower MW fuvic acid fraction; Santin et al., 2009). Component 6, also a humic-like component and found to be a photo-sensitive and microbially-produced component, received showed highest abundance in fractions 5 to 8 but was less abundant in fractions 2to 4 . This was typified by sample SRS2 which had no contribution of component 6 to fraction 3 and $\sim 1 \%$ relative abundance contributions to fraction which dominated by fractions 2,3 , and 4 . This finding could possibly explain the reason why $\mathrm{C} 2$ versus $\mathrm{C} 6$ and $\mathrm{C} 3$ versus $\mathrm{C} 6$ were found to be inversely correlated in Everglades groundwater and surface water respectively (Chen et al., 2010) as they may be dominated by different MW fractions. Components 7 and 8 classified as a protein-like components (Chen et al., 2010; Yamashita et al., 2010), displayed a very interesting distribution with significantly higher relative contributions to the first (high MW) and the last (low MW) size fractions but somewhat depleted in the medium-sized fractions 3 and 4. This implies that protein-like components in these samples are likely representative of macromolecular proteins (high MW) and small 

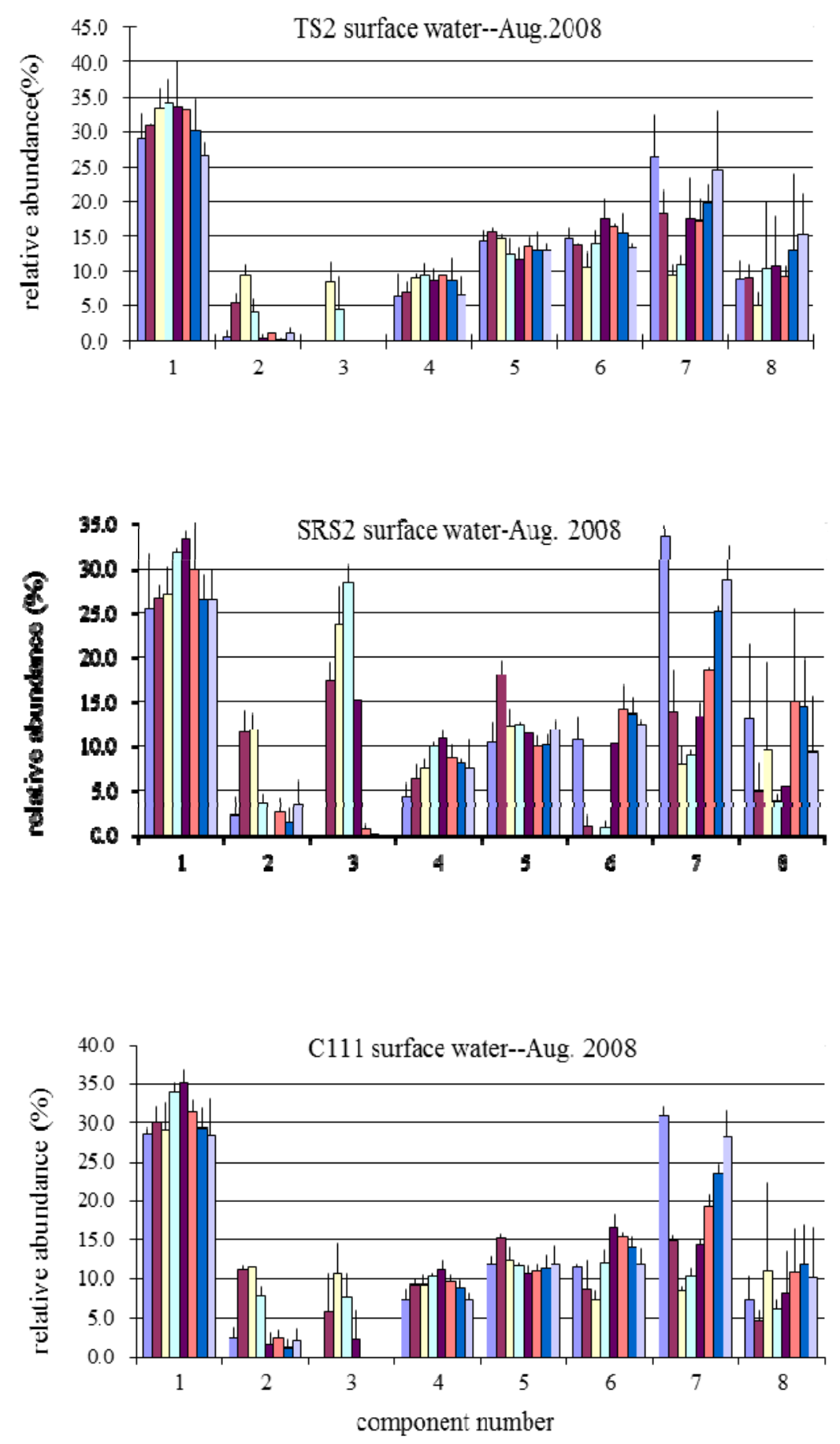

Fig.5.3 Chromatograms of size exclusion chromatography (SEC) with UV-Vis detector $(\lambda=280 \mathrm{~nm})$ and splitting of eight fractions according to the peaks. 
peptides and/or amino acids (low MW). This distribution is largely opposite to that of component 2 and component 3 , In order to evaluate statistically the observed trends in PARAFAC distribution with respect to MW fractions, a PCA analysis was performed on the data available for sample SRS2 (Fig.5.5). Principal component 1 accounted for $48 \%$ and Principal component 2 accounted for another $28 \%$ of the variability. Principal component 1 (PC1) seems to be a source-related variable, with a positive correlation for the humic-like components and a negative correlation with the microbial humic-like and protein-like components. In contrast principal component 2

Table 5.3 Contributions of EEM-PARAFAC components to each fractions.

\begin{tabular}{|c|c|c|c|c|c|c|c|c|}
\hline & $\% \mathrm{C} 1$ & $\% \mathrm{C} 2$ & $\% \mathrm{C3}$ & $\%$ C4 & $\% \mathrm{C5}$ & $\% \mathrm{C6}$ & $\% \mathrm{C7}$ & $\% \mathrm{C} 8$ \\
\hline \multicolumn{9}{|l|}{ TS2 site } \\
\hline fraction 1 & 29.0 & 0.5 & 0.0 & 6.4 & 14.3 & 14.6 & 26.4 & 8.7 \\
\hline fraction2 & 30.8 & 5.5 & 0.0 & 7.0 & 15.8 & 13.8 & 18.2 & 8.9 \\
\hline fraction 3 & 33.5 & 9.3 & 8.5 & 9.1 & 14.7 & 10.5 & 9.4 & 5.1 \\
\hline fraction4 & 34.2 & 4.0 & 4.5 & 9.4 & 12.6 & 13.8 & 11.0 & 10.4 \\
\hline fraction5 & 33.7 & 0.4 & 0.0 & 8.7 & 11.7 & 17.5 & 17.4 & 10.7 \\
\hline fraction 6 & 33.3 & 1.1 & 0.0 & 9.3 & 13.4 & 16.5 & 17.3 & 9.1 \\
\hline fraction7 & 30.3 & 0.1 & 0.0 & 8.5 & 12.8 & 15.5 & 19.8 & 13.0 \\
\hline fraction8 & 26.4 & 1.0 & 0.0 & 6.6 & 12.9 & 13.4 & 24.5 & 15.2 \\
\hline \multicolumn{9}{|l|}{ SRS2 site } \\
\hline fraction 1 & 25.6 & 2.2 & 0.0 & 4.3 & 10.4 & 10.8 & 33.7 & 13.1 \\
\hline fraction2 & 26.7 & 11.7 & 17.3 & 6.3 & 18.1 & 1.1 & 13.9 & 4.9 \\
\hline fraction 3 & 27.1 & 12.0 & 23.6 & 7.5 & 12.3 & 0.0 & 8.0 & 9.5 \\
\hline fraction4 & 31.8 & 3.6 & 28.5 & 10.0 & 12.5 & 0.9 & 9.0 & 3.8 \\
\hline fraction5 & 33.3 & 0.0 & 15.2 & 10.8 & 11.5 & 10.3 & 13.4 & 5.5 \\
\hline fraction6 & 30.0 & 2.7 & 0.7 & 8.7 & 10.0 & 14.1 & 18.6 & 15.1 \\
\hline fraction7 & 26.6 & 1.6 & 0.1 & 8.3 & 10.1 & 13.7 & 25.3 & 14.4 \\
\hline fraction8 & 26.6 & 3.5 & 0.0 & 7.4 & 11.9 & 12.5 & 28.7 & 9.3 \\
\hline \multicolumn{9}{|l|}{ C111 site } \\
\hline fraction1 & 28.6 & 2.4 & 0.0 & 7.3 & 11.8 & 11.5 & 31.0 & 7.3 \\
\hline fraction2 & 30.0 & 11.2 & 5.8 & 9.3 & 15.3 & 8.8 & 14.9 & 4.7 \\
\hline fraction3 & 29.2 & 11.5 & 10.7 & 9.3 & 12.4 & 7.3 & 8.5 & 11.0 \\
\hline fraction 4 & 34.0 & 7.8 & 7.7 & 10.3 & 11.8 & 12.1 & 10.3 & 6.0 \\
\hline fraction5 & 35.1 & 1.5 & 2.1 & 11.1 & 10.7 & 16.7 & 14.4 & 8.3 \\
\hline fraction 6 & 31.4 & 2.3 & 0.0 & 9.7 & 11.0 & 15.4 & 19.3 & 10.9 \\
\hline fraction7 & 29.3 & 1.1 & 0.0 & 8.9 & 11.3 & 14.0 & 23.4 & 11.9 \\
\hline fraction8 & 28.4 & 2.0 & 0.0 & 7.4 & 11.8 & 11.9 & 28.3 & 10.2 \\
\hline
\end{tabular}


seems to be controlled by the molecular size, showing a positive correlation with fractions 4 to 6 , while the high and low MW fractions are negatively correlated with PC2. The distributions shown in the figure seem to confirm that the medium-size fractions were dominated by humic-like components, particularly $\mathrm{C} 1, \mathrm{C} 4$ and $\mathrm{C} 6$. As seen in Fig.5.5, fractions 1, 7, and 8, which were dominated by protein-like components $\mathrm{C} 7$ and $\mathrm{C} 8$, correlated negatively with principal component 1 , while fractions 2 and 3 and to some extent fraction 5 correlated positively with principal component 1 .

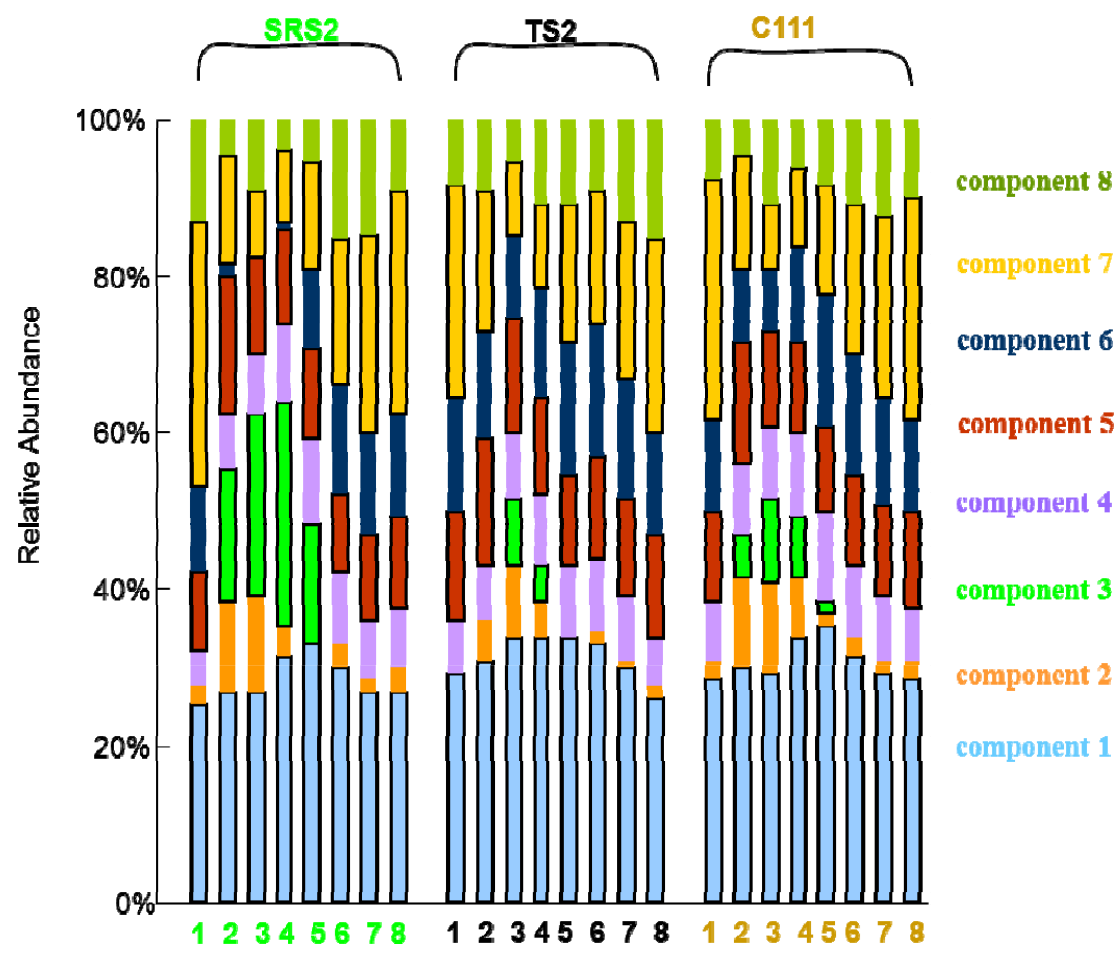

Fig.5.4 Cross-fractionation cross-site comparison of DOM composition. 

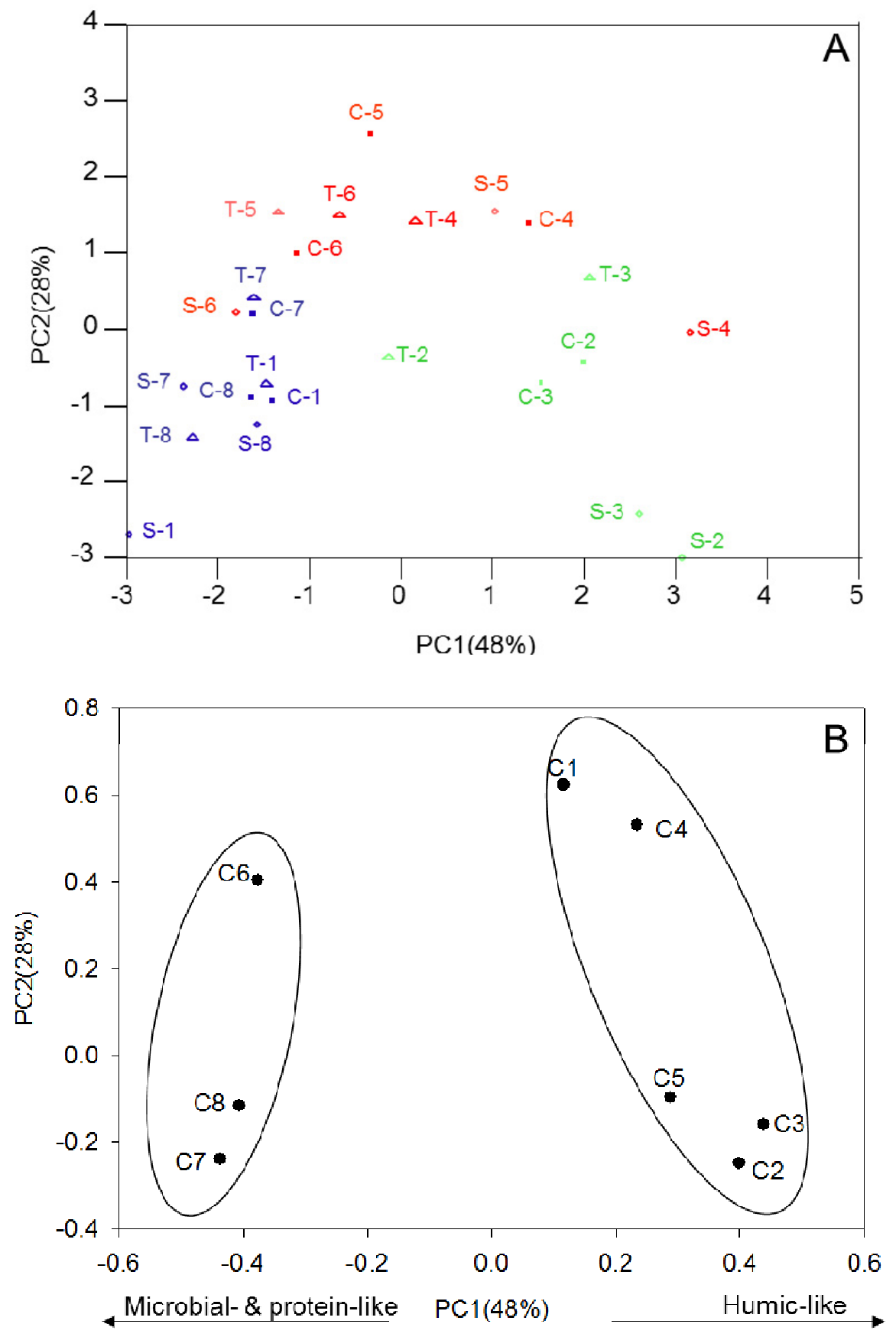

Fig.5.5 PCA of all fractions from all three sites. (A - score plot) S-1 to S-8 represent eight fractions for surface water sample from the SRS site, T-1 to T-8 from the TS site; $\mathrm{C}-1$ to $\mathrm{C}-8$ from the C111 site. (B - loading plot) PARAFAC components $\mathrm{C} 1$ to $\mathrm{C} 8$. 
The results here are consistent with a previous study by Her et al. (2003) that protein-like DOM had high AMW and middle fractions had high aromaticity, but here a clear enrichment in protein-like fluorescence is also apparent for the low MW fraction. The almost homogeneous distribution of PARAFAC components across the molecular weight continuum is a very interesting finding! It's believed that very similar fluorescent spectra could be produced from fluorophores of vastly different composition, such as poly-phenols and amino acids (Maie et al., 2007), which were also determined to have different MW. The presence of such compounds with similar spectral characteristics in all MW fractions is unlikely, and has recently been proven not to be adequate to describe spectroscopic propertied of DOM. Therefore, supramolecular associations of humic substances (Sutton and Sposito, 2005; del Vecchio and Blough, 2004) and other DOM components, and intermolecular binding between for example proteins and humic substances (Aiken et al., 1985) would be a more plausible explanation for the existence of an almost homogeneous distribution of EEM-PARAFAC components along a wide range of MW in DOM. In this respect, a previous DOM reactivity study found that the EEM-PARAFAC components degradation kinetics data could be fitted into a multi-pool degradation model, but that the same PARAFAC component showed very different decay rates based on sample origin (Chen; this thesis Chapter 3). This observation can be explained in two ways: different molecular weight fractions containing the same PARAFAC components show different reactivity due to the different composition and structure of these supramolecular associations of fluorophores. In any case, 
differences in composition or differences in speciation, will present variations in reactivity, which in fact can be significant (Chen; this thesis Chapter 3). This calls for caution when using EEM-PARAFAC components as environmental reactivity proxies as their presence in bulk DOM samples can represent a great variety of complex structures or molecular associations within a wider range of MW, and consequently affect reactivity.

\subsubsection{Cross-site comparison of FI and EEM-PARAFAC components}

Peat-based freshwater site SRS2 showed highest UV absorbance at $280 \mathrm{~nm}$, followed by marl-based freshwater site TS2 and then canal site C111 (Fig.5.2), reflecting higher DOC content and higher terrestrial-derived aromatic DOM for this site. This is not surprising since SRS2 receives peat-derived DOM. As seen from Fig.5.3 and Fig.5.7, the relative abundance (\%) of C3 at site SRS2 was much higher: $7.3 \%, 23.6 \%, 28.5 \%, 15.2 \%, 0.7 \%, 0.1 \%$ for fractions $2,3,4,5,6$, and 7 , respectively, as compared with TS2 site: $8.5 \%, 4.5 \%$, for fractions 2 and 3, and C111 site: $5.8 \%, 10.7 \%, 7.7 \%, 2.1 \%$ for fractions $2,3,4,5$, respectively. The not mentioned fractions were $0 \%$ for all three abovementioned sites. In contrast, the relative abundance (\%) of C6 at site SRS2 was generally lower, especially in fractions 2, 3, and 4. These mirrored the DOM composition differences among different sites within the same Everglades ecosystem, potentially attributable to the different soil types, degree of microbial activity, and anthropogenic effects. In the TS site, the microbial activity is higher and could enhance the production of microbial humic-like 
component 6 . The canal site $\mathrm{C} 111$ receives higher nutrients and thus higher likely features microbial activity.

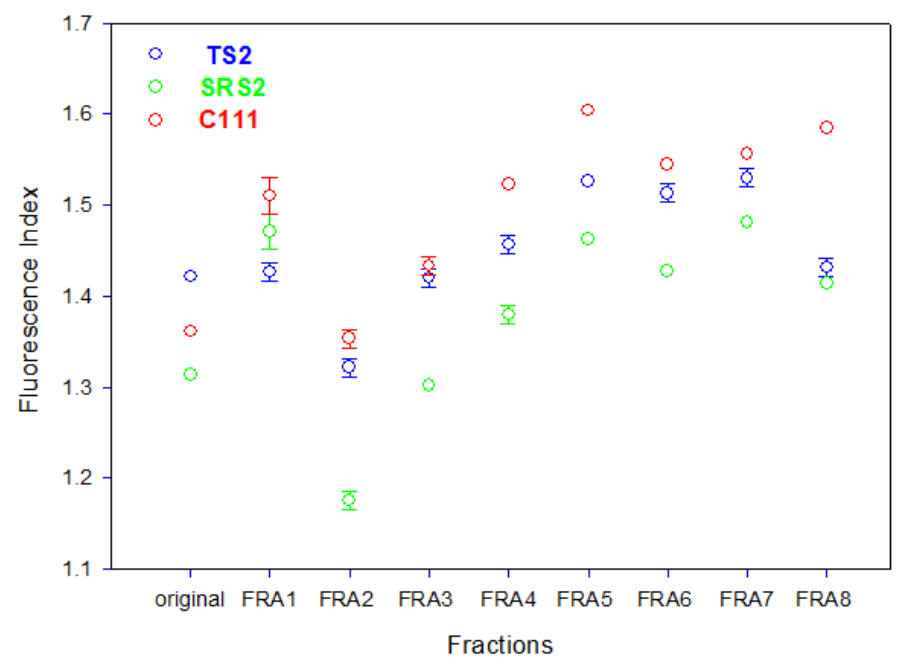

Fig.5.6 Trends in Fluorescence Index (FI) starting from the original whole sample to eight fractions with elution order. FRA = fraction.
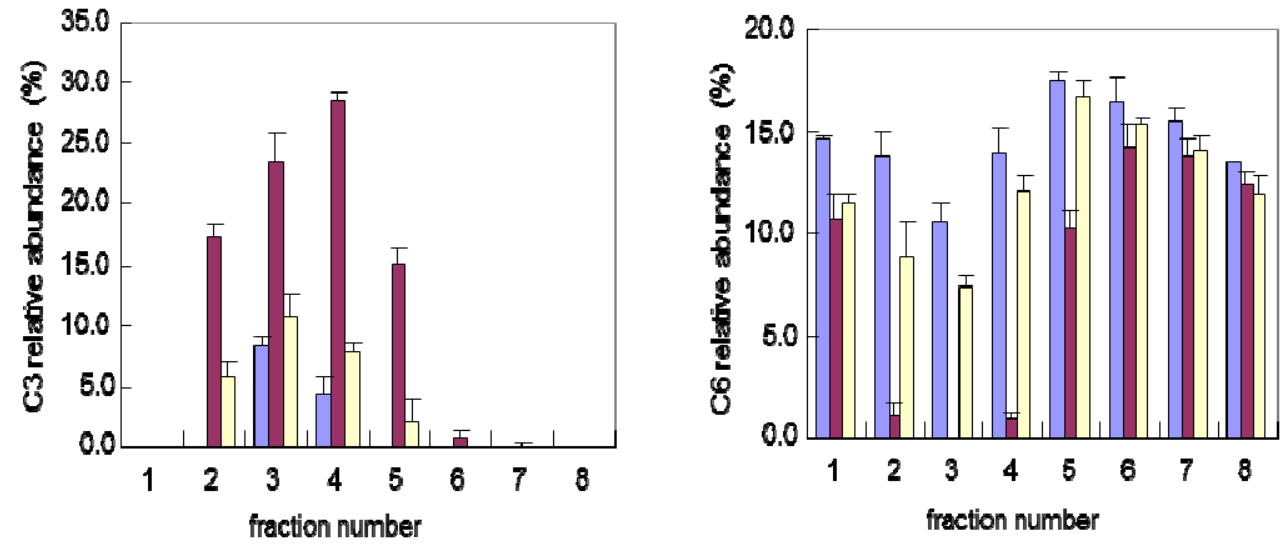

Fig.5.7 Comparison of component 3 (C3) and component 6 (C6) among three sites and eight fractions: peat-based freshwater marsh site SRS2; marl-based freshwater marsh site TS2; and canal site C111. 


\subsection{Conclusions:}

The molecular weight distributions of dissolved organic matter (DOM) was investigated using size exclusion chromatography (SEC) followed by EEM-PARAFAC. The results showed multiple PARAFAC components contribute to each of the eight MW fractions, indicative of a fairly homogeneous distribution of PARAFAC components along the MW continuum. The most likely explanation of this observation is that DOM is composed of heterogeneous molecular associations of components with varying fluorescence characteristics (PARAFAC components) in the form of supramolecular structures distributed throughout the MW range of DOM.

While most fluorophores were represented along the MW continuum, some MW fractions were distinctly different in composition, suggesting that the supramolecular associations that make up the DOM MW range are not simply associations of linearly increasing 'polymers', but can have specific compositional characteristics within the MW range. While high and low MW fractions were enriched in protein-like fluorophores, and can be explained by the presence of proteins and peptides and/or amino acids, other fractions presented very specific fluorescence characteristics. This suggests that very specific molecular associations are part of the DOM pool. While these MW distribution characteristics were generally observed for all samples, they were somewhat different for different sampling sites. Again, this may due to differences in DOM sources, biogeochemical conditions and other presently unknown drivers. The exact composition, structure and the environmental conditions for the formation of these molecular associations remains 
unknown at this point, and further research in this area is needed to better understand their dynamics in aquatic environments.

Overall, this study confirmed and highlighted the complex nature of DOM components of different MW and suggests that DOM speciation differences may result in important variations in reactivity and associated environmental implications. 


\section{REFERENCES:}

Abdulla, H. A. N., Minor, E. C., Dias, R. F., Hatcher, P. G., 2010a.Changes in the compound classes of dissolved organic matter along an estuarine transect: A study using FTIR and ${ }^{13}$ CNMR. Geochimica et Cosmochimica Acta 74: 3815-3838.

Abdulla, H. N., Minor, E. C., Hatcher, P. G., 2010b.Using Two-Dimensional Correlations of 13C NMR and FTIR To Investigate Changes in the Chemical Composition of Dissolved Organic Matter along an Estuarine Transect. Environ. Sci. Technol. 44: 8044-8049.

Aiken, G., McKnight, D., Wershaw, R. and MaCcarthy, P. 1985. Humic Substances in Soil, Sediments, and Water, John Wiely \& Sons.

Amon, R.M.W. and Benner, R. 1994. Rapid cycling of high-molecular-weight dissolved organic matter in the ocean. Nature 369: 550-552.

Arnon, R.M.W. and Benner, R. 1996. Bacterial utilization of different size classes of dissolved organic matter. Limnol. Oceanogr. 41(1): 41-51.

Arnosti, C., Microbial Extracellular Enzymes and Their Role in Dissolved Organic Matter Cycling. In Aquatic Ecosystems, Findlay, S. E., Sinsabaugh, R. L., Eds. Academic Press: 2003, pp 316-337.

Baker, A. and Genty, D. 1999. Fluorescence wavelength and intensity variations of cave waters. Journal of Hydrology 217(1-2): 19-34.

Baker, A. 2001. Fluorescence Excitation-Emission Matrix Characterization of Some Sewage-Impacted Rivers. Environmental Science \& Technology 35: 948-953.

Baker, A. 2002. Spectrophotometric discrimination of river dissolved organic matter. River Research and Applications 16(16): 3203-3213.

Bauer, J. E., P. M. Williams, and E. M. Druffel. 1992. ${ }^{14} \mathrm{C}$ activity ofdissolved organic carbon fractions in the north central Pacific and Sargasso Sea. Nature 357: 667-670.

Balcarczyk, K. L., Jones, J. B. J., Jaffe, R., Maie, N., 2009.Stream dissolved organic matter bioavailability and composition in watersheds underlain with discontinuous permafrost. Biogeochemistry 94: 255-270.

Benner, R., Kaiser, K., 2010.Biological and photochemical transformations of Amino acids and lignin phenols in riverine dissolved organic matter. Biogeochemistry 
Boreen, A. L., Edhlund, B. L., Cotner, J. B., McNeill, K., . 2008.Indirect Photodegradation of Dissolved Free Amno Acids: The Contribution of Singlet Oxygen and Differential Reactivity of DOM from Various Sources. Environ. Sci. Technol 42: 5492-5498.

Borisover, M., Laor, Y., Parparov, A., Bukhanovsky, N., and Lado, M. 2009. Spatial and seasonal patterns of fluorescent organic matter in Lake Kinneret (Sea of Galilee) and its catchment basin. Water Research 43: 3104-3116.

Boyer, J.N. 2006a. Shifting N and P limitation along a north-south gradient of mangrove estuaries in South Florida. Hydrobiologia 269: 167-177.

Boyer, J.N. and Fourqurean, J.W. 1997. Spatial Characterization of Water Quality in Florida Bay and Whitewater Bay by Multivariate Analyses: Zones of Similar Influence. Estuaries 20(4): 743-758.

Boyer, J.N. and Fourqurean, J.W. 1999. Seasonal and Long-term Trends in the Bay (1989-1997). Estuaries 22(2B): 417-430.

Boyer, J.N., Dailey, S.K., Gibson, P.J., Rogers, M.T. and Mir-Gonzalez, D. $2006 \mathrm{~b}$. The role of dissolved organic matter bioavailability in promoting phytoplankton blooms in Florida Bay. Hydrobiologia 569: 71-85.

Bradner, A., McPherson, B.F., Miller, R.L., Kish, G. and Bernard, B. 2005. Quality of Ground Water in the Biscayne Aquifer in Miami-Dade,Broward, and Palm Beach Counties,Florida,1996-1998,with Emphasis on Contaminants: U.S. Geological Survey Open-File Report 2004-1438, p. 20.

Briceño, H.O. and Boyer, J.N. 2010. Climatic Controls on Phytoplankton Biomass in a Sub-tropical Estuary, Florida Bay, USA. Estuaries and Coasts 33: 541-553.

Bro, R. 1997. PARAFAC. Tutorial and applications. Chemomemcs and Intelligent Laboratory Systems 38: 149-171.

Cai, Y., Monsaluda, S., Jaffé, R. and Jones, R.D. 2000. Gas chromatographic determination of organomercury following aqueous derivatization with sodium tetraethylborate and sodium tetraphenylborate Comparative study of gas chromatography coupled with atomic fluorescence spectrometry, atomic emission spectrometry and mass spectrometry. Journal of Chromatography A 876: 147-155.

Cabaniss, S., Zhou, Q., Maurice, P.A., Chin, Y.-p. and Aiken, G.R. 2000. A Log-Normal Distribution Model for the Molecular Weight of Aquatic Fulvic Acids. Environ. Sci. Technol. 34: 1103-1109. 
Chen, M., Price, R. M., Yamashita, Y., Jaffé, R., 2010.Comparative study of dissolved organic matter from groundwater and surface water in the Florida coastal Everglades using multi-dimensional spectrofluorometry combined with multivariate statistics. Applied Geochemistry 25: 872-880.

Chen, R. and Twilley, R.R. 1999. Patterns of Mangrove Forest Structure and Soil Nutrient Dynamics Along the Shark River Estuary, Florida. Estuaries 22(4): 955-970.

Clark, C. D., HIscock, W. T., Millero, F. J., Hitchcock, G., Brand, L., Miller, W. L., Ziolkowski, L., Chen, R. F., Zika, R. G., 2004.CDOM distribution and $\mathrm{CO}_{2}$ production on the Southwest Florida Shelf. Marine Chemistry 89: 145-167.

Clark, C. D., Litz, L. P., Grant, S. B., 2008. Salt marshes as a source of chromophoric dissolved organic matter (CDOM) to Southern California coastal waters. Limnol. Oceanogr. 53(5): 1923-1933.

Chin, Y.-P., Aiken, G.R. and Danielsen, K.M. 1997.Binding of Pyrene to Aquatic and Commercial Humic Substances: The Role of Molecular Weight and Aromaticity. Environ. Sci. Technol. 31: 1630-1635.

Chin, Y.-P., Traina, S.J., Swank, C.R. and Backhus, D. 1998.Abundance and properties of dissolved organic matter in pore waters of a freshwater wetland. Limnol. Oceanogr. 43(6): 1287-1296.

Coble, P.G. 1996. Characterization of marine and terrestrial DOM in seawater using excitation-emission matrix spectroscopy. Marine Chemistry 51(4): 325-346.

Coble, P.G., Del Castillo, C. and Avril, B. 1998.Distribution and optical properties of CDOM in the Arbian Sea during the 1995 Southwest Monsoon. Deep-sea Research (Part II) 45: 2195-2223.

Corbett, R.D., Chanton, J., Burnett, W., Dillon, K., Rutkowski, C. and Fourqurean, J.W. 1999.Patterns of groundwater discharge into Florida Bay. Limnology \& Oceanography 44(4): 1045-1055.

Corbett, R.D., Dillon, K., Burnett, W. and Chanton, J. 2000. Estimating the groundwater contribution into Florida Bay via natural tracers, ${ }^{222} \mathrm{Rn}$ and $\mathrm{CH}_{4}$. Limnology \& Oceanography 45(7): 1546-1557.

Cory, R.M. and M cKnight, D.i.M. 2005. Fluorescence Spectroscopy Reveals Ubiquitous Presence of Oxidized and Reduced Quinones in Dissolved Organic Matter. Env. Sci. Technol. 39: 8142-8149. 
Cunningham, K.J, Renken, R.A., Wacker, M.A., Zygnrerski, M.R., Robinson, E., Shapiro, A.M., and Wingard, G.L. 2006.Applicaton of carbonate cyclostratigraphy and borehole geophysics to delineate porosity and preferential flow in the karst limestone of the Biscayne aquifer, SE Florida. In Harmon, R.S., and Wicks, C., eds., Perspectives on karst geomorphology, hydrology, and geochemistry - A tribute to Derek C. Ford and William B. White, GSA Special Paper 404: 121-208.

Davis, J., Benner, R. 2007.Quantitative estimates of labile and semi-labile dissolved organic carbon in the western Arctic Ocean: A molecular approach. Limnol. Oceanogr. 52(6): 2434-2444.

Davis, J., Kaiser, K., Benner, R., 2009.Amino acid and amino sugar yields and compositions as indicators of dissolved organic matter diagenesis. Organic Geochemistry 40: 343-352.

Davis, S. E., Childers, D. L., Noe, G. B., 2006.The contribution of leaching the rapid release of nutrients and carbon in the early decay of wetland vegetation. Hydrobiologia 569: 87-97.

Egeberg, P.K. and Alberts, J.J. 2003. HPSEC as a prepative fractionation technique for studies of natural organic matter (NOM). Environ Technol. 24(3): 309-318.

Fellman, J. B., D’Amore, D. V.,Hood, E., Boone, R. D., 2008.Fluorescence characteristics and biodegradability of dissolved organic matter in forest and wetland soils from coastal temperate watersheds in southeast Alaska. Biogeochemistry 88: 169-184.

Fellman, J. B., Hood, E., D’Amore, D. V., Edwards, R. T., White, D., 2009a.Seasonal changes in the chemical quality and biodegradability of dissolved organic matter exported from soils to streams in coastal temperate rainforest watersheds. Biogeochemistry 95: 277-293.

Fellman, J. B., Hood, E., Edwards, R. T., D’Amore, D. V., 2009b.Changes in the concentration, biodegradability, and fluorescent properties of dissolved organic matter during stormflows in coastal temperate watersheds. Jounal of Geophysical Research 114: G01021,doi:10.1029/2008JG000790.

Fellman, J. B., Hood, E., Spencer, R. G. M., 2010.Fluorescence spectroscopy opens new windows into dissolved organic matter dynamics in freshwater ecosystems: A review. Limnol. Oceanogr. 55(6): 2452-2462.

Fellman, J.B., Miller, M.P., Cory, R.M., D'Amore, D.V. and White, D. 2009c. Characterizing Dissolved Organic Matter Using PARAFAC Modeling of 
Fluorescence Spectroscopy: A Comparison of Two Models. Environmental Science \& Technology 43(16): 6228-6234.

Findlay, S. E. G., Sinsabaugh, R. L., Aquatic Ecosystems: Interactivity of Dissolved Organic Matter. Academic Press: 2003.

Fish, J.E., and Stewart, M. 1991. Hydrogeology of the surficial aquifer system, Dade County, Florida, U.S Geological Survey Water Resources Investigation Report., 90-4108.

Fourqurean, J.W., and Robblee, M.B. 1999 Florida Bay: A history of recent ecological changes. Estuaries. 22(2B): 345-357.

Fourqurean, J.W., Zieman, J.C. and Powell, G.V.N. 1992. Phosphorus limitation of primary production in Florida Bay:Evidence from $\mathrm{C}: \mathrm{N}: \mathrm{P}$ ratios of the dominant seagrass Thalassia testudinum. Limnol. Oceanogr. 37(1): 162-117 161.

Gaiser, E.E., Scintoa, L.J., Richardsb, J.H., Jayachandran, K., Childers, D.L., Trexlerb, J.C. and Jones, R.D. 2004.Phosphorus in periphyton mats provides the best metric for detecting low-level $\mathrm{P}$ enrichment in an oligotrophic wetland. Water Research 38: 507-516.

Genereux, D., and Slater, E. 1999. Water exchange between canals and surrounding aquifer and wetlands in the southern Everglades, USA, J. Hydrology, 219: 153-168.

Gonsior, M., Peake, B. M., Cooper, W. T., Podgorski, D., D’Andrilli, J., Cooper, W. J., 2009.Photochemically Induced Changes in Dissolved Organic Matter Identified by Ultrahigh Resolution Fourier Transform Ion Cyclotron Resonance Mass Spectrometry. Environ. Sci. Technol. 43(3): 698-703.

Gonsior, M., Peake, B. M., Cooper, W. T., Podgorski, D. C., D'Andrilli, J., Dittmar, T., Cooper, W. J., 2011.Characterization of dissolved organic matter across the Subtropical Convergence off the South Island, New Zealand. Marine Chemistry 123: 99-110.

Grebel, J. E., Pignatello, J. J., Song, W., Cooper, W. J., Mitch, W. A., 2009. Impact of halides on the photobleaching of dissolved organic matter. Marine Chemistry 115: 134-144.

Hansell, D.A. and Carlson, C.A. 2002. Biogeochemistry of Marine Dissolved Organic Matter. Chapter 10: Chromophoric DOM in the Coastal Environment, Academic Press. 
Harvey, J.W., and McCormick, P.V. 2009. Groundwater's significance to changing hydrology, water chemistry, and biological communities of a floodplain ecosystem, Everglades, South Florida, USA. Hydrgeology Journal, 17: 185-201.

Harvey, J.W., Newlin, J.T. and Krupa, S.L. 2006. Modeling decadal timescale interactions between surface water and ground water in the central Everglades, Florida, USA. Journal of Hydrology 320: 400-420.

Helms, J.R., Stubbins, A., Ritchie, J.D. and Minor, E.C. 2008. Absorption spectral slopes and slope ratios as indicators of molecular weight, source, and photobleaching of chromophoric dissolved organic matter. Limnology \& Oceanography 53(3): 955-969.

Her, N., Amy, G., McKnight, D., Sohn, J. and Yoon, Y. 2003.Characterization of DOM as a function of MW by fluorescence EEM and HPLC-SEC using UVA, DOC, and fluorescence detection. Water Research 37: 4295-4303.

Hopkinson Jr., C. S., Vallino, J. J., Nolin, A., 2002.Decomposition of dissolved organic matter from the continental margin. Deep-Sea Research II 49: 4461-4478.

Housari, F.., Vione, D., Chirona, S., Barbati, S., 2010.Reactive photoinduced species in estuarine waters. Characterization of hydroxyl radical, singlet oxygen and dissolved organic matter triplet state in natural oxidation processes. Photochemical \& Photobiological Sciences 9: 78-86.

Hudson, N., Baker, A. and Reynolds, D. 2007. Fluorescence analysis of dissolved organic matter in natural, waste and polluted waters-a review. River. Res. Applic. 23: 631-649.

Jaffé, R., Boyer, J.N., Lu, X., Maie, N., Yang, C., Scully, N.M. and Mock, S. 2004. Source characterization of dissolved organic matter in a subtropical mangrovedominated estuary by fluorescence analysis. Marine Chemistry 84: 195-210.

Jaffé, R., McKnight, D., Maie, N., Cory, R., McDowell, W. H., Campbell, J. L., 2008. Spatial and temporal variations in DOM composition in ecosystems: The importance of long-term monitoring of optical properties J. Geophys. Res. 113: G04032, doi:10.1029/2008JG000683.

Jee, S. H., Kim, Y. J., Ko, S. O., 2010.Transformation of dissolved organic matter by oxidative polymerization with horseradish peroxidase. Water Science \& Technology 62(2).

Jiang, J. and Kappler, A. 2008. Kinetics of Microbial and Chemical Reduction of 
Humic Substances: Implications for Electron Shuttling. Env. Sci. Technol. 42(10): 3563-3569.

Jiao, N., Herndl, G. J., Hansell, D. A., Benner, R., et al., 2010. Microbial production of recalcitrant dissolved organic matter: long-term carbon storage in the global ocean. Nature Reviews Microbiology 8: 593-599.

Jones, V., Ruddell, C., Wainwright, G., Rees, H., Jaffe, R., Wolff, G., 2004, Onedimensional and two-dimensional polyacrylamide gel electrophoresis: a tool for protein characterization in aquatic samples. Marine Chemistry 85: 63- 73.

Kaiser, K. and Benner, R. 2009. Biochemical composition and size distribution of organic matter at the Pacific and Atlantic time-series stations. Marine Chemistry 113: $63-77$.

Koch, B. P., Ludwichowski, K.-U., Kattner, G., Dittmar, T., Witt, M., 2008. Advanced characterization of marine dissolved organic matter by combining reversed-phase liquid chromatography and FT-ICR-MS. Marine Chemistry 111: 233-241.

Lamont-Black, J., Baker, A., Younger, P.L. and Cooper, A.H. 2005. Utilising seasonal variations in hydrogeochemistry and excitation-emission fluorescence to develop a conceptual groundwater flow model with implications for subsidence hazards: an example from Co. Durham, UK. Environmental Geology 48: 320-335.

Lapworth, D.J., Gooddy, D.C., Butcher, A.S. and Morris, B.L. 2008. Tracing groundwater flow and sources of organic carbon in sandstone aquifers using fluorescence properties of dissolved organic matter (DOM). Applied Geochemistry 23: 3384-3390.

Larsen, L.G., Aiken, G.R., Harvey, J.W., Noe, G.B., and Crimaldi, J.P. 2010. Using fluorescence spectroscopy to trace seasonal DOM dynamics, disturbance effects, and hydrologic transport in the Florida Everglades. Journal of Geophysical Research 115.

Lepane, V. and Kudrjashova, M., 2001. High-performance Size Exclusion Chromatographic Characterization of Humic Substances and Dissolved Organic Matter from Baltic Aquatic Environment. Oil Shale 18(4): 350-372.

Light, S.S. and Dineen, J.W., 1994. Everglades: The ecosystem and its restoration. Davis, S.M. and Ogden, J.C. (eds), St. Lucie Press, Delray Beach, FL.

Lou, T. and Xie, H., 2006. Photochemical alteration of the molecular weight of dissolved organic matter. Chemosphere 65: 2333-2342. 
Lu, F., Chang, C.-H., Lee, D.-J., He, P.-J., Shao, L.-M. and Su, A., 2009, Dissolved organic matter with multi-peak fluorophores in landfill leachate. Chemosphere 74: $575-582$.

Lu, X. and Jaffé, R., 2001. Interaction between Hg (II) and natural dissolved organic matter: a fluorescence spectroscopy based study. Water Research 35(7): 1793-1803.

Lu, X.Q., Maie, N., Hanna, J.V., Childers, D.L. and Jaffé, R., 2003. Molecular characterization of dissolved organic matter in freshwater wetlands of the Florida Everglades. Water Research 37: 2599-2606.

Maie, N., Yang, C., Miyoshi, T., Parish, K.J. and Jaffe, R., 2005. Chemical characteristics of dissolved organic matter in an oligotrophic subtropical wetland /estuarine ecosystem. Limnology and Oceanography 50(1): 23-35.

Maie N., Boyer J., Chenyong Y., \& Jaffe R., 2006a. Spatial, geomorphological, and seasonal variability of CDOM in estuaries of the Florida Coastal Everglades. Hydrobiologia 569: 135-150.

Maie, N., Jaffé, R., Miyoshi, T., Childers, D. L., 2006c. Quantitative and qualitative aspects of dissolved organic carbon leached from senescent plants in an oligotrophic wetland. Biogeochemistry 78: 285-314.

Maie, N., Parish, K. J., Watanabe, A., Knicker, H., Benner, R., Abe, T., Kaiser, K., Jaffe, R., 2006b. Chemical characteristics of dissolved organic nitrogen in an oligotrophic subtropical coastal ecosystem. Geochimica et Cosmochimica Acta 70: 4491-4506.

Maie, N., Scully, N. M., Pisani, O., Jaffe, R., 2007.Composition of a protein-like fluorophore of dissolved organic matter in coastal wetland and estuarine ecosystems. Water Research 41: 563 - 570.

Maie, N., Pisani, O. and Jaffé, R., 2008. Mangrove tannins in aquatic ecosystems: Their fate and possible influence on dissolved organic carbon and nitrogen cycling. Limnology \& Oceanography 53(1): 160-171.

Marschnera, B., Kalbitz, K., 2003. Controls of bioavailability and biodegradability of dissolved organic matter in soils. Geoderma 113: $211-235$.

McKnight, D.M., Boyer, E.W., Westerhoff, P.K., Doran, P.T., Kulbe, T. and Andersen, D.T., 2001.Spectrofluorometric Characterization of dissolved organic matter for indication of precursor organic material and aromaticity. Limnology \& Oceanography 46(1): 38-48. 
Minor, E. C., Pothen, J., Dalzell, B. J., Abdulla, H., Mopper, K. M., 2006. Effects of salinity changes on the photodegradation and ultraviolet-visible absorbance of terrestrial dissolved organic matter. Limnol. Oceanogr. 51 (5): 2181-2186.

Mopper, K., Stubbins, A., Ritchie, J. D., Bialk, H. M., Hatcher, P. G., 2007.Advanced Instrumental Approaches for Characterization of Marine Dissolved Organic Matter: Extraction Techniques, Mass Spectrometry, and Nuclear Magnetic Resonance Spectroscopy. Chem. Rev. 107: 419-442.

Moran, M. A., Covert, J. S., 2003.Photochemically Mediated Linkages between Dissolved Organic Matter and Bacterioplankton. In Aquatic Ecosystems, Findlay, S. E., Sinsabaugh, R. L., Eds. Academic Press: 253.

Moran, M. A., Zepp, R. G., 2000.UV Radiation Effects on Microbes and Microbial Processes. In Microbial Ecology of the Oceans, Kirchman, D. L., Ed. WILEY-LISS.

Murphy, K.R., Stedmon, C.A., Waite, T.D. and Ruiz, G.M., 2008.Distinguishing between terrestrial and autochthonous organic matter sources in marine environments using fluorescence spectroscopy. Marine Chemistry 108(1-2): 40-58.

Noe, G.B., Childers, D.L. and Jones, R.D., 2001. Phosphorus Biogeochemistry and the Impact of Phosphorus Enrichment: Why Is the Everglades so Unique? Ecosystems 4: 603-624.

Obernosterer, I., Benner, R., 2004.Competition between biological and photochemical processes in the mineralization of dissolved organic carbon. Limnol. Oceanogr. 49(1): $117-124$.

Ogawa, H., Amagai, Y., Koike, I., Koike, K., Benner, R., 2001.Production of Refractory Dissolved Organic Matter by Bacteria. Science 292: 917-920.

Ohno, T., Bro, R., 2006.Dissolved Organic Matter Characterization Using Multiway Spectral Decomposition of Fluorescence Landscapes. Soil Sci. Soc. Am. J. 70: 2028 2037.

Omori, Y., Hama, T., Ishii, M. and Saito, S., 2010. Relationship between the seasonal change in fluorescent dissolved organic matter and mixed layer depth in the subtropical western North Pacific. Journal of Geophysical Reserach 115.

Opsahl, S., Benner, R., 1995.Early diage of vascubr phmt tisswes: Lignin and cutin decompo\&ion and biogeochemicai impkations. Geochimica et Cosmochimica Acta. 59(23): 4889-4904. 
Ortega-Retuerta, E., Reche, I., Pulido-Villena, E., Agustí, S., Duarte, C. M., 2010.Distribution and photoreactivity of chromophoric dissolved organic matter in the Antarctic Peninsula (Southern Ocean). Marine Chemistry 118: 129-139.

Parish, K., 2006. Chemical characterization of dissolved organic matter in an oligotrophic subtropical coastal ecosystem. MS Thesis, Florida International University, 187 pages.

Parker, G. G., Ferguson, G.E., Love, S.K. and others.,1955. Water Resources of Southeastern Florida--with special reference to the geology and ground water of the interior Miami area: U.S. Geological Survey Water-Supply Paper 1255: pp. 1-4 \& 157.

Peretyazhko, T. and Sposito, G., 2006.Reducing capacity of terrestrial humic acids. Geoderma 137: 140-146.

Perminova, I.V., 1999. Size Exclusion Chromatography of Humic Substances: Complexities of Data Interpretation Attributable To Non-Size Exclusion Effects. Soil Science 164(11): 834-840.

Price, R.M. and Swart, P.K., 2006a. Geochemical indicators of groundwater recharge in the surficial aquifer system, Everglades National Park, Florida,USA. in Harmon, R.S., and Wicks, C., eds., Perspectives on karst geomorphology, hydrology, and geochemistry - A tribute volume to Derek C. Ford and William B. White: Geological Society of America Special Paper 404: 251-266. doi: 10.1130/2006.2404(21).

Price, R.M., Swart, P.K. and Fourqurean, J.W., 2006b. Coastal groundwater discharge - an additional source of phosphorus for the oligotrophic wetlands of the Everglades. Hydrobiologia 569: 23-36.

Price, R.M., Zafer, T., Happell, J.D., and Swart, P.K., 2003. Use of tritium and helium to define groundwater flow conditions in Everglades National Park, Water Resources Research 39(9): 1267.

Qualls, R. G., Richardson, C. J., 2003.Factors controlling concentration, export, and decomposition of dissolved organic nutrients in the Everglades of Florida. Biogeochemistry 62: 197-229.

Ratasuk, N. and Nanny, M.A., 2007. Characterization and Quantification of Reversible Red-ox Sites in Humic Substances. Environmental Science \& Technology 41(22): 7844-7850.

Reese, R.S. and Cunningham, K.J., 2000. Hydrogeology of the Gray Limestone 
aquifer in southern Florida: U.S. Geological Survey Water Resources Investigation Report 99-4213: 244.

Robblee, M.B., Barber, T.R., Carlson, P.R.J., Durako, M.J., Fourqurean, J.W., Muehlstein, L.K., Porter, D., Yarbro, L.A., Zieman, R.T. and Zieman, J.C., 1991. Mass mortality of the tropical seagrass Thalassia testudinum in Florida Bay (USA). Marine ecology progress series. 71(3): 297-299.

Santin, C., Yamashita, Y., Otero, X.L., Alvarez, M.A. and Jaffe, R., 2009. Characterizing humic substances from estuarine soils and sediments by excitation-emission matrix spectroscopy and parallel factor analysis. . Biogeochemistry 96(1-3): 131-147.

Schmitt-Kopplin, P., Hertkorn, N., Schulten, H.-R., Kettrup, A., 1998.Structural Changes in a Dissolved Soil Humic Acid during Photochemical Degradation Processes under $\mathrm{O}_{2}$ and $\mathrm{N}_{2}$ Atmosphere. Environ. Sci. Technol. 32: 2531-2541.

Scott, D.T., McKnight, D.M., Blunt-Harris, E.L., Kolesar, S.E. and Lovley, D.R., 1998. Quinone Moieties Act as Electron Acceptors in the Reduction of Humic Substances by Humics-Reducing Microorganisms. Environmental Science \& Technology 32: 2984-2989.

Scully, N. M., Maie, N., Dailey, S. K., Boyer, J. N., Jones, R. D., Jaffé, R., 2004. Early diagenesis of plant-derived dissolved organic matter along a wetland, mangrove, estuary ecotone. Limnol. Oceanogr. 49(5): 1667-1678.

Senesi, N., Miano, T.M., Provenzano, M.R. and Brunett, G., 1991.Characterization, differentiation, and classification of humic substances by fluorescence spectroscopy Soil Science 152: 259-271.

Shank, G.C., Lee, R., Vähätalo, A., Zepp, R.G. and Bartels, E., 2010.Production of chromophoric dissolved organic matter from mangrove leaf litter and floating Sargassum colonies. Marine Chemistry 119: 172-181.

Shank, G. C., Zepp, R. G., Vähätalo, A., Lee, R., Bartels, E., 2010. Photobleaching kinetics of chromophoric dissolved organic matter derived from mangrove leaf litter and floating Sargassum colonies. Marine Chemistry 119: 162-171.

Siegenthaler, U., Sarmiento, J. L., 1993. Atmospheric carbon dioxide and the ocean. Nature 365: 119-125.

Southworth, b. A., Voelker, B. M., 2003.Hydroxyl radical Production via the PhotoFenton Reaction in the Presence of Fulvic Acid. Environ. Sci. Technol. 37:1130-1136. 
Spencer, R. G. M., Stubbins, A., Hernes, P. J., Baker, A., Mopper, K., Aufdenkampe, A. K., Dyda, R. Y., Mwamba, V. L., Mangangu, A. M., Wabakanghanzi, J. N., Six, J., 2009.Photochemical degradation of dissolved organic matter and dissolved lignin phenols from the Congo River. J. Geophys. Res. 114: G03010, 12 PP.

Stedmon, C. A., Markager, S., 2005a.Tracing the production and degradation of autochthonous fractions of dissolved organic matter by fluorescence analysis. Limnol. Oceanogr. 50(5): 1415-1426.

Stedmon, C.A. and Markager, S., 2005b. Resolving the variability in dissolved organic matter fluorescence in a temperate estuary and its catchment using PARAFAC analysis. Limnol. Oceanogr. 50(2): 686-697.

Stedmon, C. A., Markager, S., Tranvik, L., Kronberg, L., Slatis, T., Martinsen, W., 2007. Photochemical production of ammonium and transformation of dissolved organic matter in the Baltic Sea. Marine Chemistry 104: 227-240.

Stedmon, C.A. and Bro , Rasmus, 2008. Characterizing dissolved organic matter fluorescence with parallel factor analysis: a tutorial. Limnology and Oceanography: Methods 6: 572-579.

Stober, J., Scheidt, D., Jones, R., Thornton, K., Ambrose, R. and France, D., 1996. South Florida ecosystem assessment monitoring for adaptive management: implications for ecosystem restoration.

Stubbins, A., Spencer, R. G. M., Chen, H., Hatcher, P. G., Mopper, K., Hernes, P. J., Mwamba, V. L., Mangangu, A. M., Wabakanghanzi, J. N., Six, J., 2010. Illuminated darkness: Molecular signatures of Congo River dissolved organic matter and its photochemical alteration as revealed by ultrahigh precision mass spectrometry. Limnol. Oceanogr. 55(4): 1467-1477.

Thurman, E.M., 1985. Humic Substances in Soil, Sediment, and water. Aiken, G., McKnight, D. and Wershaw, R.

Tranvik, L. J., Bertilsson, S., 2001. Contrasting effects of solar UV radiation on dissolved organic sources for bacterial growth. Ecology Letters 4: 458-463.

U.S. Environmental Protection Agency 1996. Water quality protection program for the Florida Keys National Marine Sanctury. First Biennial Report to Congress.

Vouvé, F., Cotrim da Cunha, L., Serve, L., Vigo, J. and Salmon, J.-M., 2009. Spatio-temporal variations of fluorescence properties of dissolved organic matter 
along the River Têt (Pyrénées-Orientales, France). Chemistry and Ecology 25(6): 435-452.

Wang, Y., Hsieh, Y.P., Landing, W.M., Choi, Y.H., Salters, V. and Campbell, D., 2002. Chemical and carbon isotopic evidence for the source and fate of dissolved organic matter in the northern Everglades. Biogeochemistry 61: 269-289.

Weishaar, J.L., Aiken, G.R., Bergamaschi, B.A., Fram, M.S., Fujii, R. and Mopper, K., 2003. Evaluation of Specific Ultraviolet Absorbance as an Indicator of the Chemical Composition and Reactivity of Dissolved Organic Carbon. Environmental Science \& Technology 37(20): 4702-4708.

Wilcox, W.M., Solo-Gabriele, H. M., and Sternberg, L.O., 2004. Use of stable isotopes to quantify flows between the Everglades and urban areas in Miami-Dade County Florida. Journal of Hydrology 293: 1-19.

Williams, P. M., and E. R. M. Druffel. 1987. Radiocarbon in dissolved organic carbon in the central North Pacific Ocean. Nature 330: 246- 248.

Williams, C.J., Yamashita, Y., Wilson, H.F., Jaffé, R. and Xenopoulosa, M.A., 2010. Unraveling the role of land use and microbial activity in shaping dissolved organic matter characteristics in stream ecosystems. Limnol. Oceanogr. 55: 1159-1171.

Woods, G.C., Simpson, M.J., Kelleher, B.P., Mccaul, M., Kingery, W.L. and Simpson, A.J., 2010. Online High-Performance Size Exclusion Chromatography-Nuclear Magnetic Resonance for the Characterization of Dissolved Organic Matter. Environ. Sci. Technol. 44: 624-630.

Yamashita, Y., Jaffé, R., 2008a.Characterizing the Interactions between Trace metals and Dissolved Organic Matter Using Excitation Emission Matrix and Parallel Factor Analysis. Environmental Science \& Technology 42(19): 7374-7379.

Yamashita, Y., Jaffe, R., Maie, N., Tanoue, E., 2008b. Assessing the dynamics of dissolved organic matter (DOM) in coastal environments by excitation emission matrix fluorescence and parallel factor analysis (EEM-PARAFAC). Limnol. Oceanogr. 53(5):1900-1908.

Yamashita, Y., Pant, A., Mahaffey, C., Jaffé, R., 2010b. Assessing the spatial and temporal variability of dissolved organic matter in Liverpool Bay using excitation-emission matrix fluorescence and parallel factor analysis. Ocean Dynamics. 
Yamashita, Y., Scinto, L. J., Maie, N., Jaffé, R., 2010a. Dissolved Organic Matter Characteristics Across a Subtropical Wetland's Landscape: Application of Optical Properties in the Assessment of Environmental Dynamics. Ecosystems 13: 1006-1019.

Yamashita, Y., Tanoue, E., 2003. Chemical characterization of protein-like fluorophores in DOM in relation to aromatic amino acids. Marine Chemistry 82: 255-271.

Yamashita, Y. and Tanoue, E., 2004. Chemical characteristics of amino acidcontaining dissolved organic matter in seawater. . Organic Geochemistry 35(6): 679-692. 
Appendix:
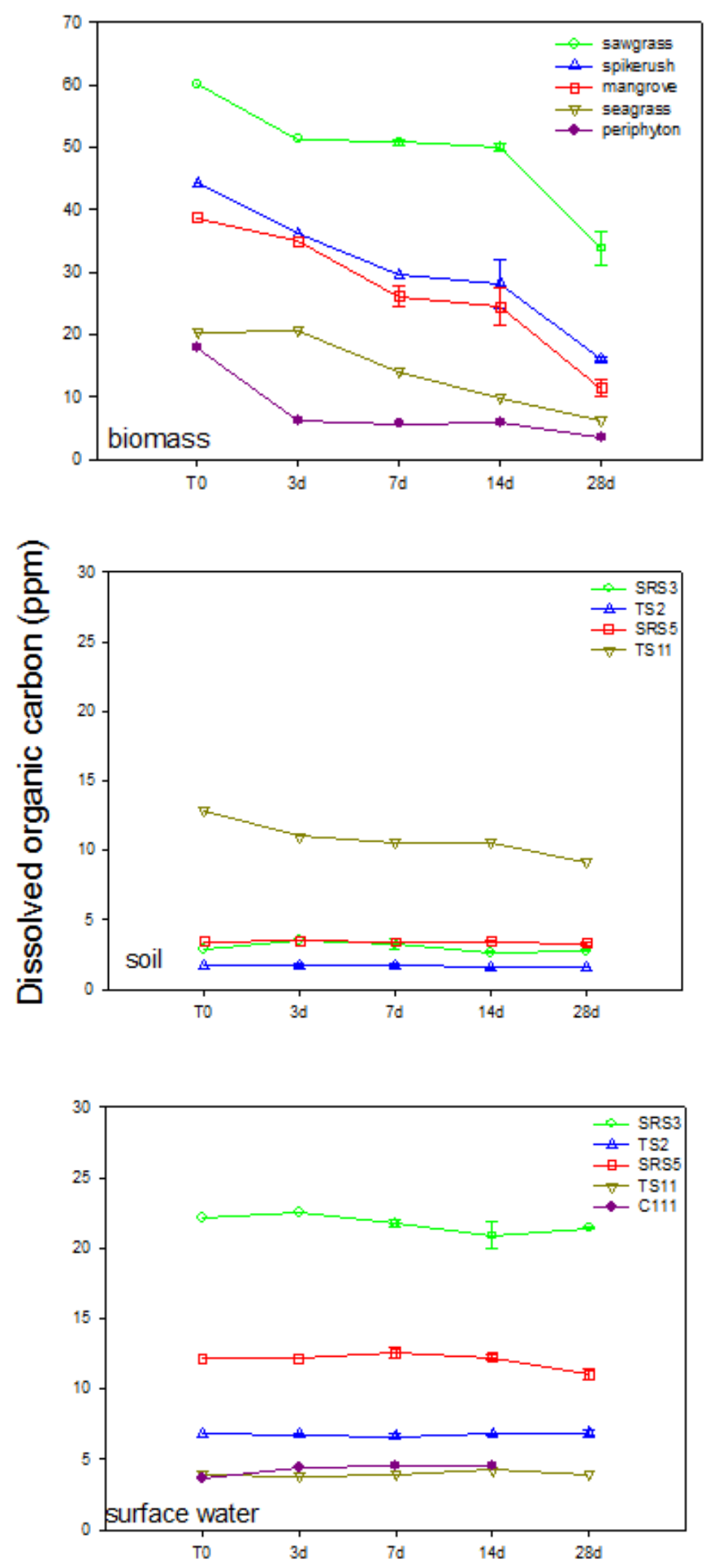

Fig. A-1Trends in DOC during biodegradation for leachates and surface water 

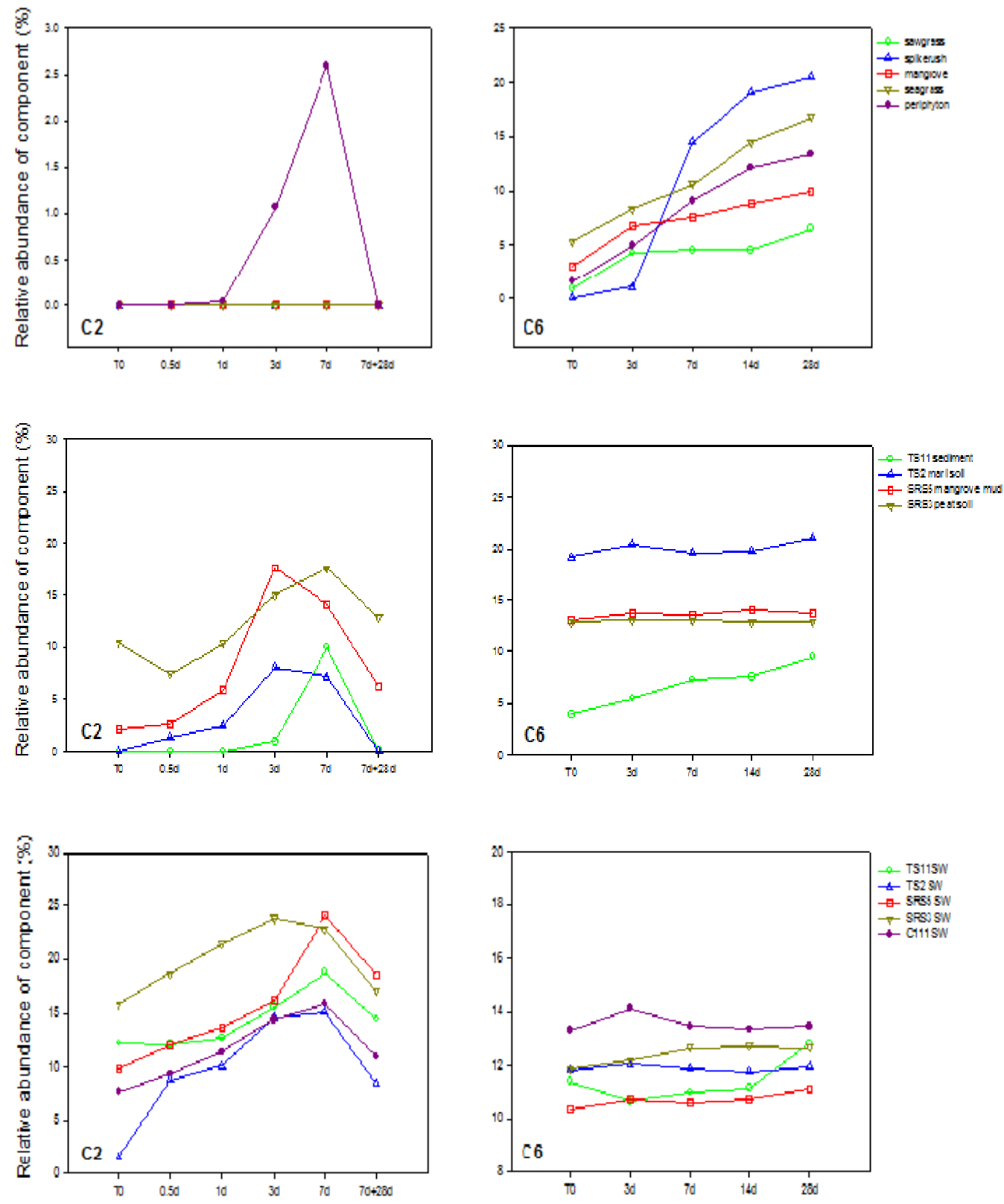

Time series (hours)

Fig. A-2 Trends in C2\% and C6\% during photo- and bio-degradation 

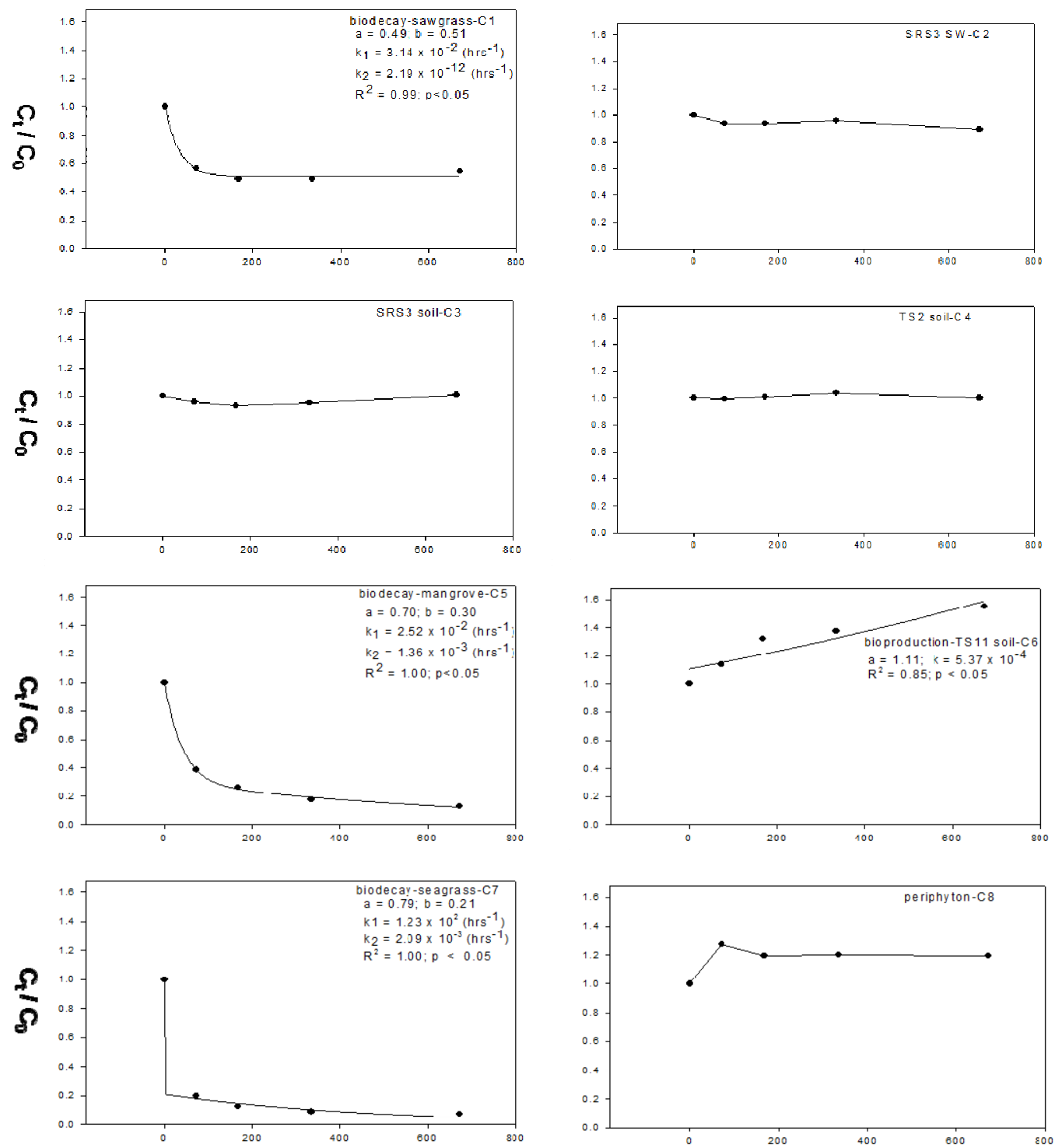

Time series (hours)

Fig. A-3 Examples of biodegradation patterns and kinetics data of EEM-PARAFAC components 

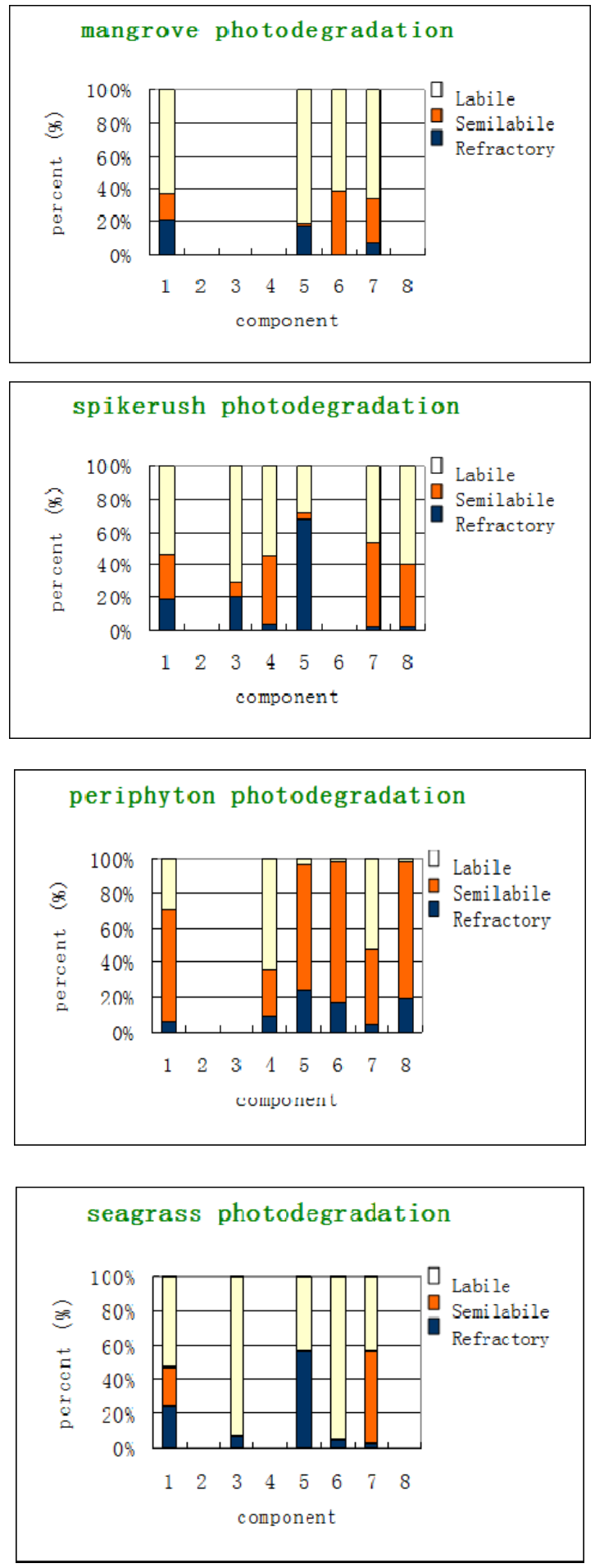

Fig. A-4 Examples of comparison of photo- (7 days) and bio-reactivity 
(28 days) of EEM-PARAFAC components for biomass leachate, soil leachate, and surface water in FCE.
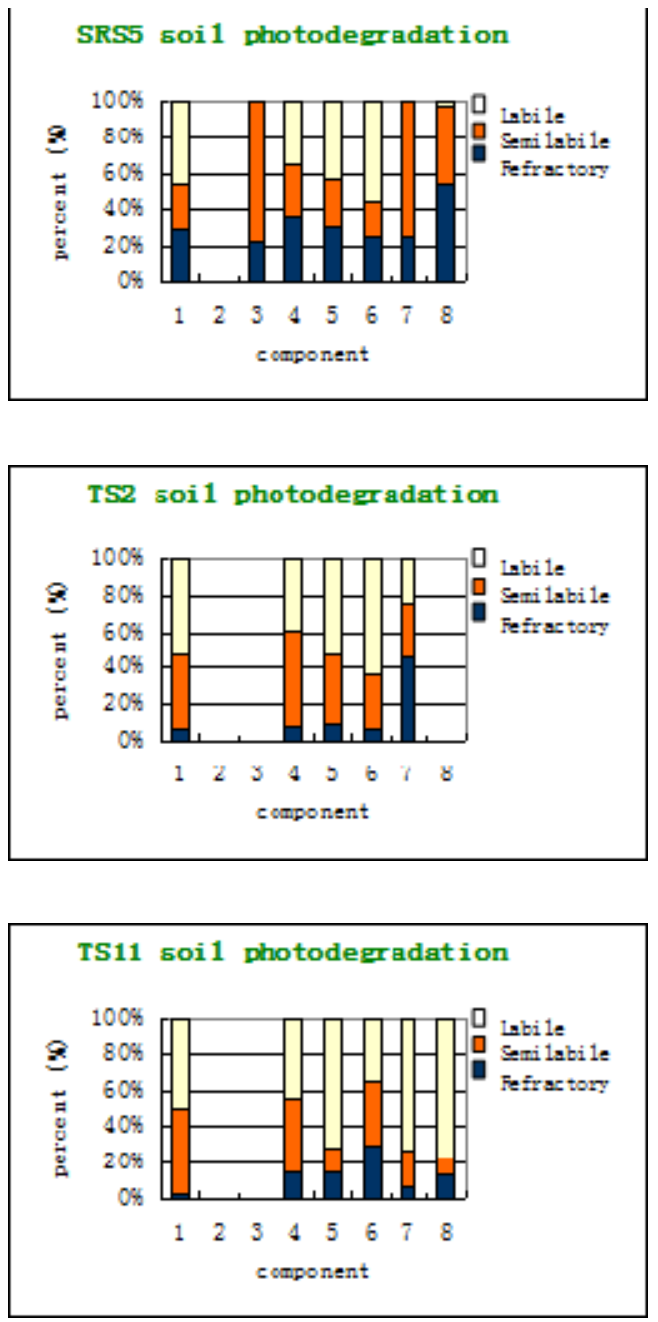

Fig. A-5 Examples of comparison of photo- (7 days) and bio-reactivity (28 days) of EEM-PARAFAC components for biomass leachate, soil leachate, and surface water in FCE. 

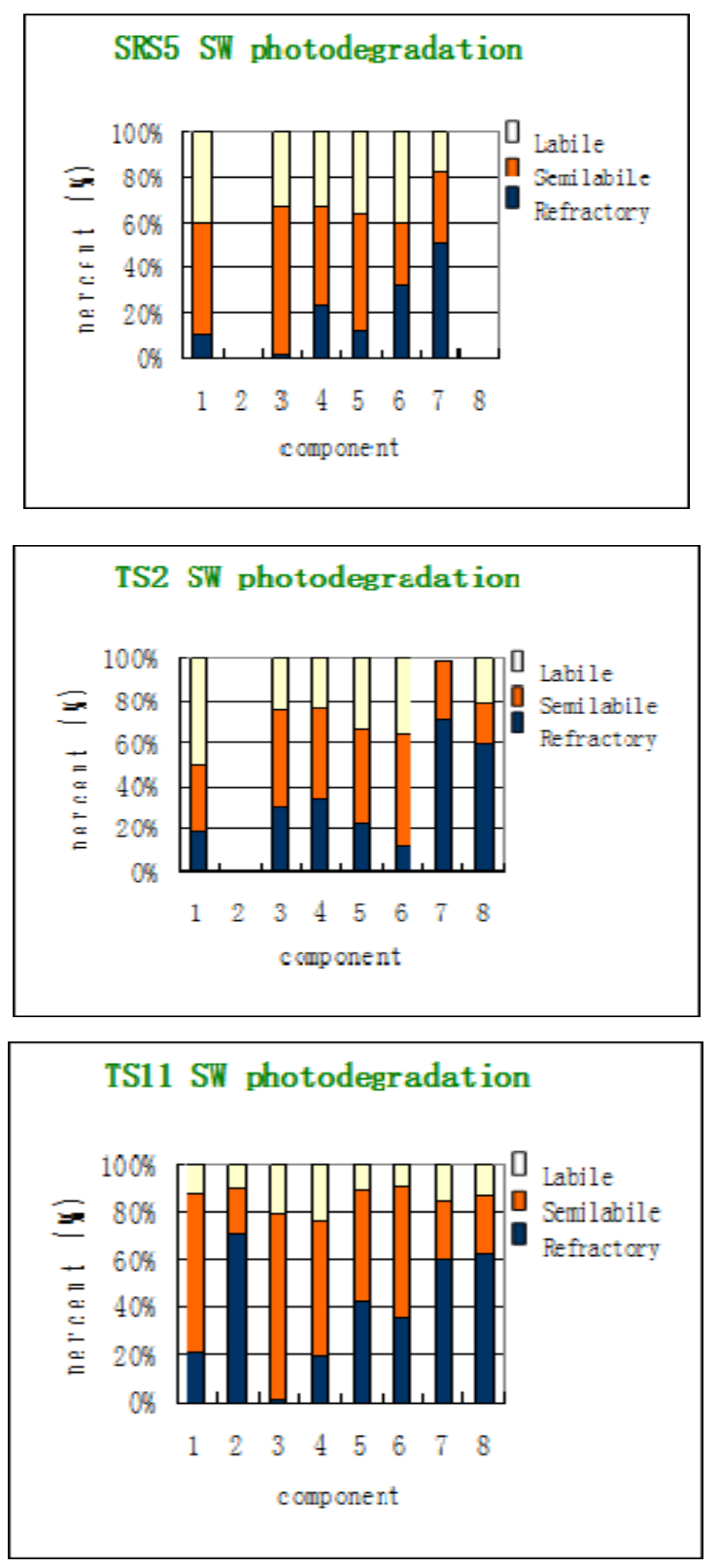

Fig. A-6 Examples of comparison of photo- (7 days) and bio-reactivity (28 days) of EEM-PARAFAC components for biomass leachate, soil leachate, and surface water in FCE. 

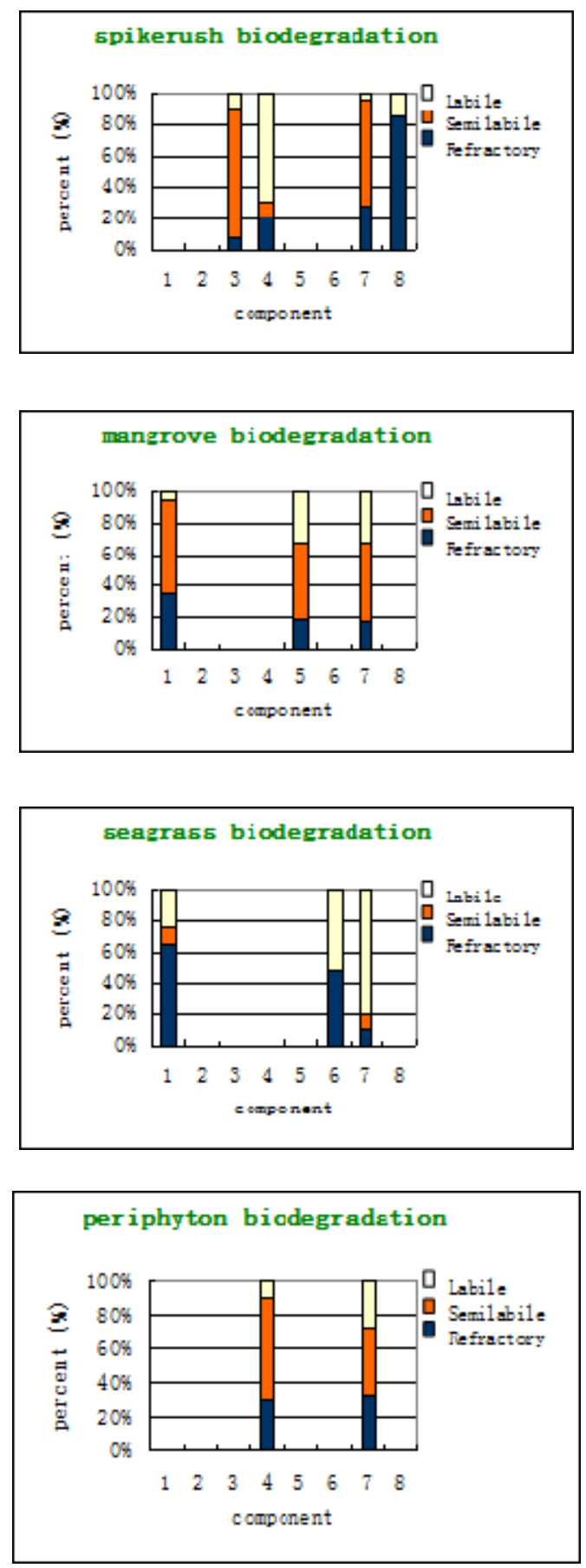

Fig. A-7 Examples of comparison of photo- (7 days) and bio-reactivity (28 days) of EEM-PARAFAC components for biomass leachate, soil leachate, and surface water in FCE. 

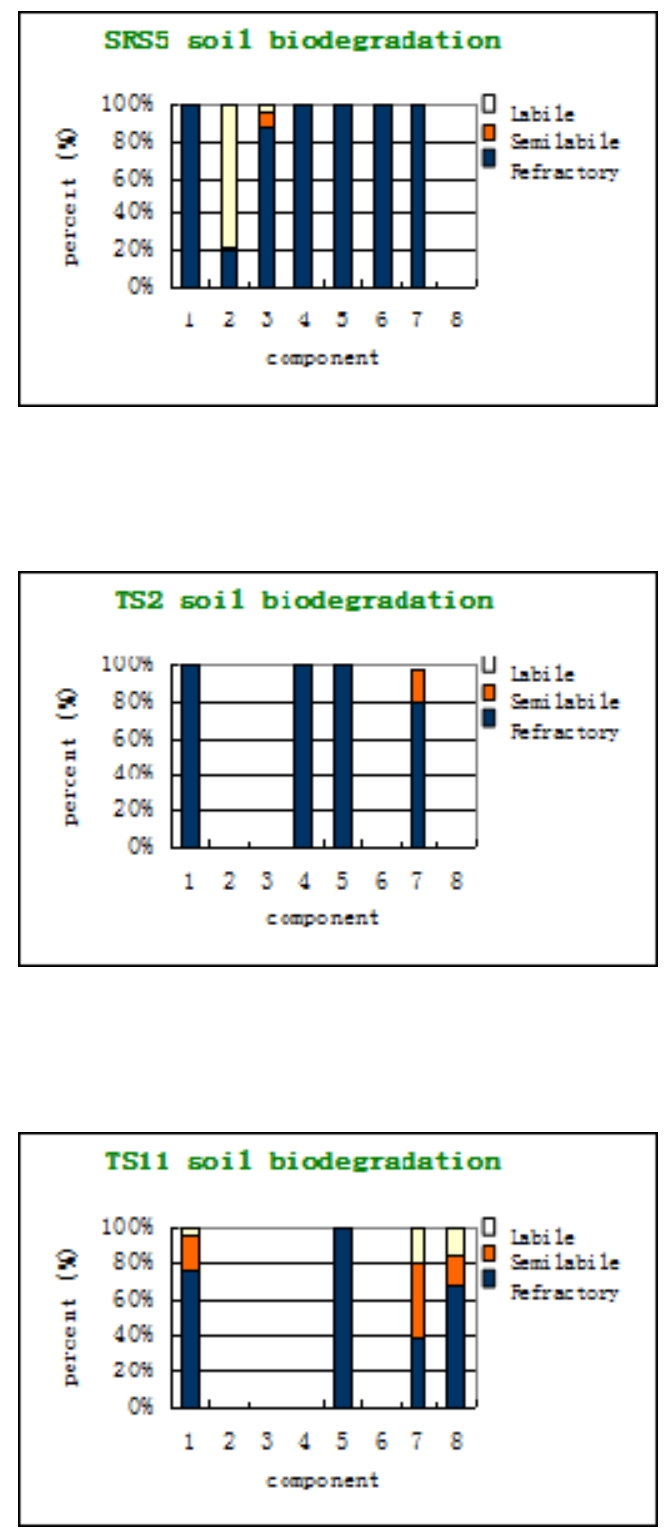

Fig. A-8 Examples of comparison of photo- (7 days) and bio-reactivity (28 days) of EEM-PARAFAC components for biomass leachate, soil leachate, and surface water in FCE. 

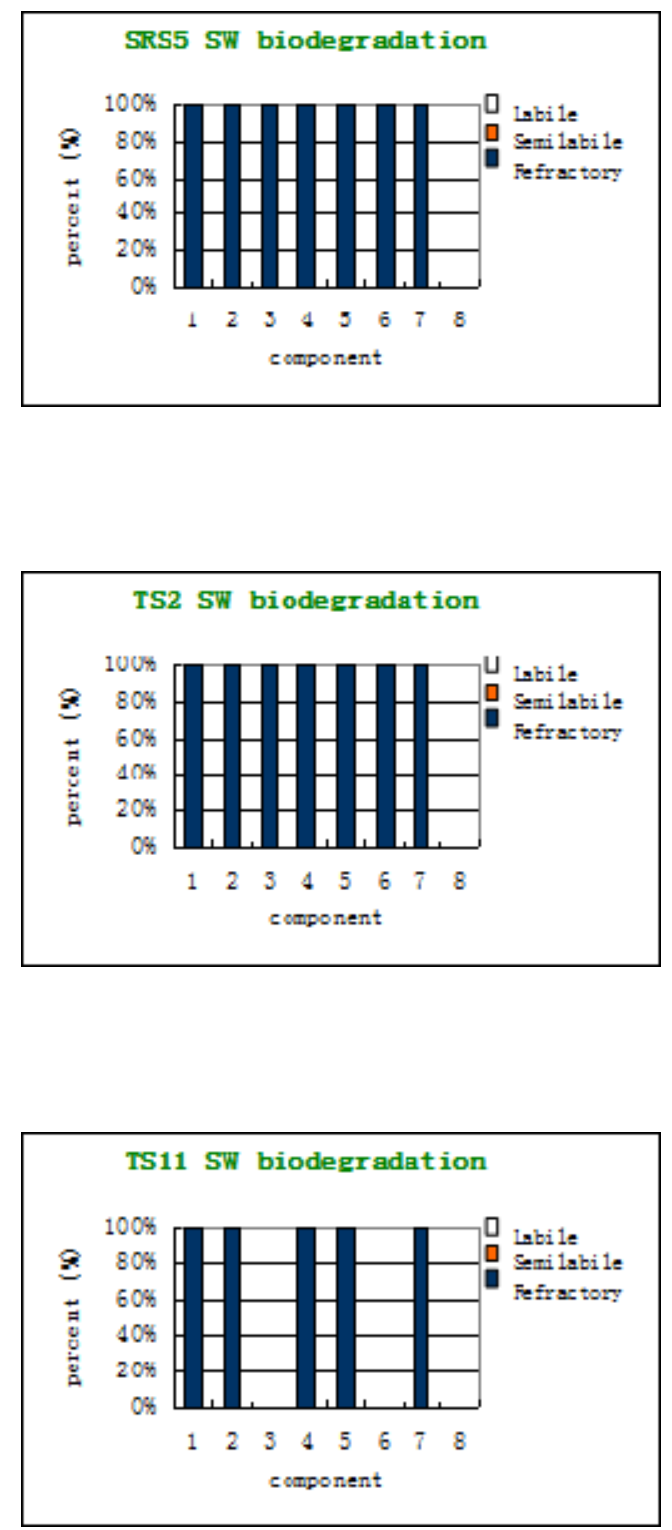

Fig. A-9 Examples of comparison of photo- (7 days) and bio-reactivity (28 days) of EEM-PARAFAC components for biomass leachate, soil leachate, and surface water in FCE. 

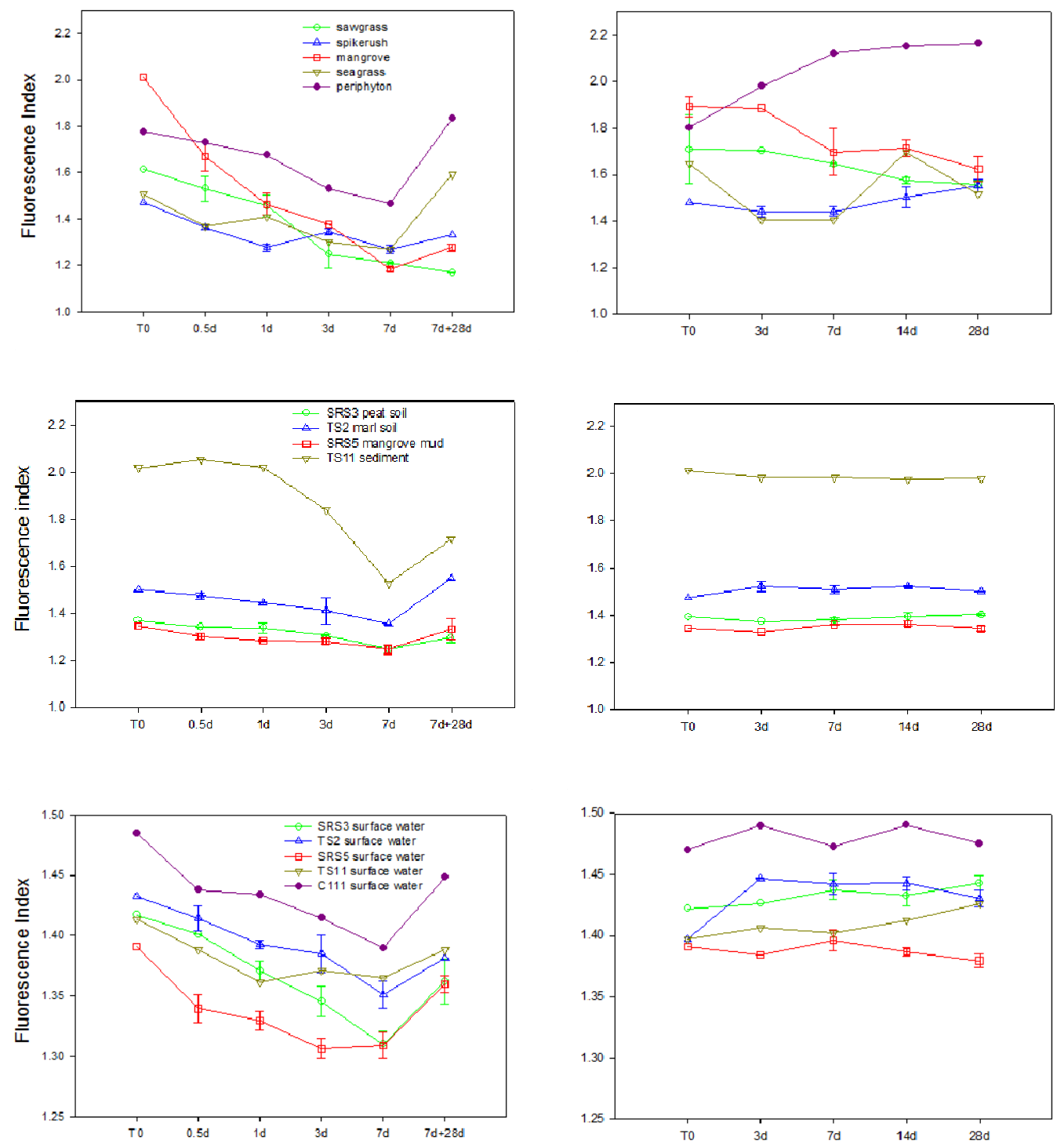

sequential 7 days photodegradation followed by 28 days bioincubation

28 days bioincubation

Fig. A-10 Examples of trends in Fluorescence Index (FI) during photo- and biodegradation 


\section{SRS 3}
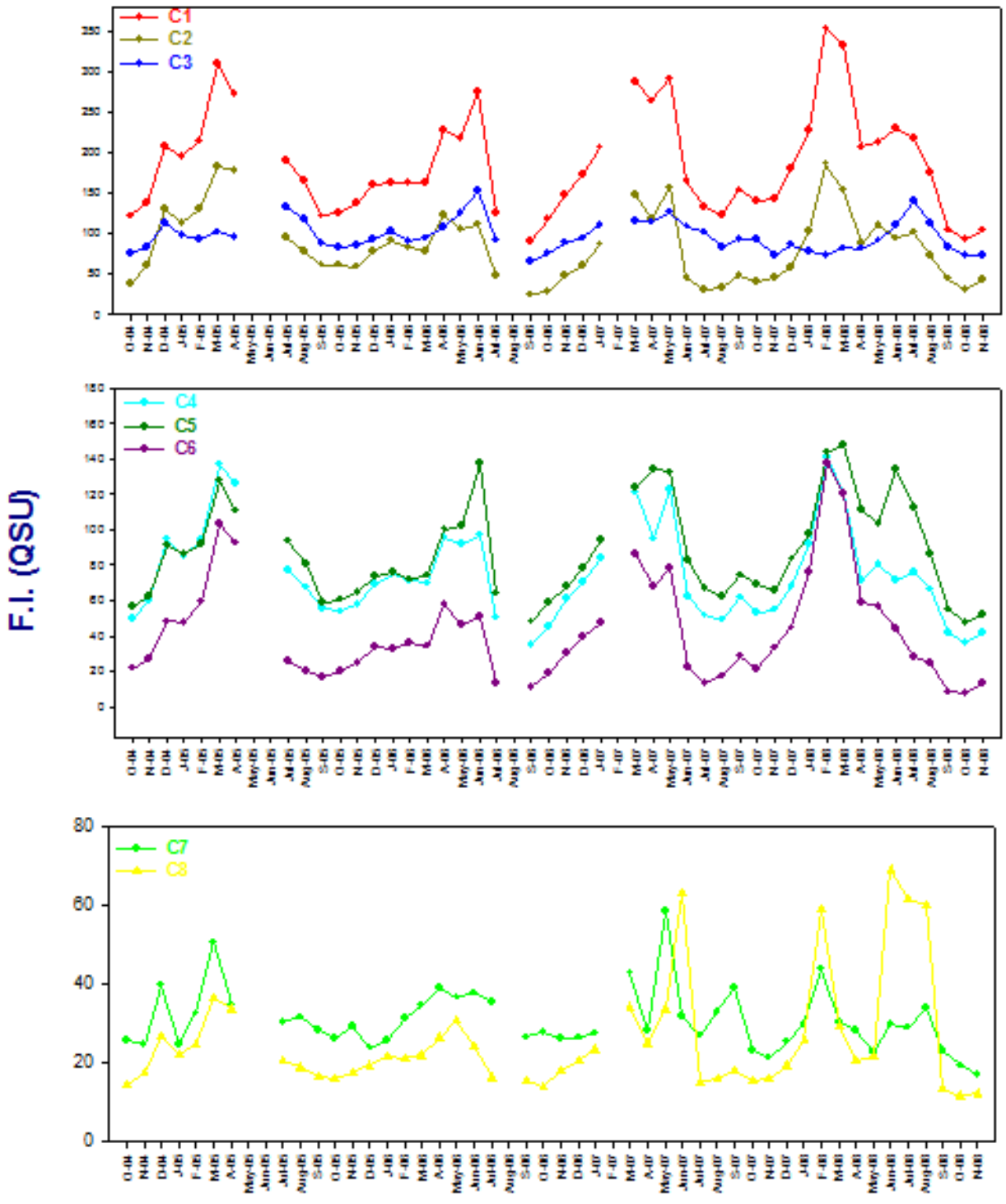

Month

Fig. A-11 Example of year-to-year temporal patterns of EEM-PARAFAC components in fluorescence intensity (QSU) at site SRS3 

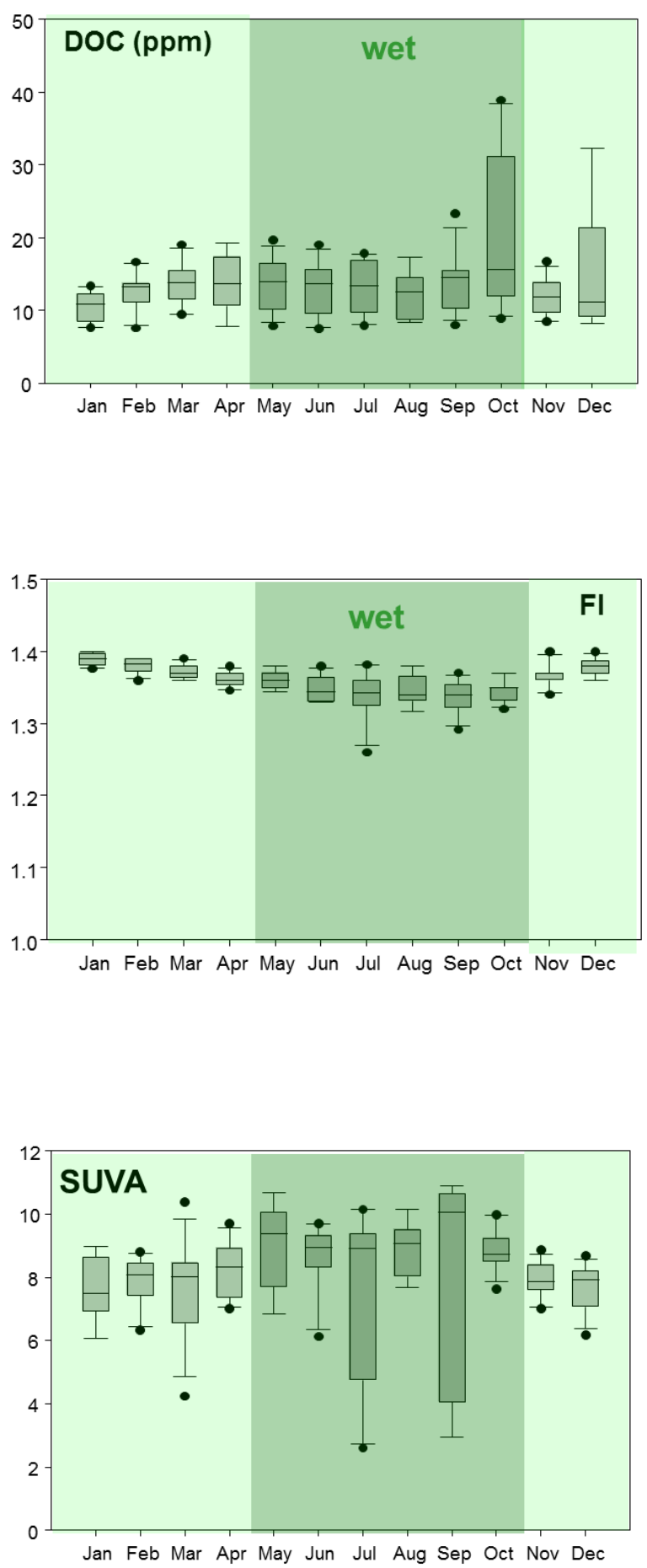

Fig. A-12 Seasonality of Mangrove marsh sites (SRS-4, SRS-5, SRS-6) 

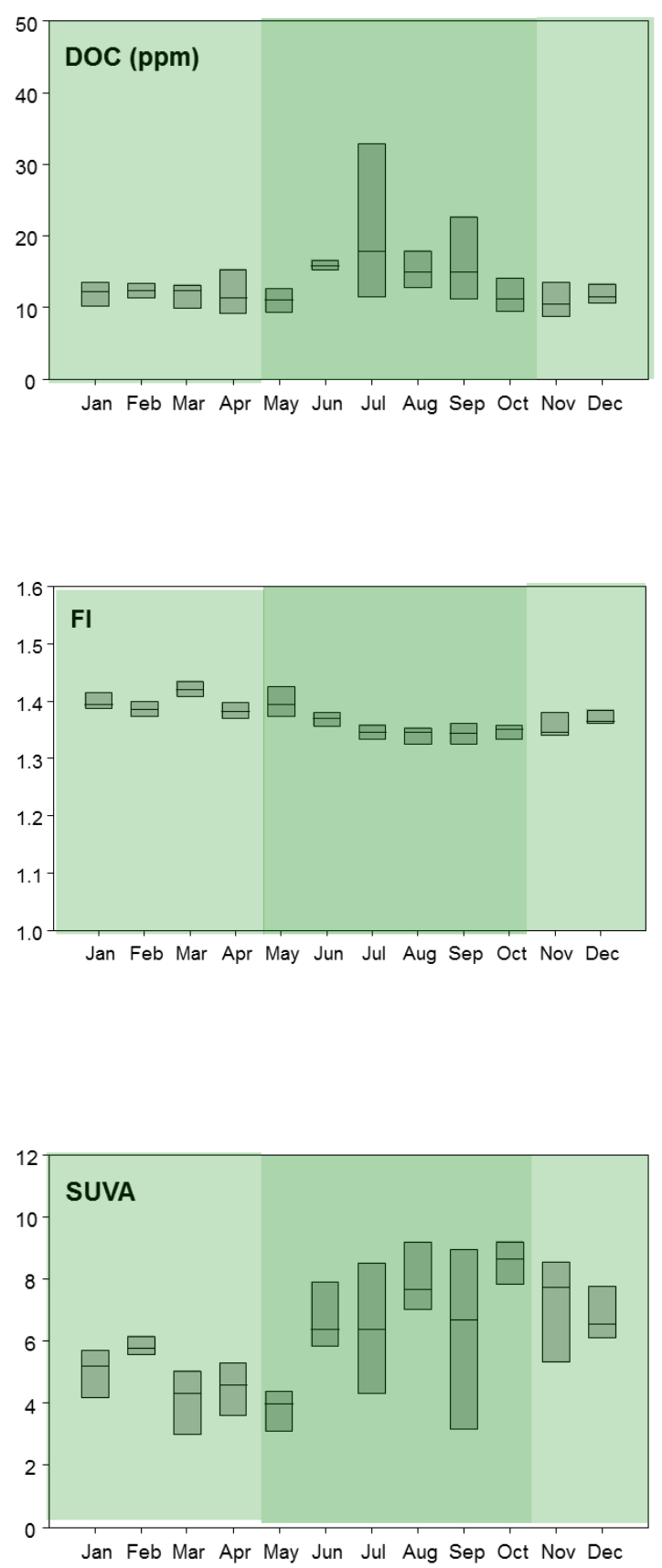

Fig. A-13 Seasonality of Mangrove marsh sites (TS/Ph-6, TS/Ph-7) 

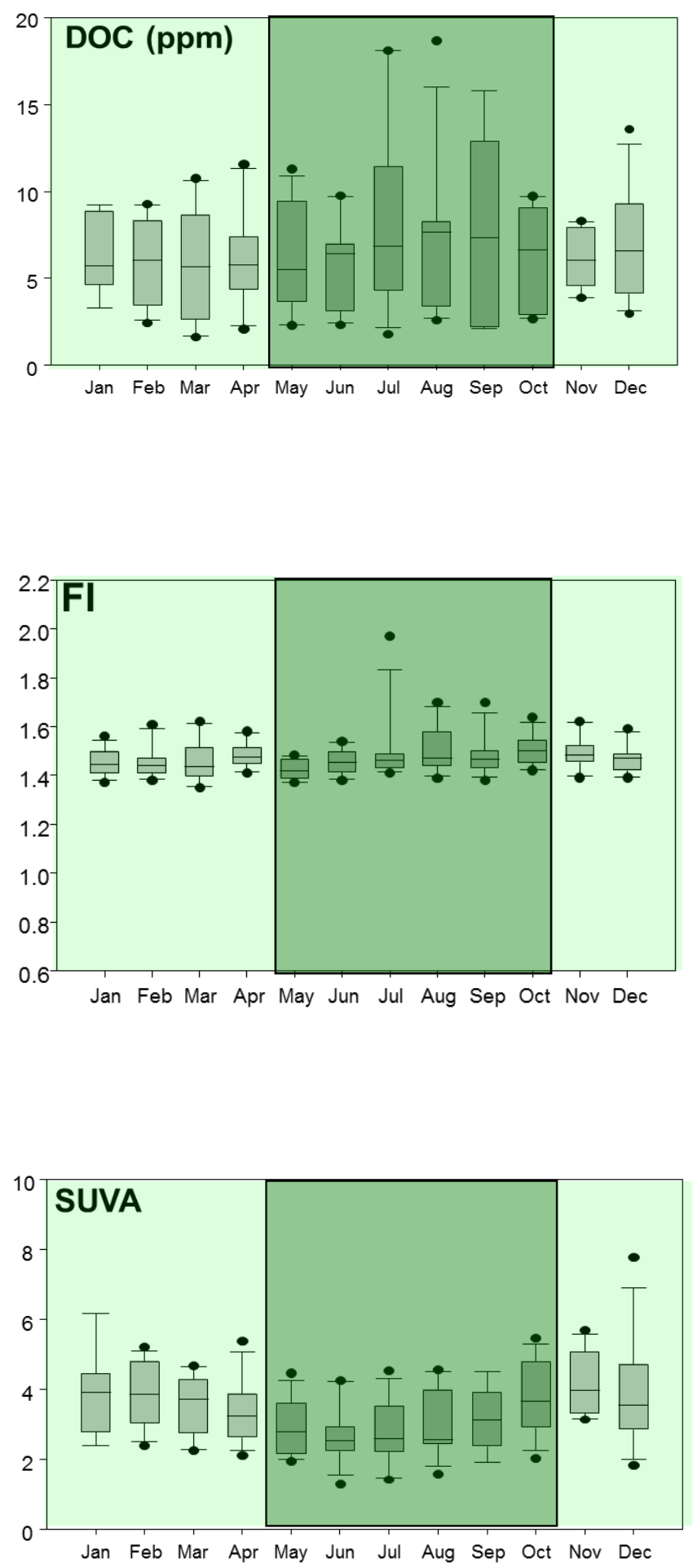

Fig. A-14 Seasonality of Florida Bay sites (TS/Ph-9, TS/Ph-10, TS/Ph-1) 
VITA

\section{MEILIAN CHEN}

Areas of Study: Environmental Analytical Chemistry, Biogeochemistry

Education:

2005-present Ph.D. Student in Department of Chemistry and Biochemistry, Florida International University, Miami, FL

1995-1998 M.S. Anal. Chem., Jinan University, Guangzhou, China

1991-1995 B.S. Harbin Engineering University, Harbin, China

Award:

Outstanding Teaching Assistant Awardee at Department of Chemistry and Biochemistry 2006-2007

Scientific Publications:

1.Chen, M. A New Method of Food Analysis - Capillary Electrophoresis. Graduate Journal of Jinan University. Guangzhou. 1997

2.Chen, M., Feng, D. Comparative Study of Bilirubin and Biliverdin via Optical and Electrochemical Methods. The $7^{\text {th }}$ Analytical Chemistry Conference. Hangzhou. 2000

3.Chen, M., Price, R., Yamashita Y., and Jaffé, R. Comparative study of dissolved organic matter from groundwater and surface water in the Florida coastal Everglades using multi-dimensional spectrofluorometry combined with multivariate statistics. Applied Geochemistry, 2010 Volume 25(6), page872-880.

4.Chen, M. and Jaffé, R. Assessment of Photo- and Bio-reactivity of Dissolved Organic Matter from Biomass and Soil leachates and Surface water in the Florida Coastal Everglade Using Excitation-emission Matrix and Parallel Factor Analysis. in prep.

5.Chen, M., Maie, N., Parish, K., and Jaffé, R. Spatial and temporal variation of dissolved organic matter in an oilgotrophic subtropical coastal wetland. in prep.

6. Chen, M., Yamashita, Y., and Jaffé, R. Size distribution of dissolved organic matter in Florida coastal Everglades: a SEC-EEM-PARAFAC approach. in prep. 
Presentations:

7.Chen, M., Maie, Jaffé, R. "Spatial and Temporal Variability of Dissolved Organic Matter in the Florida Coastal Everglades ". American Geophysical Union (AGU) Annual Meeting, 2010, San Francisco, CA USA

8.Chen, M., Maie, N., Yamashita, Y., Jaffé, R. "Dissolved Organic Matter Dynamics in the Florida Coastal Everglades ". Long Term Ecological Restoration (LTER) All Scientists Meeting (ASM), 2009, Estes Park, CO USA

9.Chen M., Maie N., Yamashita Y., and Jaffé, R. "The Dynamics of Dissolved Organic Matter in Florida Coastal Everglades as Revealed through EEM-PARAFAC and DOC Measurements". FCE-LTER All Scientists Meeting, 2009, Miami, FL USA

10.R. Jaffé, N. Maie, M. Chen, R. Cory, Y. Yamashita, L. Scinto, R. Price, J. Boyer. Characterizing the dynamics of dissolved organic matter in the Florida coastal Everglades by fluorescence Analysis", Chapman Conference for Fluorescence of Natural Organic Matter, 2008, Birmingham, England

11.R. Jaffé, M. Chen, Y. Yamashita, N. Maie, K. Parish, R. M. Price, J.Boyer, and L. Scinto. "Characterizing the Dynamics of Dissolved Organic Matter in the Florida Coastal Everglades". Florida Bay and Adjacent Marine Systems Science Conference, 2008, Naples, FL USA

12.Chen M., Price, R. and Jaffé, R. "Assessing the Sources and Transformations of Dissolved Organic Matter in Florida Coastal Everglades". FCE-LTER All Scientists Meeting, 2008, Miami, FL USA

13.Chen M., Price, R. and Jaffé, R. "Assessing the Sources and Transformations of Dissolved Organic Matter in Florida Coastal Everglades". Florida Ecology and Evolution Symposium, 2008, Lake Placid, FL USA

14.Chen, M., Pisani, O., Calvo, M, Viteri, R., Maie, N., Jaffé, R. "Dissolved Organic Matter (DOM) Dynamics in the Florida Coastal Everglades: Application of DOM Quantity and Quality Measurements" American Society for Limnology and Oceanography (ASLO), 2007, Santa Fe, NM USA

15.Chen, M., Pisani, O., Calvo, M, Maie, N., Jaffé, R. "Dissolved Organic Matter (DOM) Dynamics in the Florida Coastal Everglades", FCE-LTER All Scientists Meeting, 2007, Miami, FL USA 